\title{
INFLUENCE OF SPARK ENERGY, SPARK NUMBER, AND FLOW VELOCITY ON DETONATION INITIATION IN A HYDROCARBON-FUELED PDE
}

\author{
A Thesis \\ Presented To \\ The Academic Faculty \\ By \\ Ilissa B. Schild \\ In Partial Fulfillment \\ of the Requirements for the Degree \\ Masters of Science Mechanical Engineering
}

Georgia Institute of Technology

December, 2005 
Influence of Spark Energy, Spark Number, and Flow Velocity on Detonation Initiation in a Hydrocarbon-fueled PDE

Approved by:

Dr. Tim Lieuwen, Advisor

School of Aerospace Engineering

Georgia Institute of Technology

Dr. Ben T Zinn,

School of Mechanical Engineering

Georgia Institute of Technology

Dr. Anthony J Dean

Advanced Technology Leader

General Electric Global Research

Dr. William Wepfer

Vice Provost DLPE

Georgia Institute of Technology

Approved: November 16, 2005 


\section{ACKNOWLEDGMENTS}

I would first and foremost like to thank Dr. Tony Dean, who has been instrumental in both the conduction of this research, as well as in my personal and professional development during these early stages of my career. I also have to thank Dr. Kent Cueman for hiring me over four years ago and giving me the opportunity to work on the Pulsed Detonation Engine project. In addition, I want to acknowledge Eric Cornell whose help and expertise has been invaluable in the lab.

I also want to thank Prof. Tim Lieuwen for being my advisor on this project and helping with all the added complexities of writing a distance learning thesis. I would also like to acknowledge Dr. Ben Zinn and Dr. Bill Wepfer for serving on my Masters Thesis Committee.

Lastly I would like to thank the General Electric Edison Program for funding my graduate work as well as giving me the opportunity to conduct research in a world-class laboratory. 


\section{TABLE OF CONTENTS}

ACKNOWLEDGMENTS .............................................................................................................III

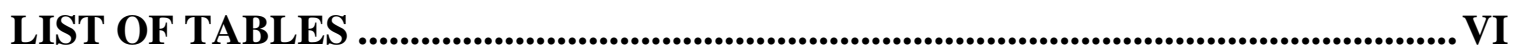

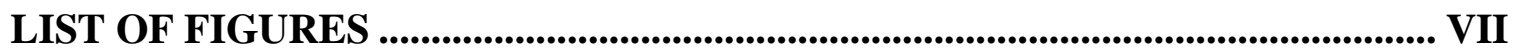

LIST OF ABBREVIATIONS.................................................................................................X

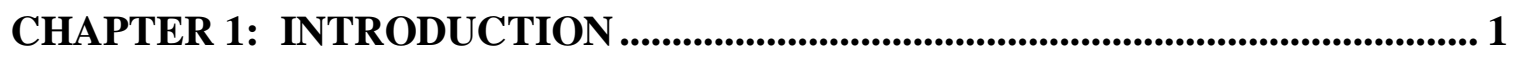

CHAPTER 2: BACKGROUND........................................................................................ 3

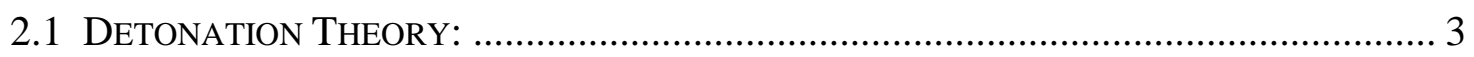

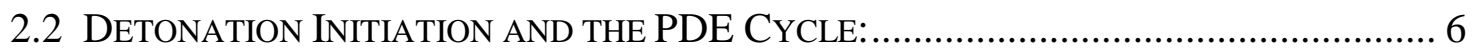

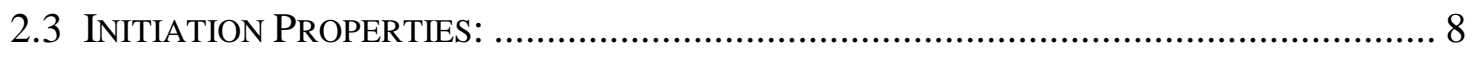

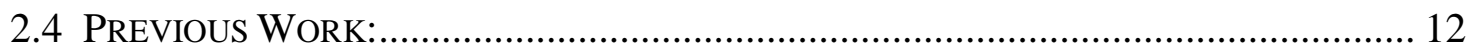

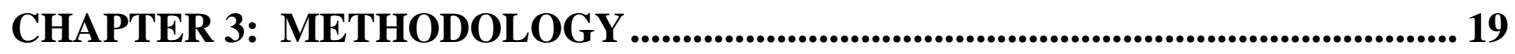

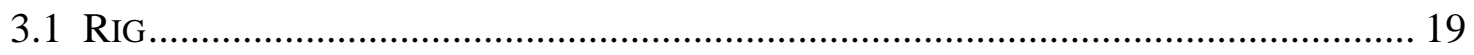

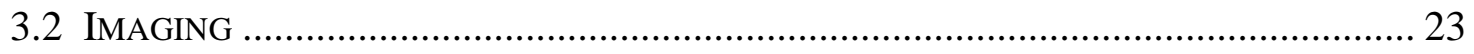

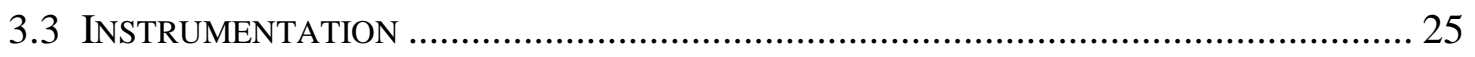

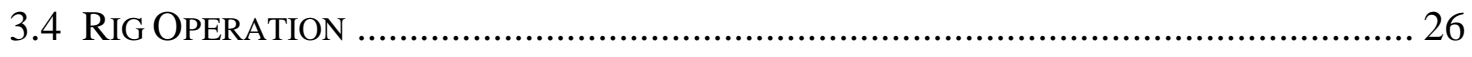

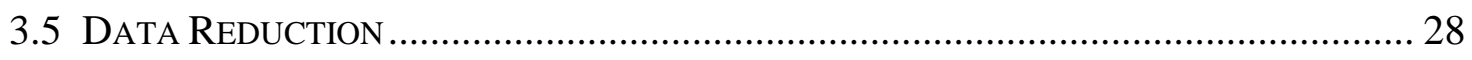

CHAPTER 4: RESULTS AND DISCUSSION_............................................................... 32

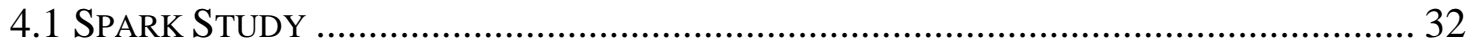

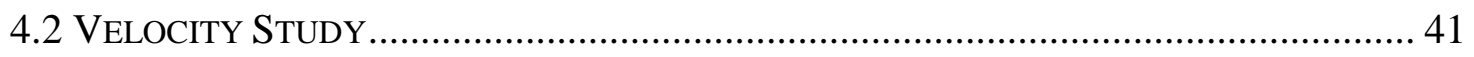




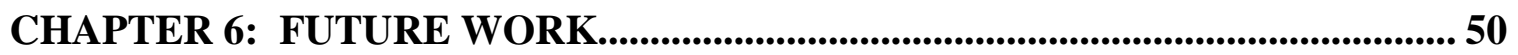

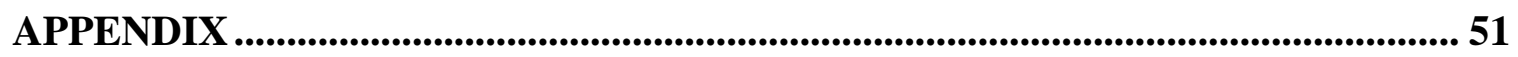

A. SPARK ENERGY/FUEL ENERGY CALCULATION: .................................................. 51

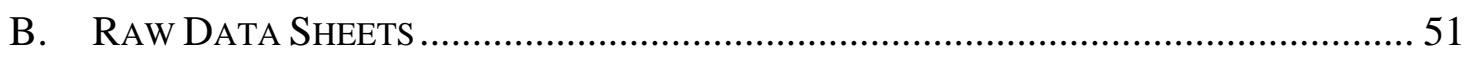

C. Selected Full Frame Shadowgraph Movies ................................................. 55

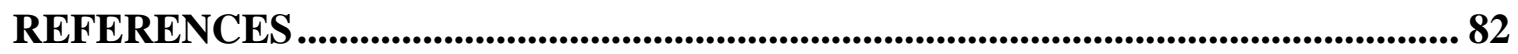




\section{LIST OF TABLES}

Table 1: Factors and responses in DDT, *those considered in this study.

Table 2: Spark study: case 1 test plan

Table 3: Spark study: case 2 test plan 28

Table 4: Velocity study test plan 28

Table 5: Table of the five air mass flowrates considered and their corresponding velocities, Mach numbers and Reynolds numbers 42 


\section{LIST OF FIGURES}

Figure 1: Rankine-Hugoniot curve with labeled combustion regimes and C-J points (for zero heat release) [5]

Figure 2: One-dimensional representation of a propagating detonation wave and corresponding values for the adiabatic combustion of a stoichiometric $\mathrm{C}_{2} \mathrm{H}_{4}$-air mixtures at $1 \mathrm{~atm}$ and $\mathrm{T}_{1}=298 \mathrm{~K}$. The reference frame is stationary with the wave. [4] 5

Figure 3: PDE cycle and timing diagram for an overfilled PDE operating at $10 \mathrm{~Hz}$. 7

Figure 4: The energy required to directly initiate a variety of fuel-air mixtures at atmospheric temperature and pressure as a function of equivalence ratio [6] 9

Figure 5: Schematic of triple points and cell size [7] 10

Figure 6: The cell size for variety of fuel-air mixtures at atmospheric temperature and pressure as a function of equivalence ratio [6]

Figure 7: Run-up curves for ethylene and hydrogen [8] 11

Figure 8: Characteristics of three different sparks tested in spark kernel growth research [9]

Figure 9: Kernel growth at 1, 2, 3, 4 and 5 ms after ignition [9] 13

Figure 10: The "go/no go" detonation peninsula measured by Frolov et. al. [11] 15

Figure 11: Experimental setup by Hickey et. al. [12] 16

Figure 12: Schematic of proposed reason for accelerated flame kernel growth with multiple spark injections [12] 16

Figure 13: Schematic of rig at GE Global Research 20

Figure 14: Perforated plate used in experiments to ensure uniform flow 20 
Figure 15: Unison Industries Model MPX-PDE spark system at GE Global Research_ 21

Figure 16: Close-up of four spark protruding into 2D section of PDE rig 22

Figure 17: Picture of PDE spark rig 23

Figure 18: Close-up of 2D section of PDE spark rig 23

Figure 19: Chemiluminescence images at various time steps of $\mathrm{C}_{2} \mathrm{H}_{4}$-air detonation in a 2" diameter tube 24

Figure 20: Phantom high-speed camera 24

Figure 21: Schematic of shadowgraph assembly 25

Figure 22: Dynamic pressure transducers and ionization probes used to measure emergence time and wavespeed 26

Figure 23: Sequential high-speed shadowgraph images tracking the flame front down the tube 29

Figure 24: Run-up plot for both the baseline and best run under Case 1 conditions. Note the dotted line corresponding to the flame front position marked by the dotted line in Figure 23. 30

Figure 25: Example PCB and ionization probe traces. The blue trace is the upstream $\mathrm{PCB}$, the red trace is the downstream PCB and the black line is the ionization probe trace

Figure 26: Plot of $t_{5}$ as a function of total energy. Trend lines are drawn between points obtained with the same number of sparks. Error bars represent the range between the two averaged detonations. 32

Figure 27: Initial shock wave emanating from 4 sparks at $1 \mathrm{~J}$ each 33

Figure 28: Initial spark kernel size $0.175 \mathrm{~ms}$ after ignition 34 
Figure 29: Comparison of initial flame acceleration $1.029 \mathrm{~ms}$ after ignition of a 1-spark at $1 \mathrm{~J}$ case versus a 4-spark each with $1 / 4 \mathrm{~J}$ case 35

Figure 30: Plot of $t_{\mathrm{e}}$ as a function of total energy. Trend lines are drawn between points obtained with the same number of sparks. Error bars represent the range between the two averaged detonations. 36

Figure 31: Sequential images from three different cases at three different time steps _ 38 Figure 32: Comparison of $t_{5}$ for Case 1 and Case 2. A single trend line was drawn through all of Case 1 data for simplicity of comparison. The Case 2 points are averaged between two detonations and the error bars represent the range between the two averaged detonations. 39

Figure 33: Comparison of two cases: $1 \mathrm{~J}$ distributed in 2 sparks and $1 \mathrm{~J}$ distributed in 4 sparks

Figure 34: Regimes 1 and 2 when comparing the influence of both airflow and spark energy 41

Figure 35: The average $t_{e}$ and $t_{5}$ for five different airflow velocity cases. The error bars represent the range between the two averaged detonations. 43

Figure 36: Sequential pictures of three velocity cases at four discrete time steps 44 Figure 37: Comparison of total length of tube traveled by wave versus total duration of time traveled 46 


\section{LIST OF ABBREVIATIONS}

$D D T$

PDE

$x_{D D T}$

$t_{D D T}$

$t_{e}$

$t_{5}$

$\mathrm{X} / \mathrm{D}$ deflagration to detonation transition

pulsed detonation engine

run-up distance

run-up time

flame emergence time from tube exit after spark

time of combustion wave to reach the $5^{\text {th }}$ obstacle, $22.9 \mathrm{~cm}$, downstream of the spark location

the ratio of $\mathrm{X}$, flame front location as measured from spark, and $\mathrm{D}$, the chamber width/diameter 


\section{CHAPTER 1: INTRODUCTION}

Pulsed Detonation Engines (PDEs) are being developed as a new and exciting method of propulsion that have the potential to revolutionize fight. They have the potential to do this by better utilizing the chemical energy content of reactive fuel/air mixtures over conventional combustion processes [1-3]. Combustion of the fuel-air mixture by a detonation wave emulates a constant volume combustion process rather than the constant pressure combustion currently used in gas turbines and ramjets. Because this mode of combustion is nearly constant volume, it allows for a significant increase in pressure in addition to the standard increase in temperature during the process. In order to harness this pressure increase and achieve a high power density, it is desirable to operate PDEs at high frequency. The process of detonation initiation directly impacts operating frequency because it dictates the length of the chamber and contibutes to the

overall cycle time. Therefore a key challenge in the development of a practical PDE is the requirement to efficiently and rapidly initiate a detonation in hydrocarbon-air mixtures.

This thesis evaluates the influence of spark energy and airflow velocity on this challenging initiation process. The influence of spark energy, number of sparks and airflow velocity on Deflagration to Detonation Transition (DDT) was studied during cyclic operation of a small-scale PDE at the General Electric Global Research Center. Experiments were conducted in a $50 \mathrm{~mm}$ square which transitions to a cylindrical channel PDE with optical access, operating with stoichiometric mixtures of ethylene and air. Total spark energy was varied from $250 \mathrm{~mJ}$ to $4 \mathrm{~J}$ and was distributed between one and four spark plugs located in the same axial location. Initial flame acceleration was imaged 
using high-speed shadowgraph and was characterized by the time to reach $20 \mathrm{~cm}$ from the spark plug. Measurements of detonation wave velocity and emergence time, the time it takes the detonation wave to exit the tube, was measured using dynamic pressure transducers and ionization probes. 


\section{CHAPTER 2: BACKGROUND}

\subsection{Detonation Theory:}

In nature there exist two types of combustion processes: deflagration (expansion) and detonation (compression). A deflagration is a subsonic combustion process after which the products are at a higher temperature, a slightly lower pressure, and a larger volume than the reactants. A detonation however, is a supersonic combustion process after which the products achieve a higher temperature and pressure than the reactants. These characteristics of a detonation can be explained by understanding the thermochemical mechanisms that drive the detonation process. One method of defining a detonation is to consider it as a shockwave followed by a combustion front which are coupled in a self-sustaining relationship. Once a shockwave has been initiated within a combustible mixture, the wave compresses the downstream reactants, thus heating and causing them to combust directly behind the wave. At the same time these hot burning gases further accelerate the wave, thus causing more compression. The two fronts, both pressure and combustion, must coincide in order for detonation conditions to exist [4].

One way to visually interpret these two possible combustion solutions is by plotting the pressure and specific volume of both the products and the reactants on a P-v diagram. For a known reactant pressure and volume the possible conservation of energy product solutions can be plotted along a curve known as the Rankine-Hugoniot. However, in order to represent actual combustion solutions, one must draw lines from the initial state to this Hugoniot curve, known as Rayleigh lines and also conserve mass and

momentum. There are however, two specific solution points, known as the Chapman- 
Jouget points, where the Rayleigh lines are tangent to the Hugoniot while still intersecting the initial state point. This can be clearly seen in Figure 1. These two points represent minimum entropy states and divide the upper component of the Hugoniot into strong and weak detonations, and the lower component into strong and weak deflagrations. Each of these regimes are characterized by a particular burned gas velocity, being either supersonic, sonic or subsonic [4].

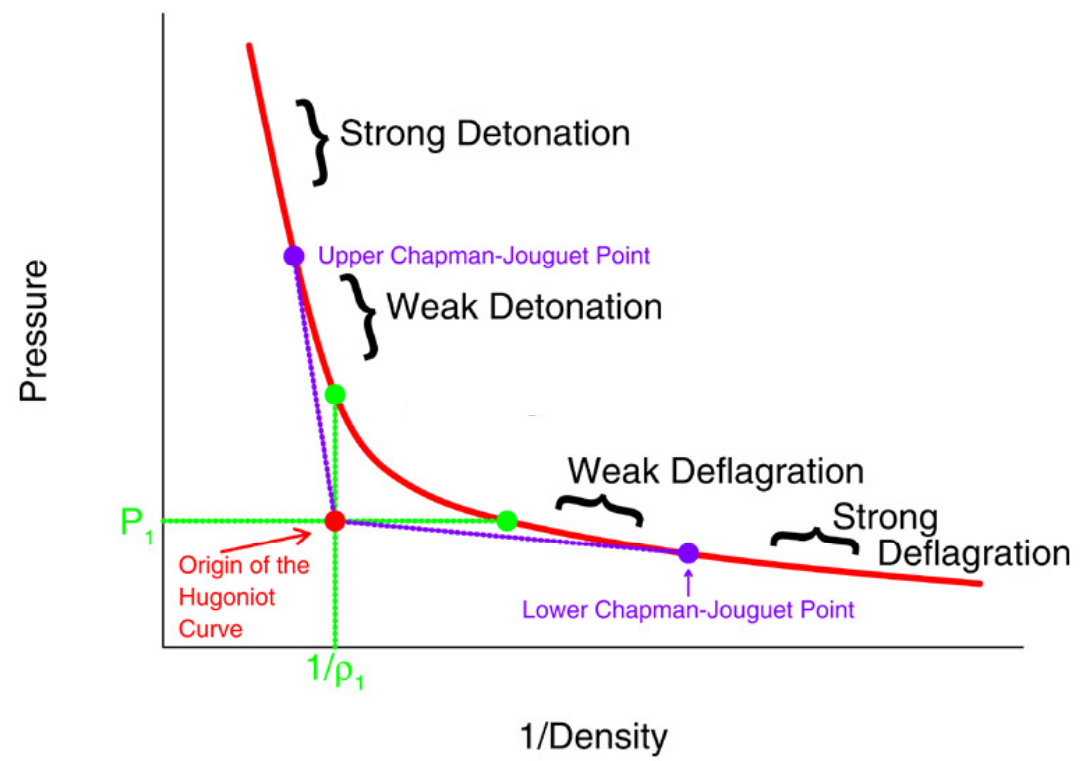

Figure 1: Rankine-Hugoniot curve with labeled combustion regimes and C-J points (for zero heat release) [5]

As this paper is focused on a detonation combustion process, the physics and fundamentals of deflagrations will no longer be discussed. At the upper C-J point, the initial coupled shock/combustion front can travel at extremely supersonic speeds and the subsequent burned gas velocity travels at exactly $M=1$, by definition. This initial shock/combustion front initial velocity is also known as the C-J velocity and it is a fuel- 
specific characteristic. In Figure 2 one can see a one-dimensional representation of a propagating detonation wave with its corresponding initial and final conditions.

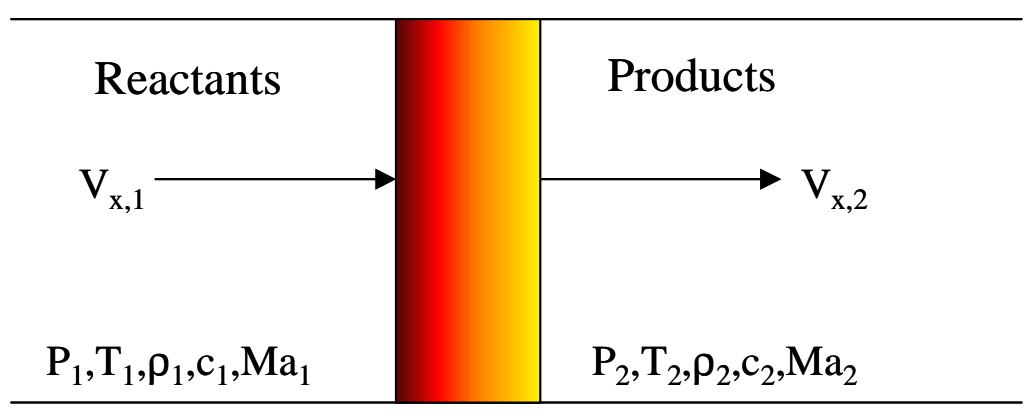

\begin{tabular}{|c|c|}
\hline Property & Detonation \\
\hline $\mathrm{Ma}_{1}$ & $5-10$ \\
\hline $\mathrm{Ma}_{2}$ & 1.0 \\
\hline $\mathrm{v}_{\mathrm{x}, 2} / \mathrm{v}_{\mathrm{x}, 1}$ & $0.4-0.7$ \\
\hline $\mathrm{P}_{2} / \mathrm{P}_{1}$ & $13-55$ \\
\hline $\mathrm{T}_{2} / \mathrm{T}_{1}$ & $8-21$ \\
\hline$\rho_{1} / \rho_{2}$ & $1.7-2.6$ \\
\hline
\end{tabular}

Figure 2: One-dimensional representation of a propagating detonation wave and corresponding values for the adiabatic combustion of a stoichiometric $\mathrm{C}_{2} \mathrm{H}_{4}$-air mixtures at $1 \mathrm{~atm}$ and $T_{1}=298 \mathrm{~K}$. The reference frame is stationary with the wave. [4]

The shockwave Mach number associated with a strong detonation (overdriven detonation) is also larger than one, however the burned gas velocity $\left(\mathrm{v}_{\mathrm{x}, 2}\right)$ is less than one. This typically results in a deceleration of the detonation velocity down to the C-J velocity. Lastly, the characteristic velocity of weak detonation products is supersonic, rather than sonic as found in C-J detonations. However as the shock component of the detonation wave passes through the combustible mixture, the flow is reduced to subsonic. In order to a weak detonation to be self-sustaining, the flow must then re-accelerate to supersonic conditions which is also very difficult to achieve. Therefore most real detonations follow the C-J detonation conditions [4]. As mentioned, the velocity of a C-J detonation is characteristic of the fuel and is approximately $1800 \mathrm{~m} / \mathrm{s}$ for the ethylene-air mixture considered in this study [1]. 


\subsection{Detonation Initiation and the PDE Cycle:}

Detonations can be formed in a variety of ways including direct initiation, shock initiation and Deflagration to Detonation Transition (DDT). Direct initiation requires a very large amount of energy to be introduced into a combustible mixture which subsequently results in an immediate detonation. Shock initiation requires that a shockwave created somewhere outside of the combustible mixture be introduced into the fuel and oxidizer, thus resulting in a detonation. Lastly, DDT is a complex process by which a deflagration flame is initiated in a combustible mixture by an energy source and accelerated along a tube until it transitions into a detonation wave. DDT is the method of detonation initiation to be studied here.

This phenomenon is typically initiated by a spark and the resulting detonation results in an instantaneous pressure rise and hence an impulse leaving the tail-end of the tube. In order to capture this impulse and utilize it for a given application (thrust, work, etc.), one must repeat the DDT process at a rapid rate, or pulse the process. This pulsing of DDT defines one of the main applications of detonations: a pulsed detonation tube, or engine (PDE, where thrust is extracted from the tail-end of the tube and can be used for propulsion). The higher the frequency of pulsation and the closer the tube is to achieving a steady state pressure rise, the more usable thrust that can be extracted. However, frequency of operation is limited by many factors resulting from the multiple steps required in a PDE cycle. Figure 3 shows the ideal PDE cycle and its corresponding timing diagram for a constant airflow, overfilled, ethylene-air mixture PDE operated at $10 \mathrm{~Hz}$. 

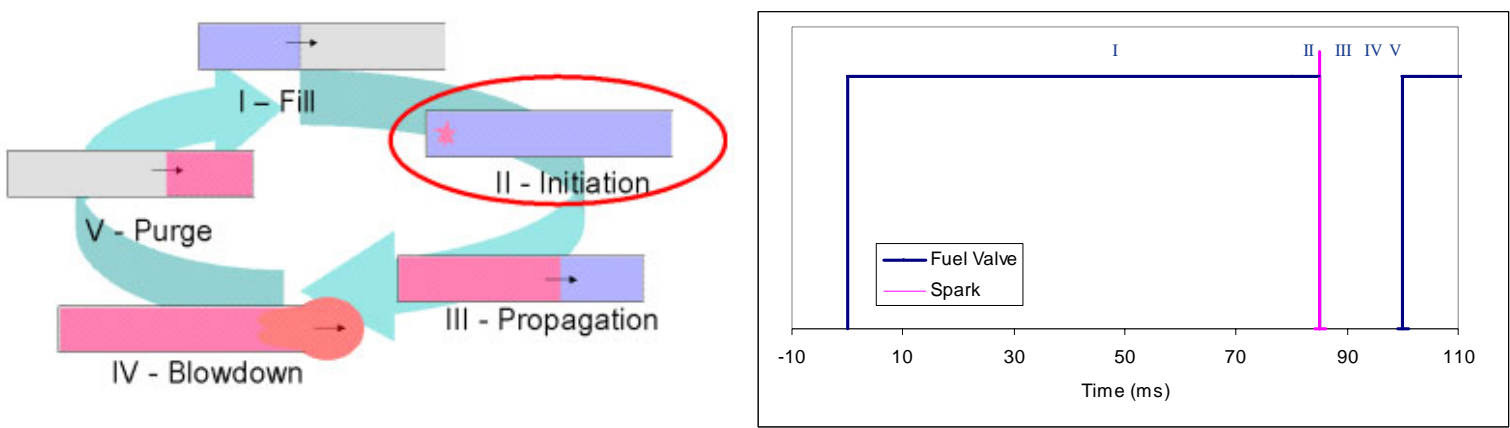

Figure 3: PDE cycle and timing diagram for an overfilled PDE operating at $10 \mathrm{~Hz}$.

When looking at this timing diagram, the longest fraction of the total cycle time is the fill step, during which a fuel-air mixture is blown into the tube. Based on the steady airflow rate, a fill percentage can be determined and controlled, dictating how much of the tube contains a combustible mixture. The fill step in Figure 3 is for an almost $200 \%$ filled tube - overfilling can be used to ensure a stoichiometric mixture and increase chances of a detonation. When running a PDE at high frequencies and for multiple cycles, this step can be significantly shortened; there have been studies on the effects of partial fill in order to achieve this reduction while still ensuring detonations. In fact, $<100 \%$ fill is vital for practical engine performance, and overfilling is typically used solely in fundamental studies. The second PDE cycle step, and the focus of this paper, is initiation. Typically by spark, initiation is the slowest and most challenging part of the DDT process (which consists of both initiation (II) and propagation (III)). Once the mixture is ignited by the spark, there is an incubation period during which the spark kernel first grows into multiple flamelets, creating isolated hot spots in recirculation zones, then a full-scale flame, and then eventually a visible accelerating deflagration combustion front. This accelerating combustion front will then transition into a 
detonation wave and propagate towards the end of the tube, step III in the PDE cycle. Finally, the wave exits the tail-end of the tube creating an impulse, step IV, and the burned products are purged from the tube by the continuous airflow, step V [1].

\subsection{Initiation Properties:}

As stated above, initiation is the most challenging part of the DDT process and the difficulty of successfully triggering a detonation and quickly accelerating it down a tube can greatly vary depending on the detonability of the fuel. Ease and speed of detonation initiation is a very important factor when conducting extensive experiments and can dictate which fuel(s) is best suited for a particular experimental goal. As found with typical deflagration combustion, the smaller hydrocarbon chain fuels are more combustible and also more detonable. Smaller hydrocarbon fuels require less dissociation of molecules and can therefore directly detonate faster and with less energy required than larger hydrocarbon fuels. This concept can be inferred when looking at the data in Figure 4. 


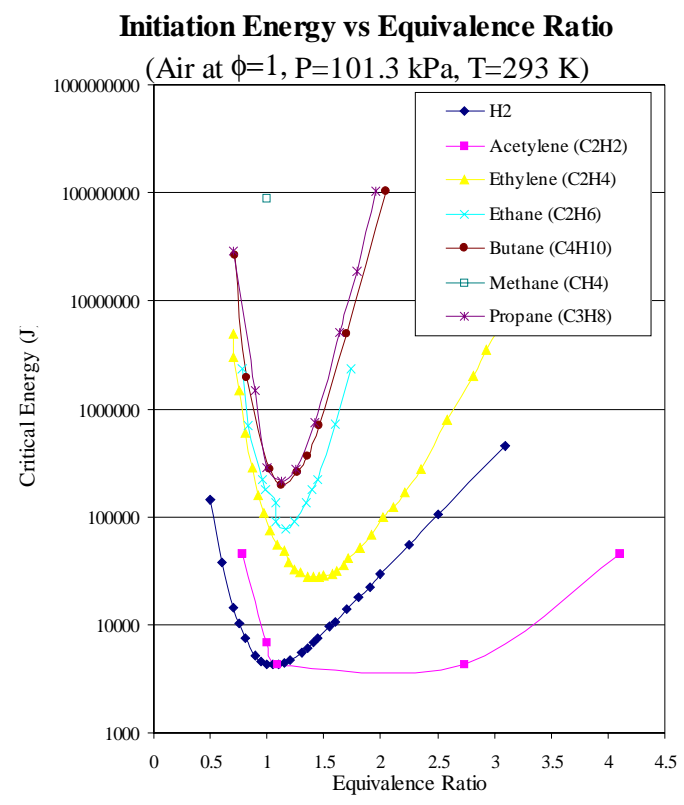

Figure 4: The energy required to directly initiate a variety of fuel-air mixtures at atmospheric temperature and pressure as a function of equivalence ratio [6]

Another factor when determining detonability of different fuels is cell size. A detonation is inherently an unsteady, turbulent, 3D structure; as it propagates down a tube, there are transverse waves that oscillate behind the shockwave. Since these transverse waves exist in three dimensions, the points at which they intersect are known as triple points. These triple points appear to "track" in diamond-like patterns along the length of tube, due to the combined transverse movement coupled with the unidirectional shockwave propagation movement. The largest distance between these tracks is known as the cell size and is again characteristic of the fuel, in addition to the temperature and pressure. A schematic can be found in Figure 5. 


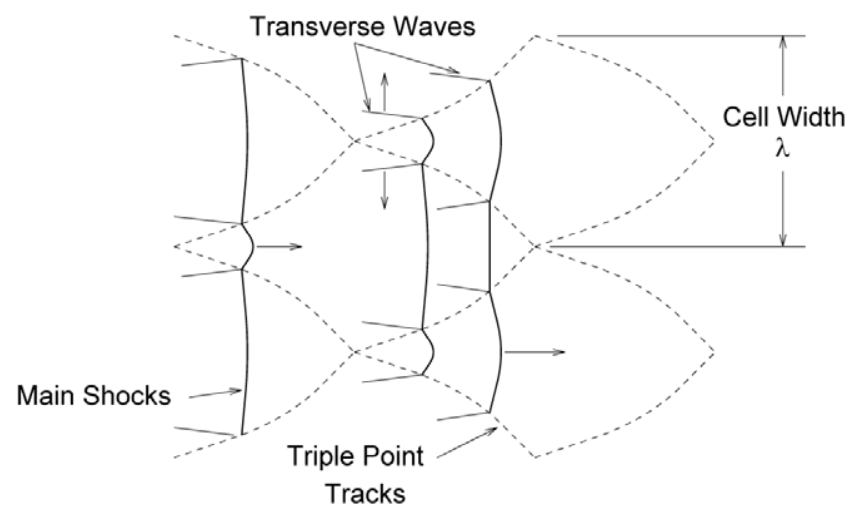

Figure 5: Schematic of triple points and cell size [7]

The cell size of a particular fuel can dictate the geometry required of the tube to achieve detonation. The diameter of the tube must be larger than the cell size, in order for a detonation to occur. Again, it is therefore easier to detonate smaller hydrocarbons with smaller cell sizes in reasonably sized geometries. In a PDE, where the potential application requires small and lightweight hardware, cell size becomes an important factor. The cell size for various fuels can be seen in Figure 6 . 


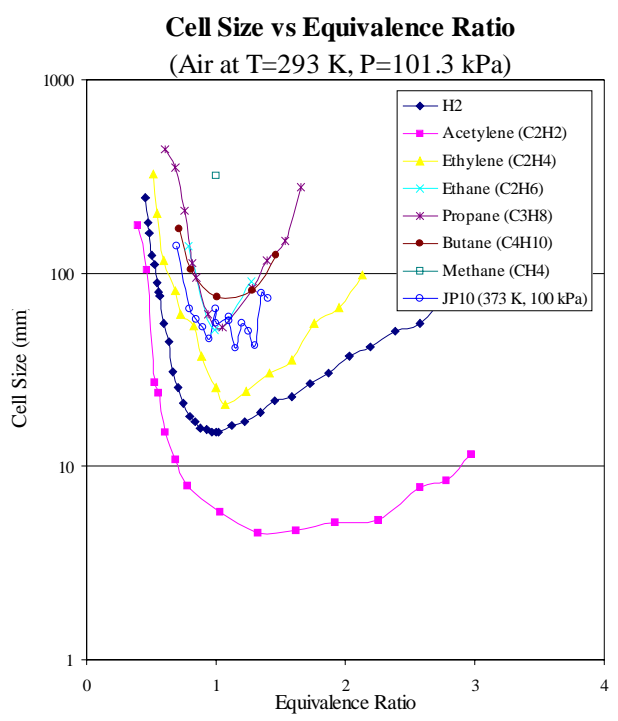

Figure 6: The cell size for variety of fuel-air mixtures at atmospheric temperature and pressure as a function of equivalence ratio [6]

From Figure 6 it is clear that acetylene and hydrogen-air mixtures are the easiest to detonate when considering cell size. Figure 7 shows how this ease of detonation translates into faster detonation wave emergence time from the tail-end of the tube. These run-up curves display how the total emergence time is largely dictated by the initial flame acceleration.

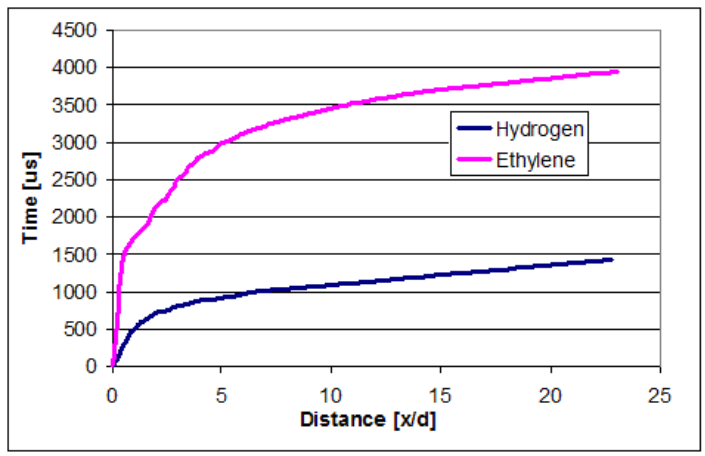

Figure 7: Run-up curves for ethylene and hydrogen [8] 
For the potential propulsion system applications of detonation science, it is important to gain an understanding of DDT initiation characteristics in the more complex hydrocarbon fuel-air mixtures such as Jet-A or JP-10. However, ethylene-air $\left(\mathrm{C}_{2} \mathrm{H}_{4}\right)$ is the fuel/air mixture to be used in this study as a compromise between the most detonable fuels and these more complex hydrocarbons.

It is clear from the above background discussion that the DDT process within the PDE cycle is comprised of many complex and experimentally challenging steps. This paper is focused on an attempt to understand and accelerate the initial flame development process during the aforementioned "dark" incubation period. This is attempted by varying the deposited energy into the system by spark from $0.25 \mathrm{~J}$ up to $4 \mathrm{~J}$. In addition, the effect of air velocity on this initial flame acceleration is also investigated to determine the potential time saving benefits of running a PDE tube at a higher airflow rate.

\subsection{Previous Work:}

The majority of spark research has been done in the internal combustion engine field on flame kernel growth. The goal in internal combustion engines is identical to that in a PDE: to increase flame kernel grown rate. In 1992, Cho et al. [9] looked at factors such as turbulence, spark duration, spark power and breakdown energy and determined their effect on flame kernel growth. Using a 4000 frame/second camera and a shadowgraph system, they evaluated three types of spark, a high power breakdown (HPBD), a low power breakdown (LPBD) and a GE High Energy Igniter (HEI) with characteristics seen in Figure 8. 


\begin{tabular}{|l|ccc|}
\hline Ignition system & HEI & LPBD & HPBD \\
\hline Supplied ignition energy & $59.8 \mathrm{~mJ}$ & $5.7 \mathrm{~mJ}$ & $60 \mathrm{~mJ}$ \\
Breakdown phase & $0.66 \mathrm{~mJ}$ & $5.7 \mathrm{~mJ}$ & $60 \mathrm{~mJ}$ \\
Glow phase & $59.1 \mathrm{~mJ}$ & & \\
Effective ignition energy & $5.35 \mathrm{~mJ}$ & $5.36 \mathrm{~mJ}$ & $56.4 \mathrm{~mJ}$ \\
Breakdown phase & $0.62 \mathrm{~mJ}$ & $5.36 \mathrm{~mJ}$ & $56.4 \mathrm{~mJ}$ \\
Glow phase & $4.73 \mathrm{~mJ}$ & & \\
Spark duration & $\sim 4.2 \mathrm{msec}$ & $\sim 100 \mathrm{nsec}$ & $\sim 100 \mathrm{nsec}$ \\
Avg. supplied spark power & $\sim 14 \mathrm{~W}$ & $\sim 57 \mathrm{KW}$ & $\sim 560 \mathrm{KW}$ \\
\hline
\end{tabular}

Figure 8: Characteristics of three different sparks tested in spark kernel growth research [9]

Cho et. al. found that a HPBD system with a delivered spark energy of $56.4 \mathrm{~mJ}$ in $~ 100$ ns had a much faster kernel growth rate than the LPBD system with an effective energy of $5.36 \mathrm{~mJ}$ in $\sim 100 \mathrm{~ns}$. Additionally, an even slower kernel growth rate was observed with the HEI which delivered $5.35 \mathrm{~mJ}$ in $\sim 4.2 \mathrm{~ms}$. Contour drawings at 1, 2, 3, 4 and 5 ms after ignition can be seen in Figure 9.
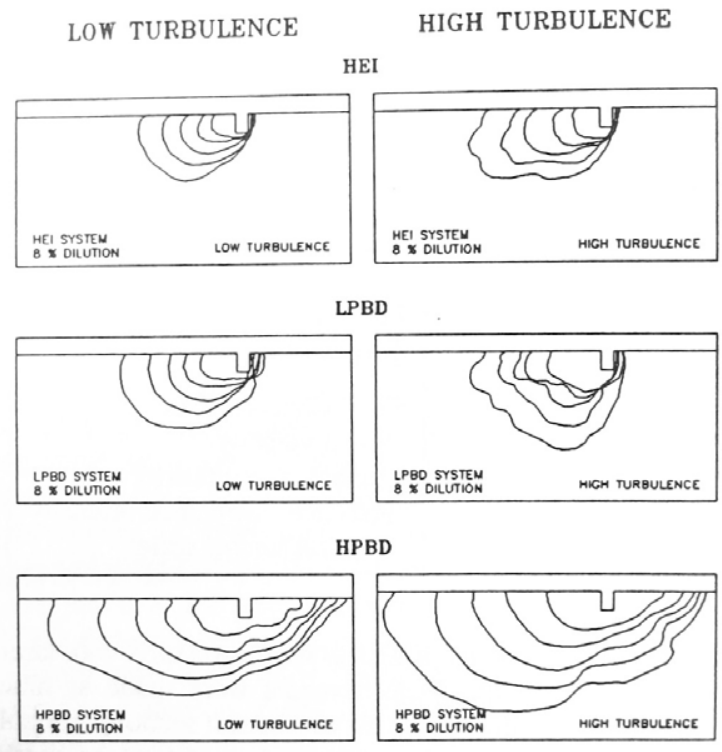

Figure 9: Kernel growth at 1, 2, 3, 4 and 5 ms after ignition [9] 
Therefore, both energy and duration have a clear effect on kernel growth rate. Other additional findings included that the initial kernel size immediately after energy deposition was largest for the higher breakdown ignition mode, however turbulence did not affect the initial kernel size at all. Turbulence did however increase the initial kernel growth rate, but this effect became less significant at higher spark energies. Lastly, the effect of increasing the spark power on growth rate was less significant when there existed more turbulence.

Similar finding were presented by Shen and Jiang [10] in 1992 when they looked at the various stages of spark energy deposition and how the augmentation of energy at each of these stages affected flame kernel growth. The spark process is divided into three parts: breakdown, arc and glow. It was found by Shen and Jiang that the augmentation of breakdown energy increased both the original flame size and the flame kernel formation in early development. However, increasing energy during the arc and glow phases had no obvious effect.

Leveraging the major relationships found between spark energy and flame kernel growth, many institutions have conducted spark studies and their affect on DDT. Additionally, researches have looked at dividing this total energy among multiple sparks and observed those effects as well. Frolov et. al. [11] conducted research at the Russian Academy of Sciences in Moscow looking at minimizing the total ignition energy (nominally $57 \mathrm{~J}$ ) by using two sparks instead of one. They found that with very "careful synchronization of the igniter triggering with the blast wave generated by the aft igniter" they could see detonations by using $2500 \mathrm{~V}$ divided among two igniters, rather than one 
igniter with $3300 \mathrm{~V}$. However, they also discovered that this successful minimization of energy only occurs in a very narrow region of precise timing. If outside of this "detonation peninsula," a detonation does not occur at all. The detonation peninsula can be seen in Figure 10.

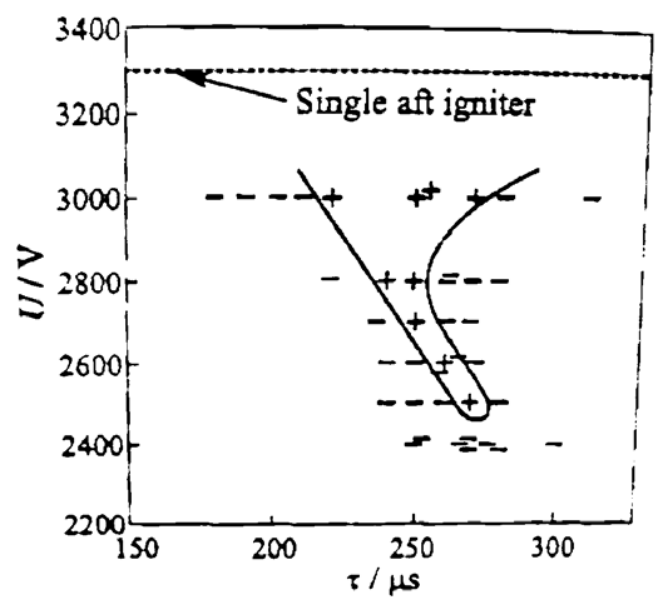

Figure 10: The "go/no go" detonation peninsula measured by Frolov et. al. [11]

Their study did not include any visualization techniques, and therefore the energy distribution phenomenon was not fully understood. Additional instrumentation such as high-speed shadowgraph visualization could add much insight into their observed trends.

Lastly, Hickey et. al. of the Royal Military College in Kingston Ontario [12] has looked at successive sparks in a 6 inch diameter tube filled with a stoichiometric propaneair mixture. Using ion probes to determine time of flame arrival, Hickey timed the subsequent downstream sparks to ignite either before, during or after flame arrival, as shown in Figure 11. 


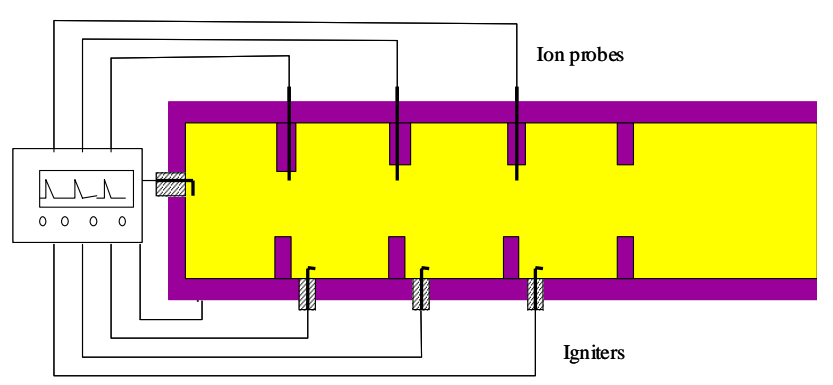

Figure 11: Experimental setup by Hickey et. al. [12]

Their most promising results were found when the subsequent sparks were ignited slightly before the arrival of the primary flame as shown in the schematic in Figure 12.

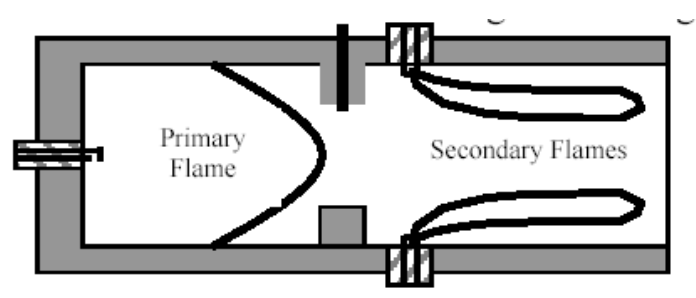

Figure 12: Schematic of proposed reason for accelerated flame kernel growth with multiple spark injections [12]

The authors state that the reasoning behind this cannot be determined without proper visualization, again motivating the techniques utilized in the current study.

Summarizing, there is significant work and motivation to support a systematic spark/energy study and to observe the effects on DDT properties. The major factors to be varied in this study are spark number, energy/spark, total energy airflow velocity. The main response to be discussed in this paper is that of emergence time $\left(t_{e}\right)-$ the time it 
takes the flame to leave the tail-end of the tube, and $t_{5}-$ the time it takes the flame to leave the high-speed camera's frame of view and also corresponding to the initial flame acceleration. Other factors are mentioned such as run-up time, $\mathrm{t}_{\mathrm{DDT}}$, (the time it takes the deflagration flame to transition to detonation) and run up distance, $\mathrm{x}_{\mathrm{DDT}}$, (the distance at which the deflagration flame to transitions to detonation, usually normalized to tube diameter) and wavespeed. Wavespeed is typically measured in order to determine whether C-J velocity was achieved thus suggesting a detonation has occurred. Table 1 shows a more complete list of possible factors and responses, with those that play an important role in this study highlighted.

Table 1: Factors and responses in DDT, *those considered in this study.

\begin{tabular}{cc}
\hline Factors & Responses \\
\hline Spark number* & Emergence time $\left(\mathrm{t}_{\mathrm{e}}\right)^{*}$ \\
Energy/spark* & $\left(\mathrm{t}_{5}\right)^{*}$ \\
Total energy* & $\mathrm{x}_{\mathrm{DDT}}$ \\
Multiple spark delays & $\mathrm{t}_{\mathrm{DDT}}$ \\
Airflow* & Wavespeed* \\
Stoichiometry & Det/no det condition \\
Mixing & \\
Turbulence & \\
Spark placement & \\
Fuel type & \\
Fill \% & \\
\hline
\end{tabular}

The main hypotheses of the study are:

1) The deposition of additional energy will decrease the emergence time and therefore decrease the overall DDT process time. 
2) Increased airflow velocity will also decrease the overall DDT process time.

Through the examination of these hypotheses, this study hopes to both visually document the complex DDT phenomena observed, and gain and understanding to drive future improvements on the PDE cycle to better achieve practical applications. 


\section{CHAPTER 3: METHODOLOGY}

\subsection{Rig}

All experimental work was conducted at the General Electric Global Research Center in Niskayuna, New York. The PDE rig was divided into two sections: a twodimensional shadowgraph section and a three-dimensional cylindrical section. Obstacles or orifice plates were used in both sections to enhance flame folding and turbulence and thus aid in flame acceleration. These obstacles had a blockage ratio of 0.43 , which is defined as the fraction of blocked cross-sectional area versus non-blocked area. Due to the two-section nature of the rig, two-dimensional versions of orifice plates were used, as seen in Figure 13. The three-dimensional obstacles were standard orifice plates. A total of 19 obstacles were downstream of the sparks, including eight in the 2D section, and 11 in the 3D section. They were installed at $5.08 \mathrm{~cm}$ intervals starting $15.0 \mathrm{~cm}$ from the aft face of the mixing perforated plate. The total rig length is $158 \mathrm{~cm}$ measured from the end-cap to the tube exit. The 2D section is $50 \mathrm{~cm}$ long and $5.08 \mathrm{~cm} \times 5.08 \mathrm{~cm}$ in crosssection and the cylindrical section is $92 \mathrm{~cm}$ long with a $5.08 \mathrm{~cm}$ inner diameter. 


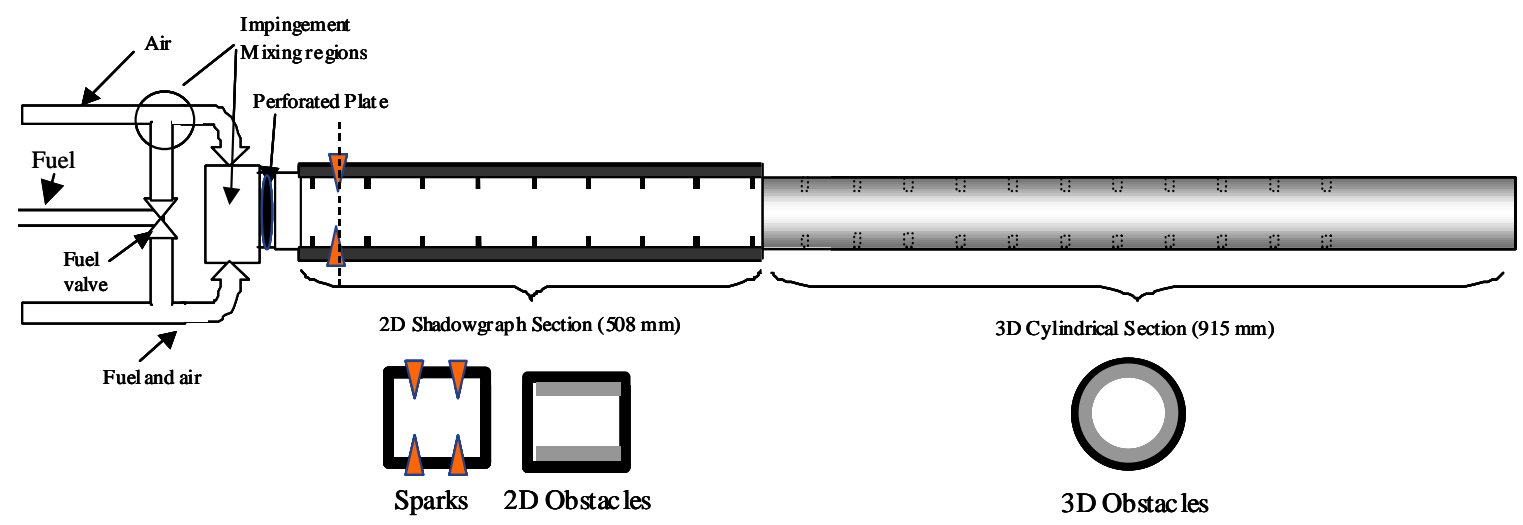

Figure 13: Schematic of rig at GE Global Research

A perforated plate was used to ensure uniform and horizontal flow. A picture of the perforated plate used, can be seen in Figure 14.

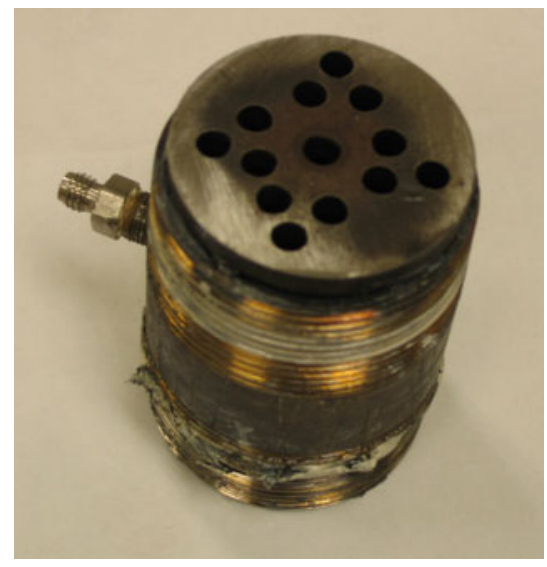

Figure 14: Perforated plate used in experiments to ensure uniform flow

A multi-channel spark ignition and valve control system was used to control the PDE, (Unison Industries Model MPX-PDE, seen in Figure 15.) 


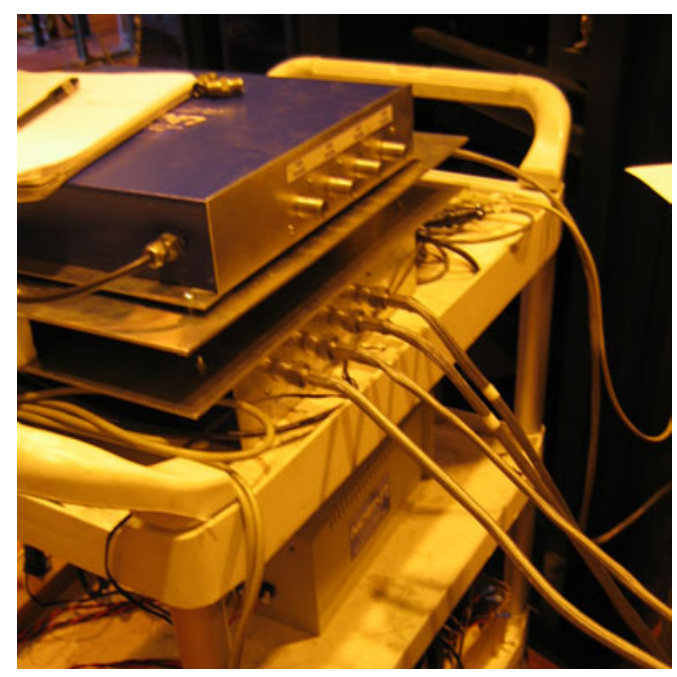

Figure 15: Unison Industries Model MPX-PDE spark system at GE Global Research

This system is PC-controlled with a graphical user interface that allows control of valve and spark timing. This system allows variable spark frequency (up to $100 \mathrm{~Hz}$ ) and variable spark energy. The stored energy for each spark can be adjusted between 0.25 and $1 \mathrm{~J}$, and the delivered energy to each spark is between $30-50 \%$ of the stored energy. In this 4 spark configuration, the maximum potential energy case corresponds to 4 sparks at $1 \mathrm{~J}$ each for a total of $4 \mathrm{~J}$. When determining the amount of chemical energy potential in a $100 \%$-filled tube containing a stoichiometric ethylene-air mixture and comparing that to the $30-50 \%$ of delivered spark energy, the spark energy remains extremely small $(\sim 0.03 \%)$ as compared to the fuel's chemical energy. This calculations can be found in the Appendix. The four sparks were placed in opposing positions in the upper and lower faces of the 2D section, as seen in Figure 13 and Figure 16. 


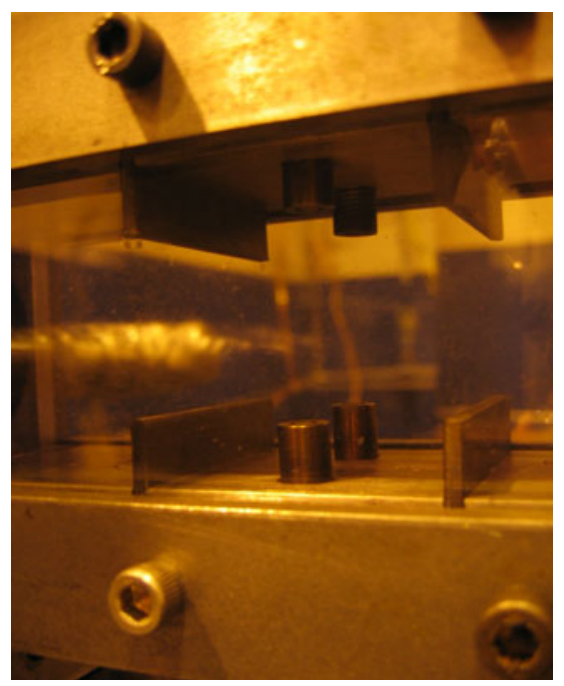

\section{Figure 16: Close-up of four spark protruding into 2D section of PDE rig}

Ambient air was flowed continuously into the tube from the upstream end through two air hoses. Fuel is pulsed via a solenoid valve through two elbows where it is then routed into each airflow hose. Fuel-air mixing occurs at these impingement zones as well as at the tube end-cap where the two fuel/air streams coincide in the main tube, as can be seen in the schematic in Figure 13. In order to vary the ratio of fuel and air to estimate the mixture's stoichiometry, one would adjust the air mass flow rate in addition to the upstream pressure in the fuel line until wavespeed was maximized (inferring a $\phi=1$ ). Pictures of the entire rig and individual sections can be seen in Figure 17 and Figure 18. 


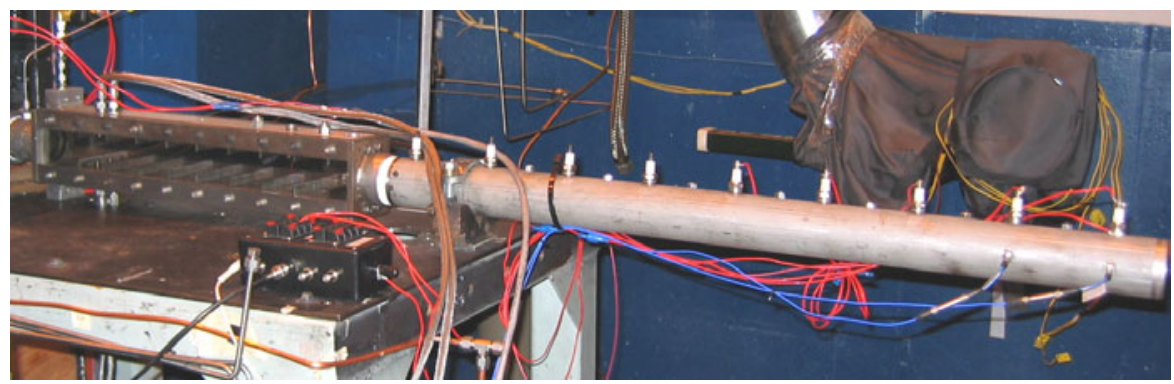

Figure 17: Picture of PDE spark rig

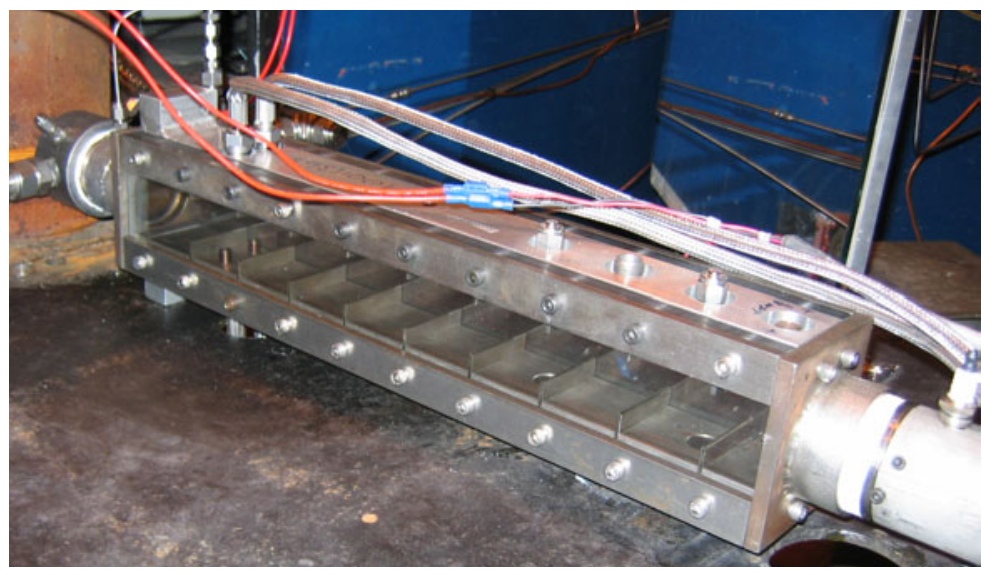

Figure 18: Close-up of 2D section of PDE spark rig

\subsection{Imaging}

In studying the DDT detonation initiation characteristics of a particular fuel, one can use high-speed digital photography to visually observe the various stages of initiation, acceleration, transition and propagation. It is clear when looking at the images in Figure 19 that there is a large amount of time that passes when little to no flame development is visible. This corresponds to the incubation period discussed previously in describing the PDE cycle. It is also clear that chemiluminescence techniques are not 
optimum for studying the intricacies of the incubation period. Therefore, shadowgraph was the chosen high-speed visualization technique in this study.

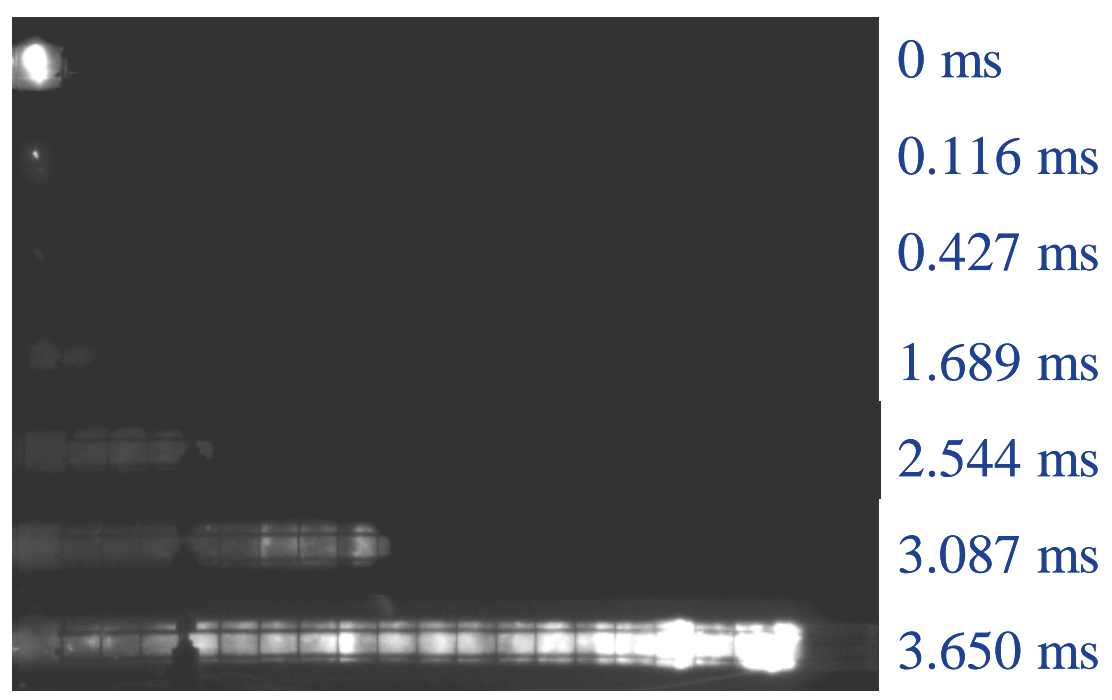

Figure 19: Chemiluminescence images at various time steps of $\mathrm{C}_{2} \mathrm{H}_{4}$-air detonation in a 2" diameter tube

Shadowgraph was used in the 2D section to visualize density gradients around the sparks and the first 5 obstacles. The movies were acquired at 51,500 frames per second at an image size of 512 x 64 pixels using a Phantom High Speed Camera, as seen in Figure 20.

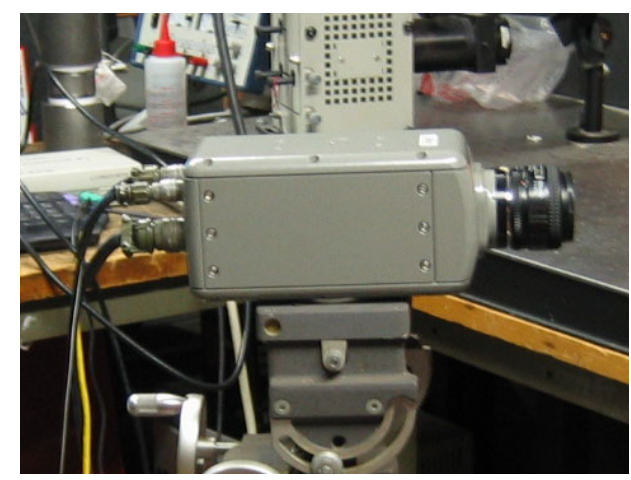

Figure 20: Phantom high-speed camera 
The shadowgraph assembly consisted of two concave mirrors, two large flat mirrors, two small flat mirrors, a high-intensity light source, a pinhole and the high-speed camera. In order to obtain clear images, it is essential that the light travels through the test section exactly perpendicular to the imaged plane. Figure 21 shows a schematic of the experimental rig as well as the setup of the mirrors, optical components and high-speed camera.

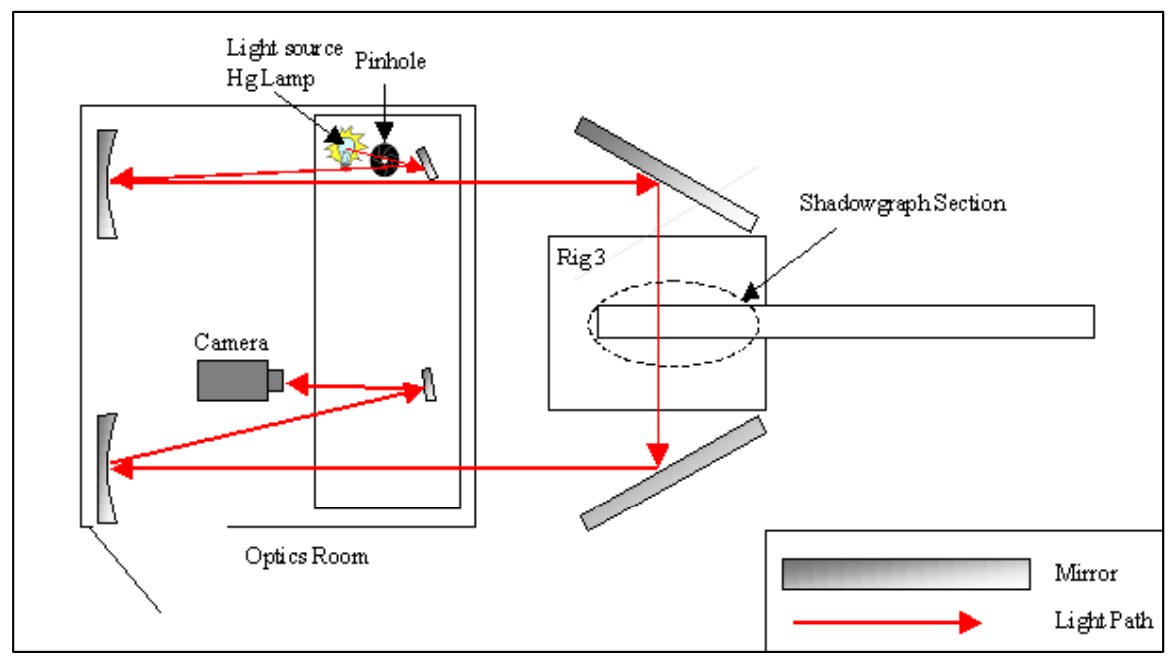

Figure 21: Schematic of shadowgraph assembly

\subsection{Instrumentation}

As stated in the background section, there are many measurable responses to characterize DDT including $\mathrm{x}_{\mathrm{DDT}}, \mathrm{t}_{\mathrm{DDT}}$, etc. In this study, $\mathrm{t}_{\mathrm{e}}$ and $\mathrm{t}_{5}$ were measured using dynamic pressure transducers/ionization probes and shadowgraph, respectively. The pressure transducers were piezo-electric PCB-brand and were placed both $50 \mathrm{~mm}$ and $152 \mathrm{~mm}$ from the end of the tube. The dual location of pressure transducers allowed not only for the determination of $t_{e}$, but also for the calculation of wavespeed. Although the 
downstream transducer was $50 \mathrm{~mm}$ from the end of the tube, it was assumed that the time to reach the last PCB was essentially the same as the time to exit the tube for a wave traveling velocities on the order of $1800 \mathrm{~m} / \mathrm{s}$. In addition, two ionization probes constructed from standard automotive spark plugs were placed at the same axial location at a radial angle of 45 degrees from the PCBs for redundancy. Both forms of instrumentation can be seen in Figure 22.

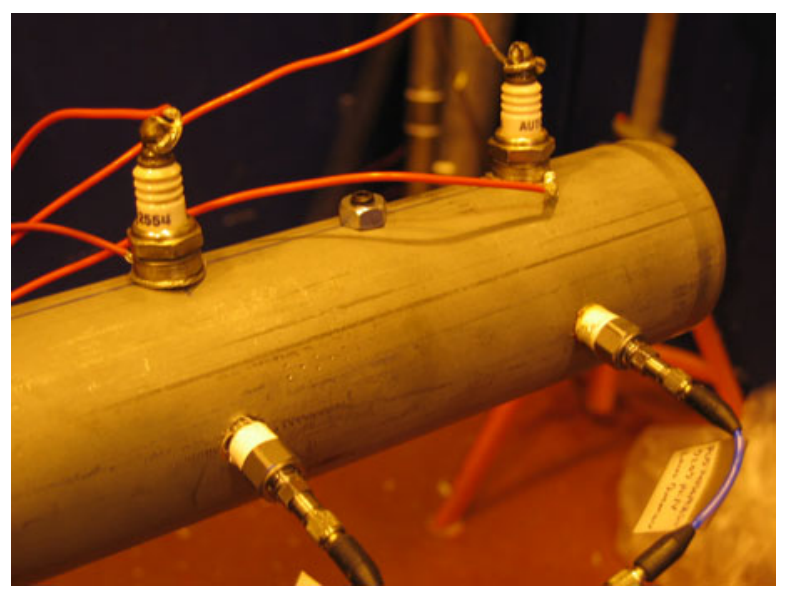

Figure 22: Dynamic pressure transducers and ionization probes used to measure emergence time and wavespeed

\subsection{Rig Operation}

This investigation was divided into two separate studies: a spark study and an airflow velocity study. The rig setup was identical for both studies, however at high airflows in the velocity study an additional fuel valve was added so that enough fuel could flow to achieve a stoichiometric mixture. For the spark study, the PDE tube was run with over $100 \%$ fill of nominally stoichiometric ethylene-air mixture at $10 \mathrm{~Hz}$. Tests were conducted at two air mass flowrates: $0.068 \mathrm{~kg} / \mathrm{s}$ (to be known as Case 1) and 0.136 
$\mathrm{kg} / \mathrm{s}$ (Case 2). For each experiment, the tube was operated for two cycles (two detonations), and the number of sparks activated and the energy per spark was varied through a series of test matrices. All data points in future plots were taken as the average of the first and second detonation. The test run plan as well as the major measured responses for Case 1 of the spark study can be seen in Table 2. Run \#1 in Case 1 is the "baseline" case to which all time increases and decreases were compared.

Table 2: Spark study: case 1 test plan

\begin{tabular}{|c|c|c|c|c|c|c|c|c|c|c|c|c|}
\hline Run \# & $\begin{array}{c}\text { Air Mass Flow } \\
(\mathrm{lb} / \mathrm{s})\end{array}$ & Spark \# & $\begin{array}{c}\text { Spark energy } \\
\mathrm{J} / \text { chan }\end{array}$ & $\begin{array}{c}\text { Air Velocity } \\
(\mathrm{ft} / \mathrm{s})\end{array}$ & Mach \# & $\begin{array}{c}\text { Spark Energy } \\
(\mathrm{J})\end{array}$ & $\begin{array}{c}\text { t5_1 } \\
(\mathrm{ms})\end{array}$ & $\begin{array}{c}\text { t5_2 } \\
(\mathrm{ms})\end{array}$ & $\begin{array}{c}\text { te1 } \\
(\mathrm{s})\end{array}$ & $\begin{array}{c}\text { WS1 } \\
(\mathrm{m} / \mathrm{s})\end{array}$ & $\begin{array}{c}\text { t2 } \\
(\mathrm{s})\end{array}$ & $\begin{array}{c}\text { WS2 } \\
(\mathrm{m} / \mathrm{s})\end{array}$ \\
\hline 1 & 0.294 & 1 & 1.005 & 189.356 & 0.163 & 1.005 & 1.689 & 1.903 & 0.002719 & 1953.8 & 0.002967 & 1881.5 \\
\hline 2 & 0.294 & 2 & 0.504 & 189.356 & 0.163 & 1.008 & 1.612 & 1.825 & 0.002648 & 2257.8 & 0.002946 & 1917.0 \\
\hline 3 & 0.293 & 3 & 0.33 & 188.712 & 0.163 & 0.99 & 1.825 & 2.058 & 0.00295 & 2073.5 & 0.003222 & 1953.8 \\
\hline 4 & 0.295 & 4 & 0.265 & 190.000 & 0.164 & 1.06 & 1.806 & 2.019 & 0.002805 & 1953.8 & 0.003045 & 2032.0 \\
\hline 5 & 0.294 & 2 & 1 & 189.356 & 0.163 & 2 & 1.631 & 1.592 & 0.002678 & 1953.8 & 0.002703 & 1917.0 \\
\hline 6 & 0.295 & 3 & 0.659 & 190.000 & 0.164 & 1.977 & 1.573 & 1.573 & 0.002555 & 1881.5 & 0.002585 & 1917.0 \\
\hline 7 & 0.305 & 4 & 0.504 & 196.441 & 0.170 & 2.016 & 1.554 & 1.67 & 0.002552 & 1917.0 & 0.002724 & 1953.8 \\
\hline 8 & 0.304 & 3 & 1.005 & 195.797 & 0.169 & 3.015 & 1.515 & 1.554 & 0.002542 & 1917.0 & 0.002607 & 1847.3 \\
\hline 9 & 0.301 & 4 & 0.753 & 193.865 & 0.167 & 3.012 & 1.437 & 1.476 & 0.002378 & 1953.8 & 0.002456 & 1881.5 \\
\hline 10 & 0.299 & 4 & 1.005 & 192.577 & 0.166 & 4.02 & 1.379 & 1.476 & 0.002402 & 1953.8 & 0.002478 & 1992.2 \\
\hline 11 & 0.302 & 1 & 0.265 & 194.509 & 0.168 & 0.265 & 2.097 & 2.66 & 0.003262 & 1847.3 & 0.003692 & 1953.8 \\
\hline 12 & 0.307 & 2 & 0.265 & 197.729 & 0.171 & 0.53 & 2.213 & 2.311 & 0.003301 & 1881.5 & 0.003441 & 1917.0 \\
\hline 13 & 0.305 & 3 & 0.265 & 196.441 & 0.170 & 0.795 & 2.155 & 1.981 & 0.00325 & 1992.2 & 0.00308 & 1917.0 \\
\hline 14 & 0.305 & 1 & 0.504 & 196.441 & 0.170 & 0.504 & 1.981 & 2 & 0.003031 & 1917.0 & 0.00313 & 1917.0 \\
\hline 15 & 0.304 & 3 & 0.504 & 195.797 & 0.169 & 1.512 & 1.786 & 2.019 & 0.00282 & 1953.8 & 0.003163 & 1881.5 \\
\hline 16 & 0.304 & 1 & 0.753 & 195.797 & 0.169 & 0.753 & 1.961 & 2 & 0.00302 & 1953.8 & 0.003183 & 1917.0 \\
\hline 17 & 0.303 & 2 & 0.753 & 195.153 & 0.168 & 1.506 & 1.767 & 1.728 & 0.002848 & 1992.2 & 0.002843 & 1917.0 \\
\hline 18 & 0.305 & 3 & 0.753 & 196.441 & 0.170 & 2.259 & 1.612 & 1.651 & 0.002629 & 1814.3 & 0.002701 & 1917.0 \\
\hline
\end{tabular}

The test plan for Case 2 of the spark study can be seen in Table 3 . 
Table 3: Spark study: case 2 test plan

\begin{tabular}{|c|c|c|c|c|c|c|c|c|c|c|c|c|}
\hline Run \# & $\begin{array}{c}\text { Air Mass Flow } \\
(\mathrm{lb} / \mathrm{s})\end{array}$ & Spark \# & $\begin{array}{c}\text { Spark energy } \\
\text { J/chan }\end{array}$ & $\begin{array}{c}\text { Air Velocity } \\
(\mathrm{ft} / \mathrm{s})\end{array}$ & Mach \# & $\begin{array}{c}\text { Spark Energy } \\
(\mathrm{J})\end{array}$ & $\begin{array}{l}5 \_1 \\
(\mathrm{~ms})\end{array}$ & $\begin{array}{l}5 \_2 \\
(\mathrm{~ms}) \\
\end{array}$ & $\begin{array}{l}\text { te1 } \\
\text { (s) }\end{array}$ & $\begin{array}{l}\text { WS1 } \\
(\mathrm{m} / \mathrm{s})\end{array}$ & $\begin{array}{l}\text { t2 } \\
\text { (s) }\end{array}$ & $\begin{array}{l}\text { WS2 } \\
(\mathrm{m} / \mathrm{s})\end{array}$ \\
\hline 1 & 0.148 & 1 & 1.005 & 95.322 & 0.082 & 1.005 & 2 & 2.097 & 0.003171 & 1722.0 & 0.003298 & 1881.5 \\
\hline 2 & 0.147 & 2 & 0.504 & 94.678 & 0.082 & 1.008 & 1.961 & 2.019 & 0.003085 & 1881.5 & 0.003195 & 1814.3 \\
\hline 4 & 0.149 & 4 & 0.265 & 95.966 & 0.083 & 1.06 & 1.884 & 1.884 & 0.002941 & 1847.3 & 0.002982 & 1917.0 \\
\hline 5 & 0.149 & 2 & 1.005 & 95.966 & 0.083 & 2.01 & 2 & 1.961 & 0.003113 & 1917.0 & 0.003131 & 1917.0 \\
\hline 6 & 0.151 & 3 & 0.659 & 97.254 & 0.084 & 1.977 & 1.845 & 1.903 & 0.002887 & 1814.3 & 0.003027 & 1953.8 \\
\hline 7 & 0.152 & 4 & 0.504 & 97.899 & 0.084 & 2.016 & 1.806 & & 0.002869 & 1782.5 & 0.002954 & 1881.5 \\
\hline 8 & 0.152 & 3 & 1.005 & 97.899 & 0.084 & 3.015 & 1.825 & 1.806 & 0.00289 & 1814.3 & 0.002894 & 2208.7 \\
\hline 9 & 0.152 & 4 & 0.753 & 97.899 & 0.084 & 3.012 & 1.728 & 1.767 & 0.002776 & 1847.3 & 0.002878 & 1917.0 \\
\hline 10 & 0.152 & 4 & 1.005 & 97.899 & 0.084 & 4.02 & 1.709 & 1.728 & 0.002754 & 2116.7 & 0.002876 & 2116.7 \\
\hline 11 & 0.152 & 1 & 0.265 & 97.899 & 0.084 & 0.265 & 2.544 & 2.388 & 0.00373 & 1881.5 & 0.003574 & 1953.8 \\
\hline 12 & 0.152 & 2 & 0.265 & 97.899 & 0.084 & 0.53 & 2 & 2.194 & 0.003107 & 1587.5 & 0.003376 & 1917.0 \\
\hline 13 & 0.152 & 3 & 0.265 & 97.899 & 0.084 & 0.795 & 1.981 & 1.942 & 0.003078 & 1751.7 & 0.003088 & 1751.7 \\
\hline 14 & 0.15 & 1 & 0.504 & 96.610 & 0.083 & 0.504 & 2.097 & 2.33 & 0.003257 & 1953.8 & 0.003554 & 2032.0 \\
\hline 15 & 0.149 & 3 & 0.504 & 95.966 & 0.083 & 1.512 & 1.845 & 1.903 & 0.002894 & 1917.0 & 0.003053 & 1881.5 \\
\hline 17 & 0.152 & 2 & 0.753 & 97.899 & 0.084 & 1.506 & 1.942 & 2.078 & 0.00313 & 1847.3 & 0.003253 & 2032.0 \\
\hline 18 & 0.152 & 3 & 0.753 & 97.899 & 0.084 & 2.259 & 1.786 & 1.864 & 0.002891 & 1722.0 & 0.002981 & 1881.5 \\
\hline
\end{tabular}

For the velocity study the spark number and energy was held constant (4 sparks each with $0.265 \mathrm{~J}$ ) while airflow was varied from $0.068 \mathrm{~kg} / \mathrm{s}$ to $0.33 \mathrm{~kg} / \mathrm{s}$. The test plan can be seen in Table 4.

Table 4: Velocity study test plan

\begin{tabular}{|c|c|c|c|c|c|c|c|c|c|c|c|c|c|}
\hline Run \# & $\begin{array}{c}\text { Air Mass Flow } \\
(\mathrm{lb} / \mathrm{s})\end{array}$ & Spark \# & $\begin{array}{c}\text { Spark energy } \\
\mathrm{J} / \mathrm{chan}\end{array}$ & $\begin{array}{c}\text { Air Velocity } \\
(\mathrm{ft} / \mathrm{s})\end{array}$ & Mach \# & Re \# & $\begin{array}{c}\text { Spark Energy } \\
(\mathrm{J})\end{array}$ & $\begin{array}{c}\text { t5_1 } \\
(\mathrm{ms})\end{array}$ & $\begin{array}{c}\text { t5_2 } \\
(\mathrm{ms})\end{array}$ & $\begin{array}{c}\text { te1 } \\
(\mathrm{s})\end{array}$ & $\begin{array}{c}\text { WS1 } \\
(\mathrm{m} / \mathrm{s})\end{array}$ & $\begin{array}{c}\text { t2 } \\
(\mathrm{s})\end{array}$ & $\begin{array}{c}\text { WS2 } \\
(\mathrm{m} / \mathrm{s})\end{array}$ \\
\hline 1 & 0.15 & 4 & 0.265 & 95.966 & 0.083 & 2621.848 & 1.06 & 1.884 & 1.884 & 2.941 & 1847.3 & 2.982 & 1917.0 \\
\hline 2 & 0.3 & 4 & 0.265 & 193.221 & 0.167 & 5278.888 & 1.06 & 1.942 & 1.961 & 2.996 & 1881.5 & 3.105 & 1881.5 \\
\hline 3 & 0.455 & 4 & 0.265 & 293.052 & 0.253 & 8006.313 & 1.06 & 1.748 & 1.534 & 2.844 & 1953.8 & 2.577 & 1953.8 \\
\hline 4 & 0.607 & 4 & 0.265 & 390.950 & 0.337 & 10680.950 & 1.06 & 1.922 & 1.689 & 2.871 & 1917.0 & 2.807 & 1847.3 \\
\hline 5 & 0.725 & 4 & 0.265 & 466.950 & 0.403 & 12757.313 & 1.06 & 1.631 & 1.651 & 2.899 & 1917.0 & 2.932 & 1953.8 \\
\hline
\end{tabular}

\subsection{Data Reduction}

There were two components to the data reduction, the first consisting of reducing high-speed shadowgraph data, and the second consisting of reducing combined PCB/ionization probe data. High-speed shadowgraph images, as seen in Figure 23, were used to determine the time dependent development of the spark kernel into the flame and its subsequent movement down the tube. 


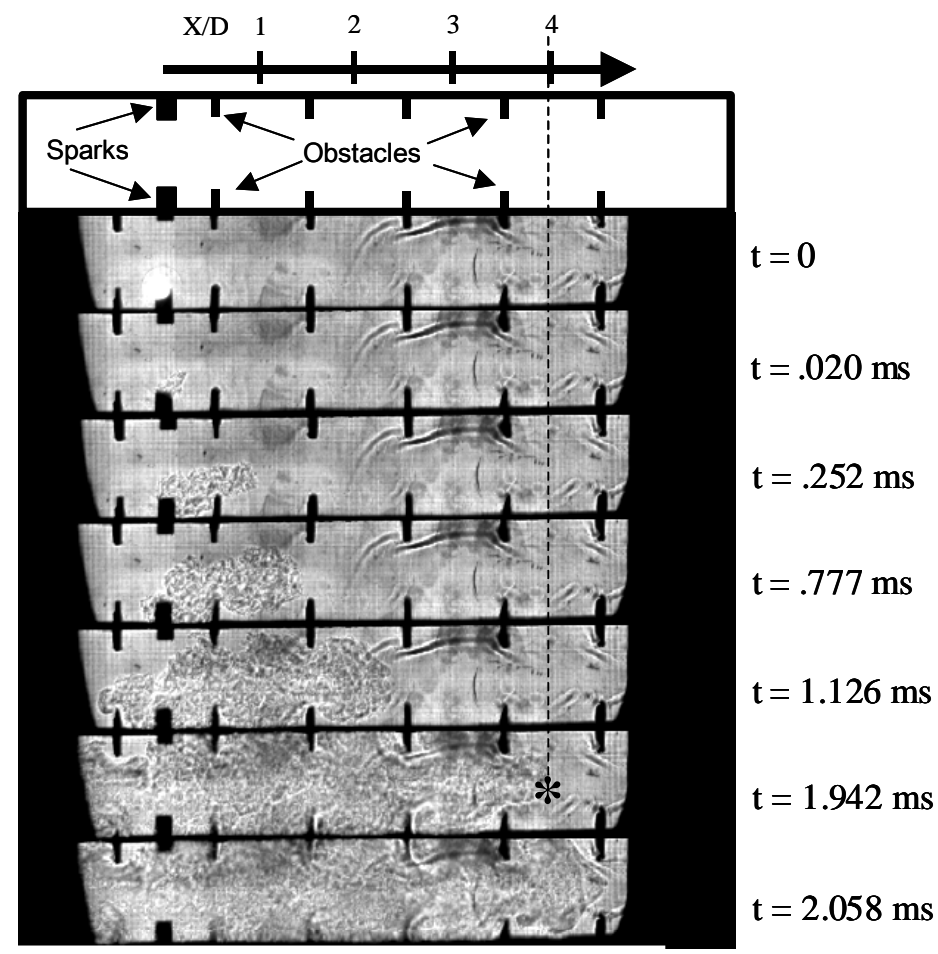

Figure 23: Sequential high-speed shadowgraph images tracking the flame front down the tube

Phantom camera software was used to track this flame front to the $5^{\text {th }}$ obstacle to create run-up plots as seen in Figure 24. These figures were made with data from the baseline case of $0.068 \mathrm{~kg} / \mathrm{s}, 1$ spark at $1 \mathrm{~J}$. The data points up to an $\mathrm{x} / \mathrm{D}$ of approximately five were obtained from the shadowgraph images, while the outer points at an $\mathrm{x} / \mathrm{D}$ of approximately 25 were obtained from the PCB/ionization probe data. All of the plotted points are from the first of two detonations at $10 \mathrm{~Hz}$, and the error bars correspond to the range between the two detonations determined at $t_{5}$ and $t_{e}$. 


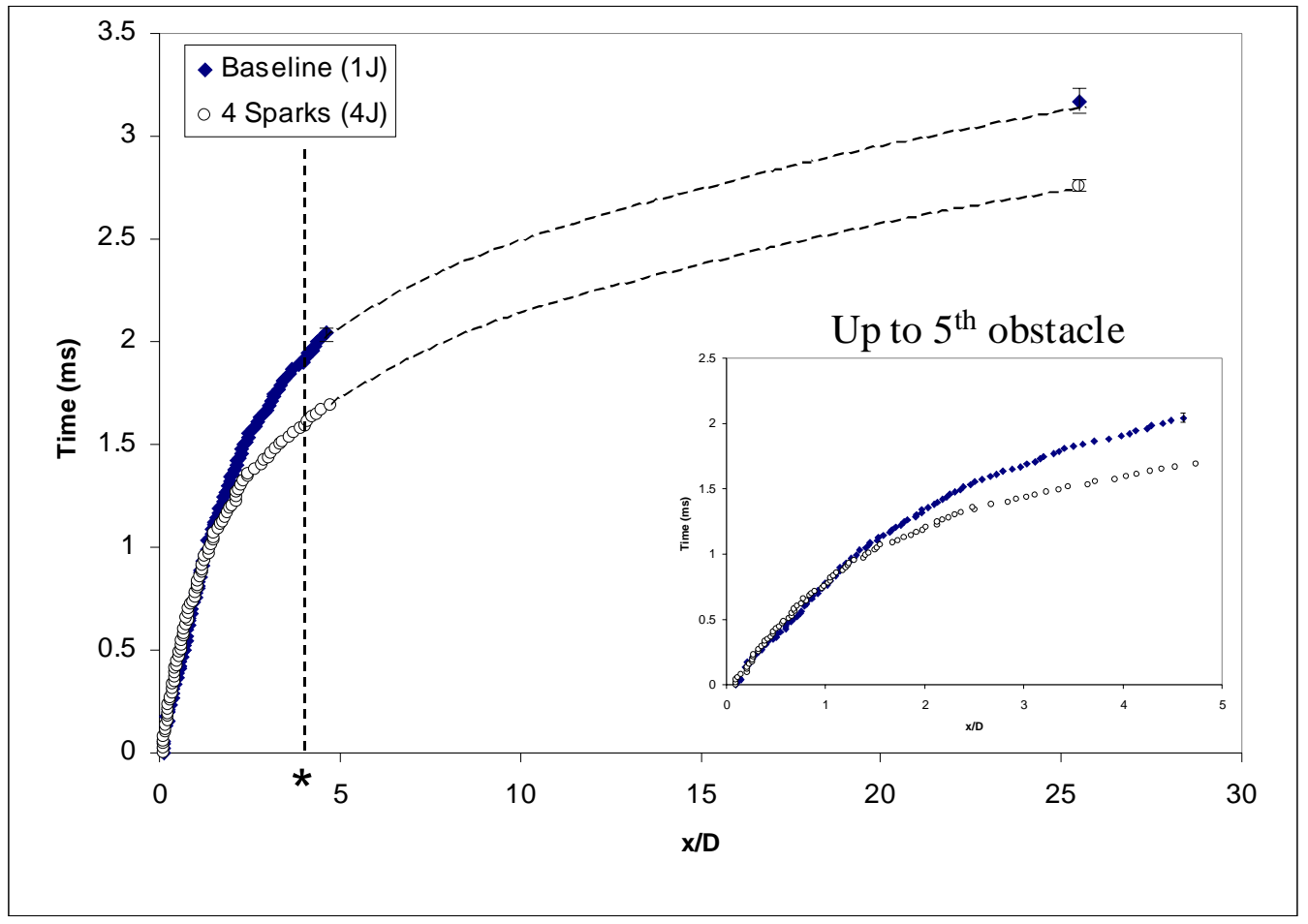

Figure 24: Run-up plot for both the baseline and best run under Case 1 conditions. Note the dotted line corresponding to the flame front position marked by the dotted line in Figure 23.

An example of PCB/ionization probe data can be seen in Figure 25. By knowing that the distance between probes was 4", one could determine both the wavespeed of the detonation wave as well as the emergence time as represented in Figure 24. It is also clear how the redundancy of both $\mathrm{PCB}$ and ionization probe signals aided in a clear reading of wave position. 


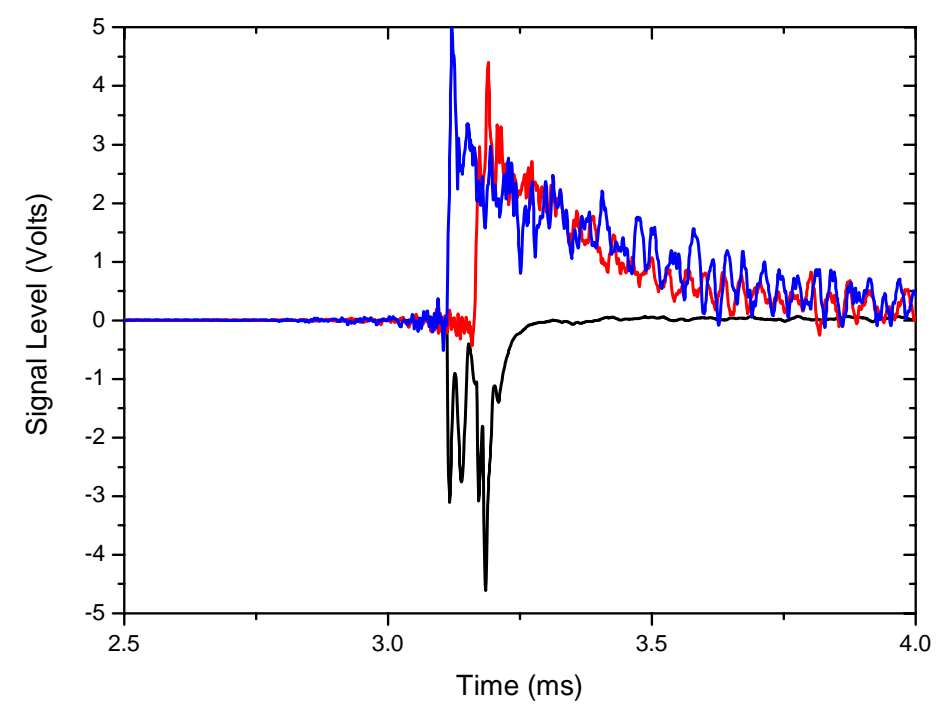

Figure 25: Example PCB and ionization probe traces. The blue trace is the upstream PCB, the red trace is the downstream PCB and the black line is the ionization probe trace 


\section{CHAPTER 4: RESULTS AND DISCUSSION}

\subsection{Spark Study}

This section looks at the effect of total energy and number of sparks on both $t_{5}$ and $t_{e}$. Figure 26 was obtained from a series of lowest airflow (Case 1), $0.068 \mathrm{~kg} / \mathrm{s}$ spark cases. All points are normalized to $2.05 \mathrm{~ms}$, the $\mathrm{t}_{5}$ for the baseline case of one spark, $1 \mathrm{~J}$. This case can be found at the intersection of the crosshairs.

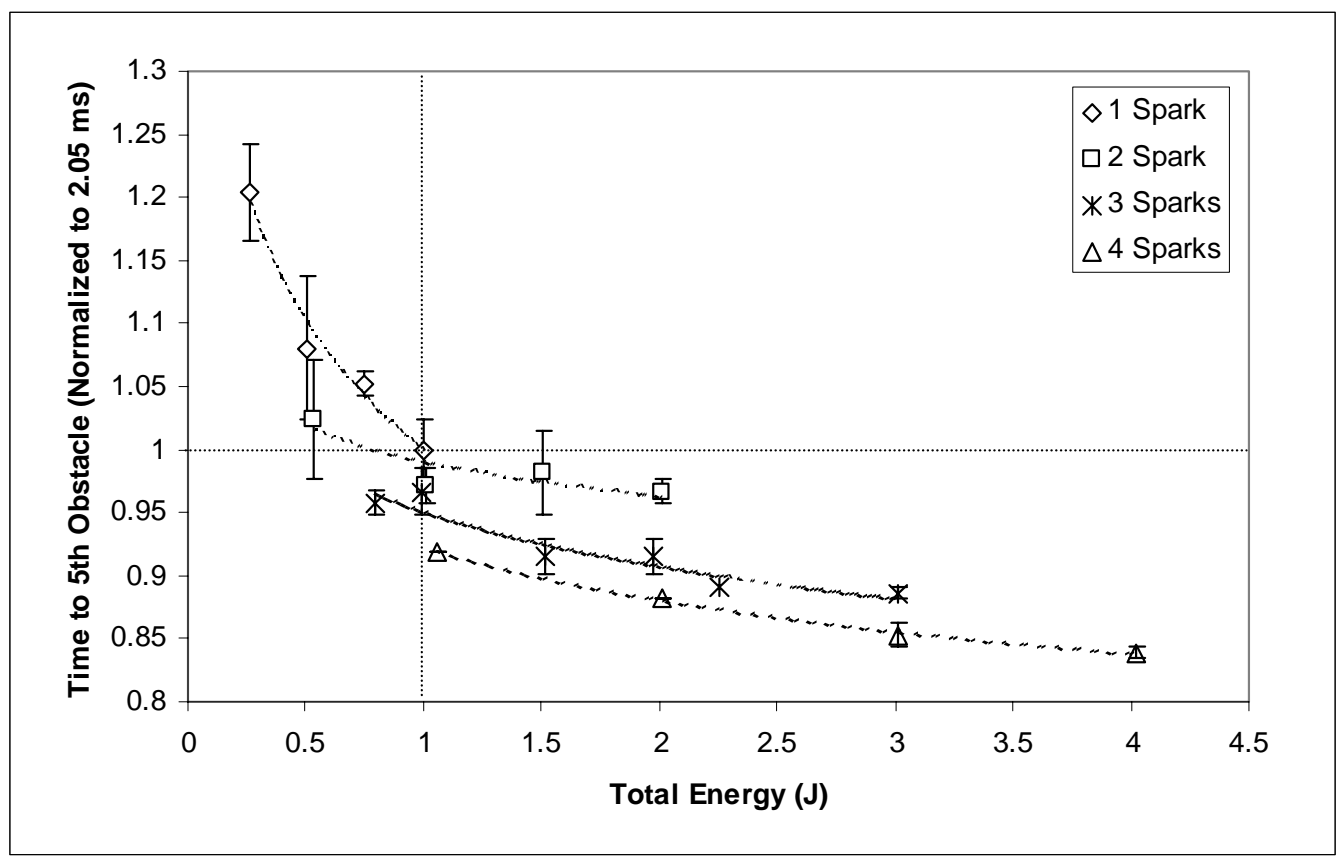

Figure 26: Plot of $t_{5}$ as a function of total energy. Trend lines are drawn between points obtained with the same number of sparks. Error bars represent the range between the two averaged detonations.

It is clear that increased total initiation energy reduces the time it takes the flame front to accelerate. This statement is most apparent in the $16 \%$ improvement over the baseline by increasing total energy from $1 \mathrm{~J}$ to $4 \mathrm{~J}$. This decreased acceleration time can be attributed 
to the relationship between the energy deposited into a fuel/air mixture by a spark, and the volume of the subsequent ignition kernel and its growth as a function of time. As in planar flame front propagation, a spherical spark benefits from a maximization of flame surface area - the more flame surface area, the more contact between the hot front and the unburned fuel/air mixture. However, for a radially propagating flame front, if the surface area of the kernel is too large as compared to the volumetric shell of burning gases, the conductive and radiative heat losses from the hot surface to the cool surrounding unburned reactants will offset the chemical energy of the burning volume, and the kernel will stop propagating [13]. As explained in the literature and evident in this study's data, a higher energy spark will create a volumetrically larger kernel due to the higher power shockwave emanating from the spark plug. According to Maly [13], "The size of the activated volume a given time after spark initiation, the temperature difference across the kernel interface, and the velocity of the interface are all substantially increased by increasing breakdown phase energy." The shockwave creating this larger volume can be visually detected in the $4 \mathrm{~J}$, 4-spark case, as seen in Figure 27.

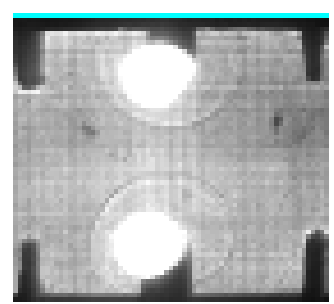

$0.039 \mathrm{~ms}$

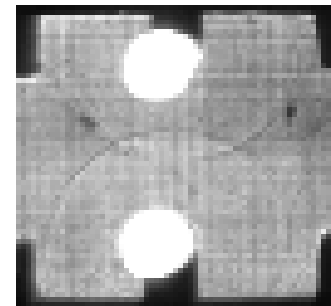

$0.058 \mathrm{~ms}$

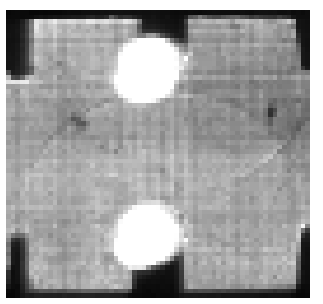

$0.077 \mathrm{~ms}$

Figure 27: Initial shock wave emanating from 4 sparks at $1 \mathrm{~J}$ each 
This more powerful shock creates faster reactant molecular dissociation and thus more rapid creation of radicals. In addition, during ignition this higher powered shock propagates farther from the ignition source and will heat the unburned mixture surrounding the spark, thus making it easier for the flame to expand to these preheated zones. All of these factors lead to overall faster reaction rates and flame spread, and give the higher energy spark an inherently larger starting kernel volume. Figure 28 shows the initial volumetric flame size for a $1 / 4 \mathrm{~J}$ spark as compared to a $1 \mathrm{~J}$ spark $0.175 \mathrm{~ms}$ after ignition. The bright breakdown phase (breakdown of reactant molecules) as seen in Figure 27 has already occurred and the shockwave has dissipated, leaving only a clear difference in flame volume and surface area. This is also consistent with the literature which explains that the "discharges and plasma geometries that produce the largest inflammation zone surface area, most rapidly, are advantageous [for accelerated kernel growth], [13]."
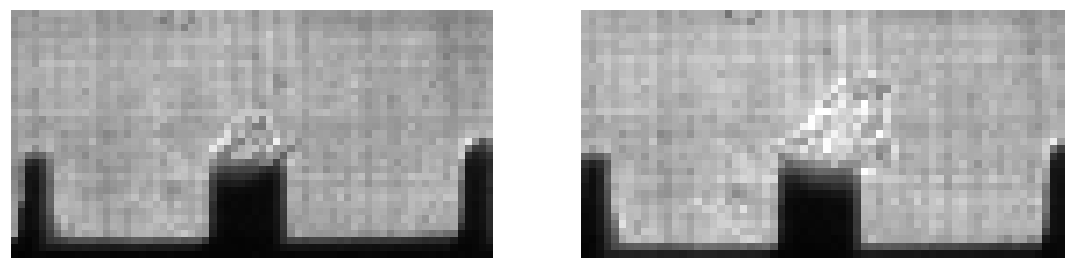

$0.175 \mathrm{~ms}$

Figure 28: Initial spark kernel size 0.175 ms after ignition

Another conclusion drawn when noting the obvious data striations by spark number in Figure 26 is the benefit of distributing energy over multiple sparks. For any given energy value, for example $1 \mathrm{~J}$, there is a clear benefit to distributing that energy over 2-4 sparks rather than concentrating the energy in just one spark. When visually comparing the full frame high-speed video images found in the Appendix a few reasons 
for this multi-spark benefit become visually apparent. If the energy is divided into four sparks versus one or two sparks, each individual spark behaves identically and each create its discrete initial kernel. These kernels will grow at their natural rate based on the specified energy input until they reach a radius at which the multiple kernels come into contact with each other. At this point the kernels coalesce and create one large kernel with a volume larger than the sum of the initial individual kernels. In order for one spark of equal total energy to reach that same volume, a longer amount of time would have had to pass. This is because in the 1-spark case the beginning stages flame of growth did not have the added benefit of the increased surface area inherent to multiple discrete smaller sparks. The volumetric benefit of multiple sparks can be seen in Figure 29. A total of $1 \mathrm{~J}$ was deposited in both cases; however this $1 \mathrm{~J}$ was deposited in one spark on the left and distributed among four sparks on the right.
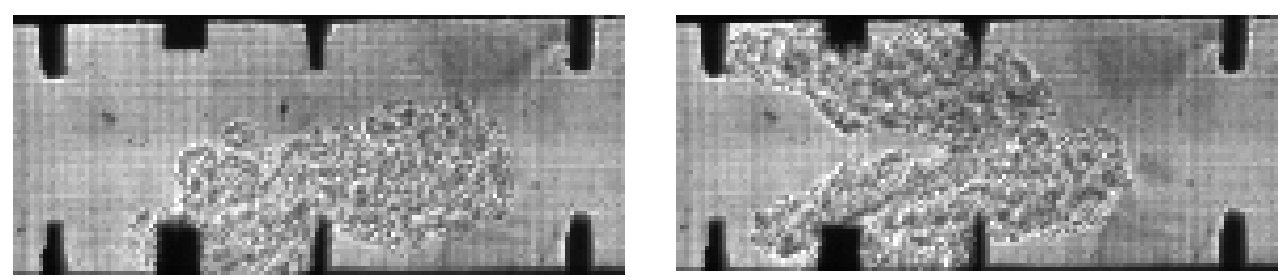

$1.029 \mathrm{~ms}$

Figure 29: Comparison of initial flame acceleration $1.029 \mathrm{~ms}$ after ignition of a 1spark at $1 \mathrm{~J}$ case versus a 4 -spark each with $1 / 4 \mathrm{~J}$ case

Other observations when looking at Figure 26 include that the decrease in $t_{5}$ by the increase of energy also seems to diminish at the highest energies tested. Two regimes begin to stand out, the first where the total energy is less that $1 \mathrm{~J}$, and the second where the total energy is greater than $1 \mathrm{~J}$. In the $\leq 1 \mathrm{~J}$ regime, $\mathrm{t}_{5}$ decreases from 1.2 to 0.91 when increasing energy from $0.25 \mathrm{~J}$ to $1 \mathrm{~J}$. However in the $\geq 1 \mathrm{~J}$ regime $\mathrm{t}_{5}$ only decreases 
from 1 to 0.84 when increasing energy from $1 \mathrm{~J}$ to $4 \mathrm{~J}$. The linear slope in the second regime is an order of magnitude smaller than that in the first regime (-0.4 versus -0.05$)$. These regimes can also be seen in Figure 26.

Additional data was taken during each of these experiments - the full emergence time. It is interesting to see how the benefits of high energy and multiple sparks compare when the data is taken milliseconds later into the total cycle time. Figure 30 shows the same experiments with the PCB pressure transducer data showing total emergence time rather than $\mathrm{t}_{5}$. The same single-spark, $1 \mathrm{~J}$ case was again used as the baseline to which all other cases were normalized.

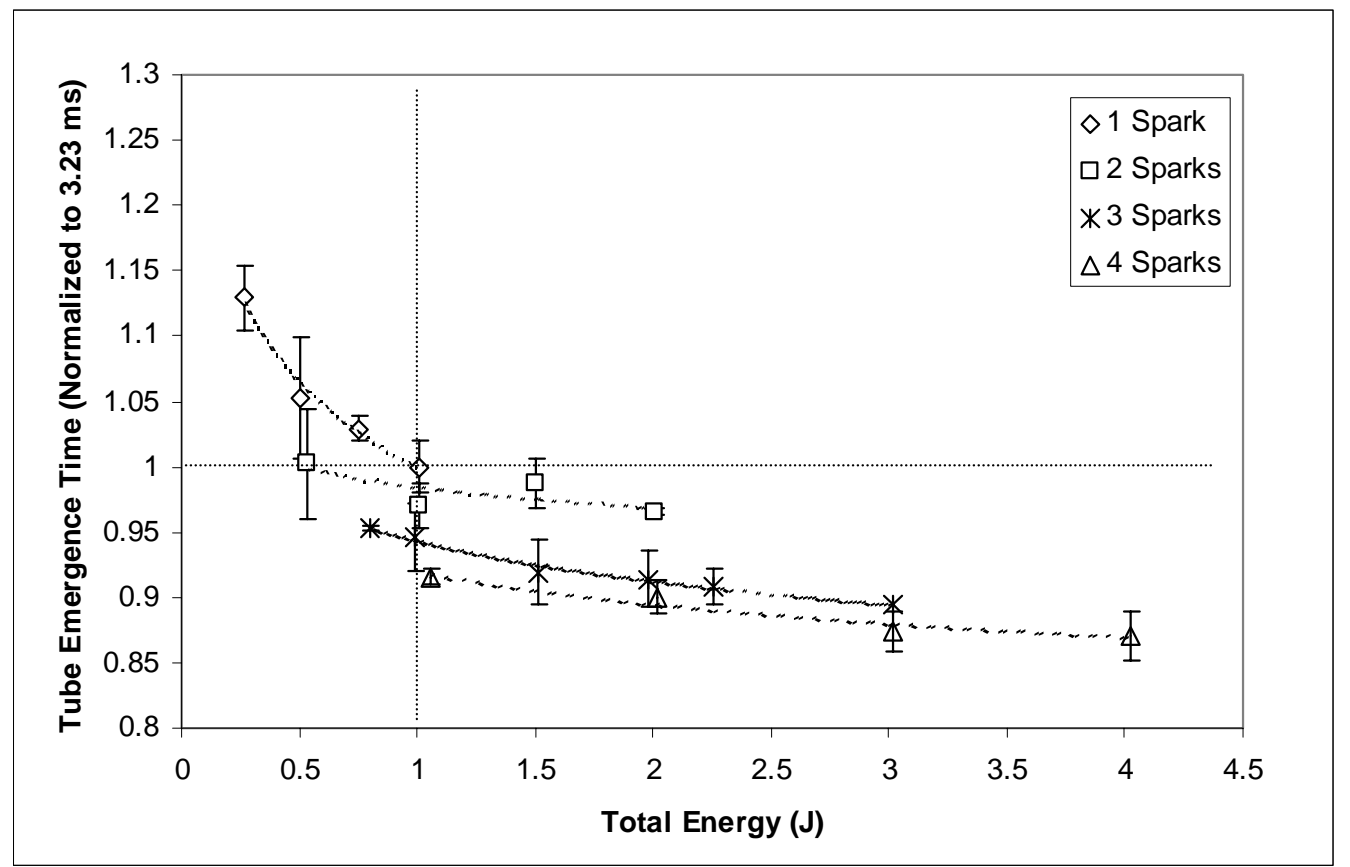

Figure 30: Plot of $t_{e}$ as a function of total energy. Trend lines are drawn between points obtained with the same number of sparks. Error bars represent the range between the two averaged detonations. 
The influence of spark energy on flame acceleration is slightly less significant when measured at the tube exit rather than at the $5^{\text {th }}$ obstacle. Emergence time, $t_{\mathrm{e}}$, decreases by $13 \%$ as compared to the $16 \%$ decrease in $t_{5}$ as spark energy increases from 1 $\mathrm{J}$ to $4 \mathrm{~J}$. This can be attributed to the fact that initial flame acceleration is the largest fraction of the total DDT time. The spark and energy effect gets diluted when adding the relatively short time difference between $t_{e}$ and $t_{5}$ to the $5^{\text {th }}$ obstacle time values. It is exactly this domination by the initial kernel development that motives this study.

Although images taken shortly after spark breakdown have already been discussed, additional insight can be gained by looking at multiple time steps of shadowgraph images showing the beginning stages of flame propagation. Figure 31 looks at three different cases: one spark containing $1 \mathrm{~J}$, two sparks, each with $1 \mathrm{~J}$ and lastly four sparks, each with $1 \mathrm{~J}$. Frames were extracted from the high-speed movies at three times after initial spark breakdown. Full versions of the baseline and 4-spark case (every frame) can be found in the Appendix. 


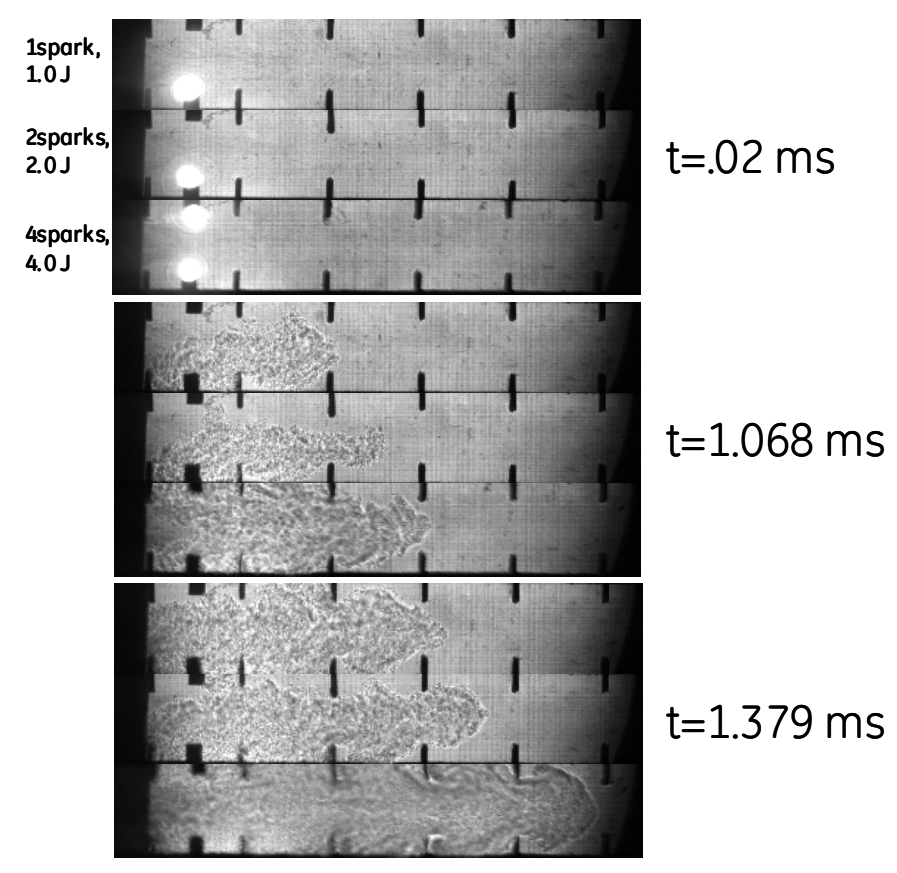

Figure 31: Sequential images from three different cases at three different time steps

At $0.02 \mathrm{~ms}$, the different number of fired sparks is apparent. In the second series of images at $1.068 \mathrm{~ms}$ after spark, one can see how the 4-spark case is pulling ahead, followed by the 2-spark which is closely followed by the 1-spark. It is also clear in the 4spark case how the kernels originating at the two sparks vertical from each other have again coalesced into one flame. It can be assumed that a similar phenomenon is occurring between two sparks positioned horizontally from each other, as found in the 2spark case in Figure 31. In the last series of images, the 4-spark case continues to accelerate faster that the others by advancing two obstacles in the same time that the other two have only advanced one. In this last 4-spark case, one can also start to see some recirculation zones just in front of each obstacle. These recirculation zones give rise to hot spots which can help to further accelerate the flame forward. 
Identical experiments were then performed at a second and higher airflow condition; the Case 2 airflow rate was $0.136 \mathrm{~kg} / \mathrm{s}$.

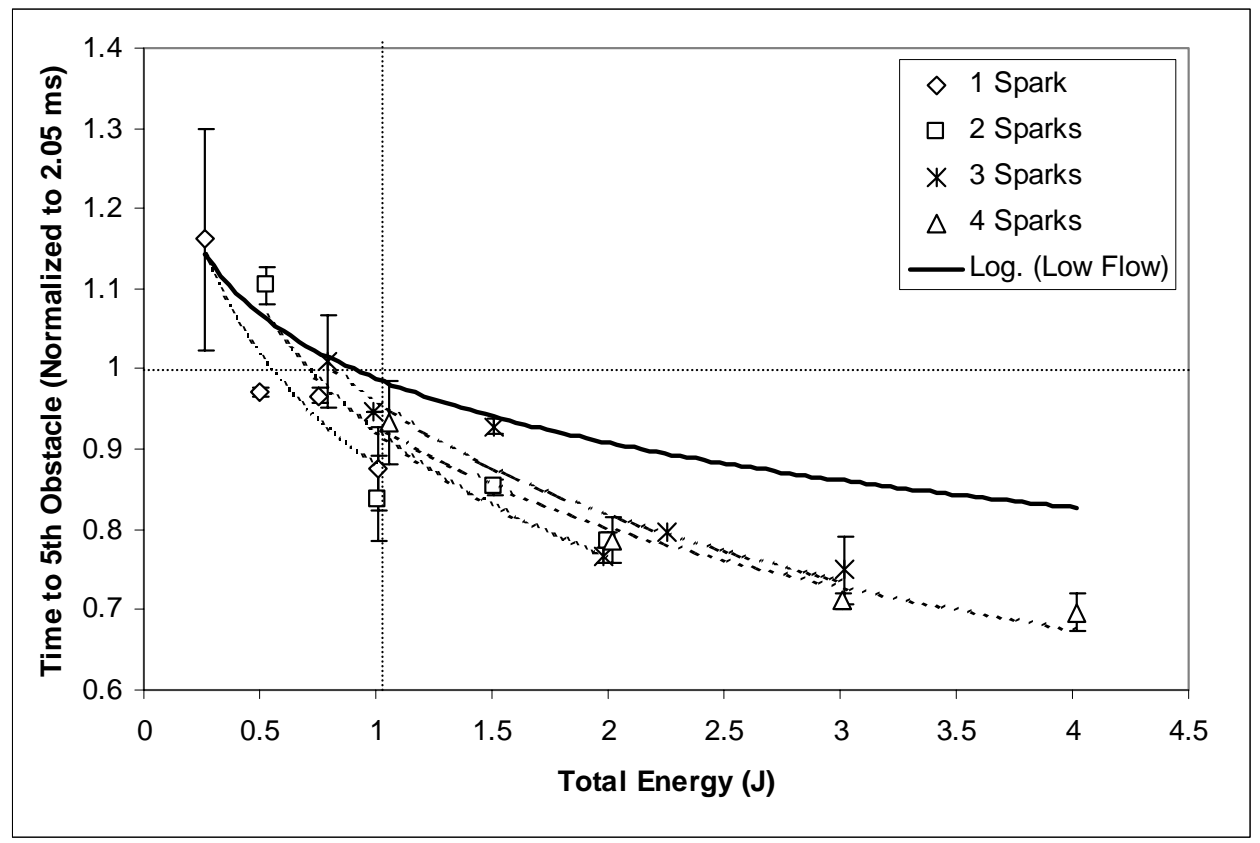

Figure 32: Comparison of $t_{5}$ for Case 1 and Case 2. A single trend line was drawn through all of Case 1 data for simplicity of comparison. The Case 2 points are averaged between two detonations and the error bars represent the range between the two averaged detonations.

The overall shape of the data is relatively similar to the lower flow case, i.e. as energy is increased, $t_{5}$ is decreased; however there are some subtle differences. First there is less of a diminishing return with increasing total energy as found in the lower flow case - the slopes do not flatten out nearly as much. The "baseline" (one spark, $1 \mathrm{~J}$ ) case at this higher flow falls at a $\mathrm{t}_{5}$ of 0.87 and the best case ( 4 sparks, $4 \mathrm{~J}$ ) decreases $\mathrm{t}_{5}$ to 0.69 giving a $20 \%$ improvement over the baseline. This is a more substantial decrease in $t_{5}$ than seen at lower flow cases. 
Additionally, the data does not line-up in clear striations by spark number as seen previously. There are obvious overlaps between spark number-dictated trends for the 2, 3 and 4 spark cases. Therefore, there does not seem to be a clear advantage to distributing the total energy among multiple sparks or concentrating it in one spark. Looking at multiple cases with a total energy of $1 \mathrm{~J}$, the 2 -spark case gives a shorter $\mathrm{t}_{5}$ than the 4 spark case. However at $3 \mathrm{~J}$, the 4 -spark case yields a faster $\mathrm{t}_{5}$ than the 3 -spark case. The clear advantage of multiple sparks as seen in the Case 1 experiments is not abundantly clear for these runs.

Perhaps this unclear benefit of multi-spark distribution stems from a higher turbulence intensity and therefore unpredictable kernel coalescence. If the higher velocity prevents the discrete kernels from reliably becoming one single volume, the advantage of energy distribution is lost and can actually hinder productive flame growth. A comparison of initial flame development in a 2-spark, total of $1 \mathrm{~J}$ case and a 4-spark, total of $1 \mathrm{~J}$ case can be seen in Figure 33. It is clear that the kernels did not optimally coalesce and as a result the 2 -spark case had a faster $t_{5}$.
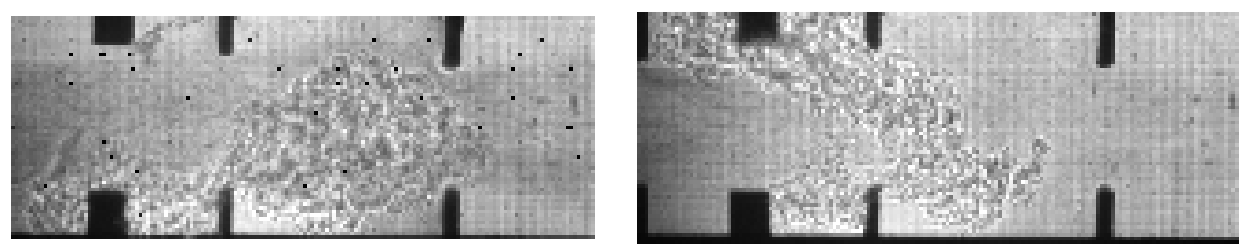

$0.913 \mathrm{~ms}$

Figure 33: Comparison of two cases: $1 \mathrm{~J}$ distributed in 2 sparks and $1 \mathrm{~J}$ distributed in 4 sparks

When comparing across $t_{5}$ and $t_{\mathrm{e}}$ from one airflow to another, one would expect $t_{5}$ and $t_{e}$ to be shorter for higher airflow cases merely due to the faster bulk flow velocity. 
This holds true for almost all total energies, however it is interesting to see that at the lowest spark energies ( $\leq 1 \mathrm{~J}$ regime), airflow seems to have a very small effect on initial flame acceleration.
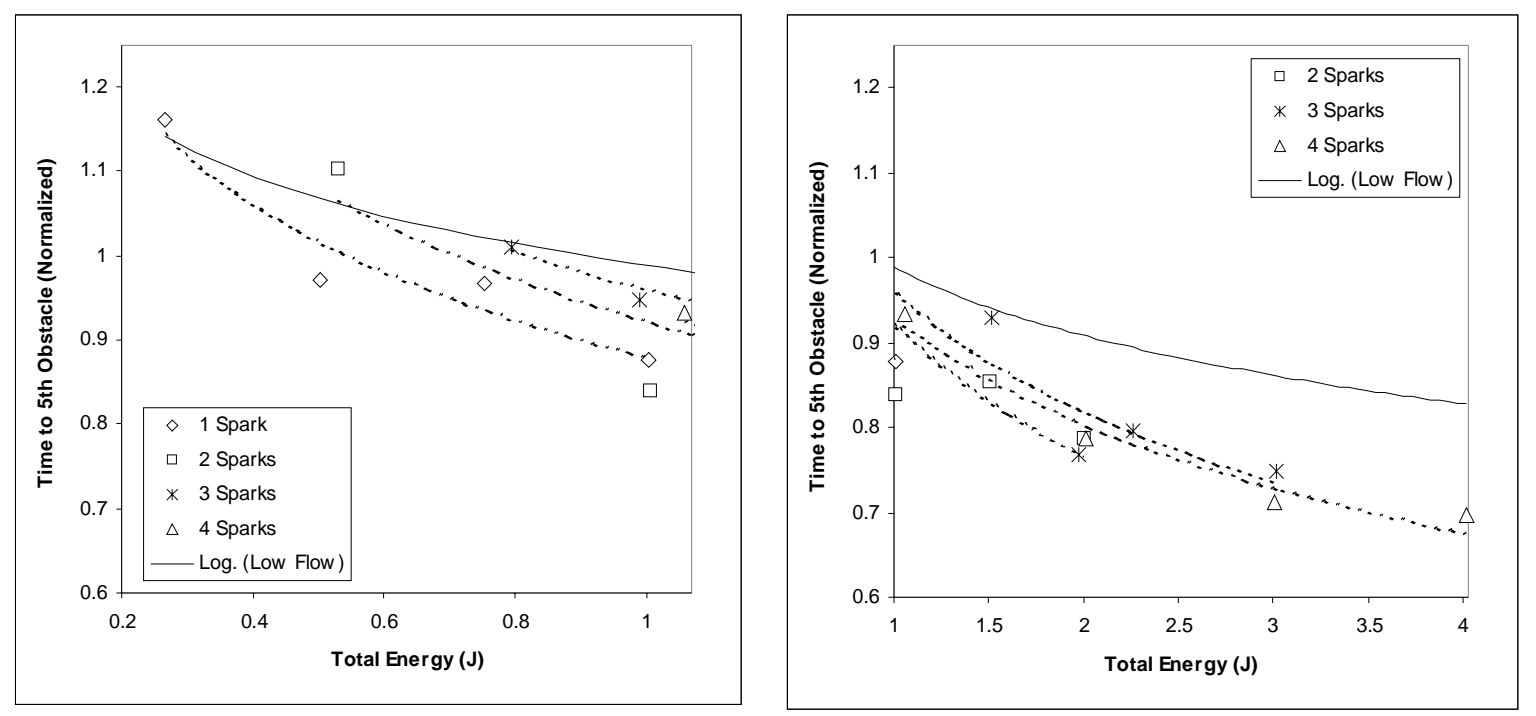

Figure 34: Regimes 1 and 2 when comparing the influence of both airflow and spark energy

In regime 1 , there is a noticable overlap of certain spark number runs at the Case 2 airflow conditions and Case 1 airflow conditions. However, in regime 2, there is a clear divergence distinguishing the effect of spark energy at Case 1 airflows versus Case 2 airflows. This increased influence of spark energy on $t_{5}$ appears to intensify with higher total spark energy. A more detailed look at the effect of airflow and velocity on initial flame acceleration will be discussed in the next section.

\subsection{Velocity Study}

This last section looks at the effect of airflow, or more importantly, velocity on $t_{5}$ and $t_{e}$. Each experiment was run with a constant spark/energy configuration with four 
sparks each at $0.265 \mathrm{~J}$ adding to a total of $1.06 \mathrm{~J}$. Five different air mass flowrates and thus velocities were considered and can be seen in Table 5 .

Table 5: Table of the five air mass flowrates considered and their corresponding velocities, Mach numbers and Reynolds numbers

\begin{tabular}{|c|c|c|c|}
\hline $\begin{array}{c}\text { Air Mass Flow } \\
(\mathrm{lb} / \mathrm{s})\end{array}$ & $\begin{array}{c}\text { Air Velocity } \\
(\mathrm{ft} / \mathrm{s})\end{array}$ & Mach \# & Re \# \\
\hline 0.15 & 95.966 & 0.083 & 2621.848 \\
\hline 0.3 & 193.221 & 0.167 & 5278.888 \\
\hline 0.455 & 293.052 & 0.253 & 8006.313 \\
\hline 0.607 & 390.950 & 0.337 & 10680.95 \\
\hline 0.725 & 466.950 & 0.403 & 12757.31 \\
\hline
\end{tabular}

The Reynolds number (assuming a smooth, obstacle-free pipe) was calculated using the following equation with the density and viscosity of air. The length scale chosen was the hydraulic diameter of the $2 \mathrm{D}$ visualization section and corresponds to the $\mathrm{D}$ in $\Pi D^{2} / 4$ for a 2" x 2" cross sectional square area.

$$
\operatorname{Re}=\frac{\rho V D_{h y d}}{\mu}=\frac{(1.21)\left[\mathrm{kg} / \mathrm{m}^{3}\right](V)[\mathrm{m} / \mathrm{s}](.0015)\left[\mathrm{m}^{2}\right]}{(1.97 E-05)\left[N \cdot s / \mathrm{m}^{2}\right]}
$$

The first two velocities (95 ft/s and $193 \mathrm{ft} / \mathrm{s}$ ) correspond to the Case 1 and Case 2 airflows discussed in the spark study, respectively. Figure 35 shows both $t_{e}$ and $t_{5}$ for each velocity case. 


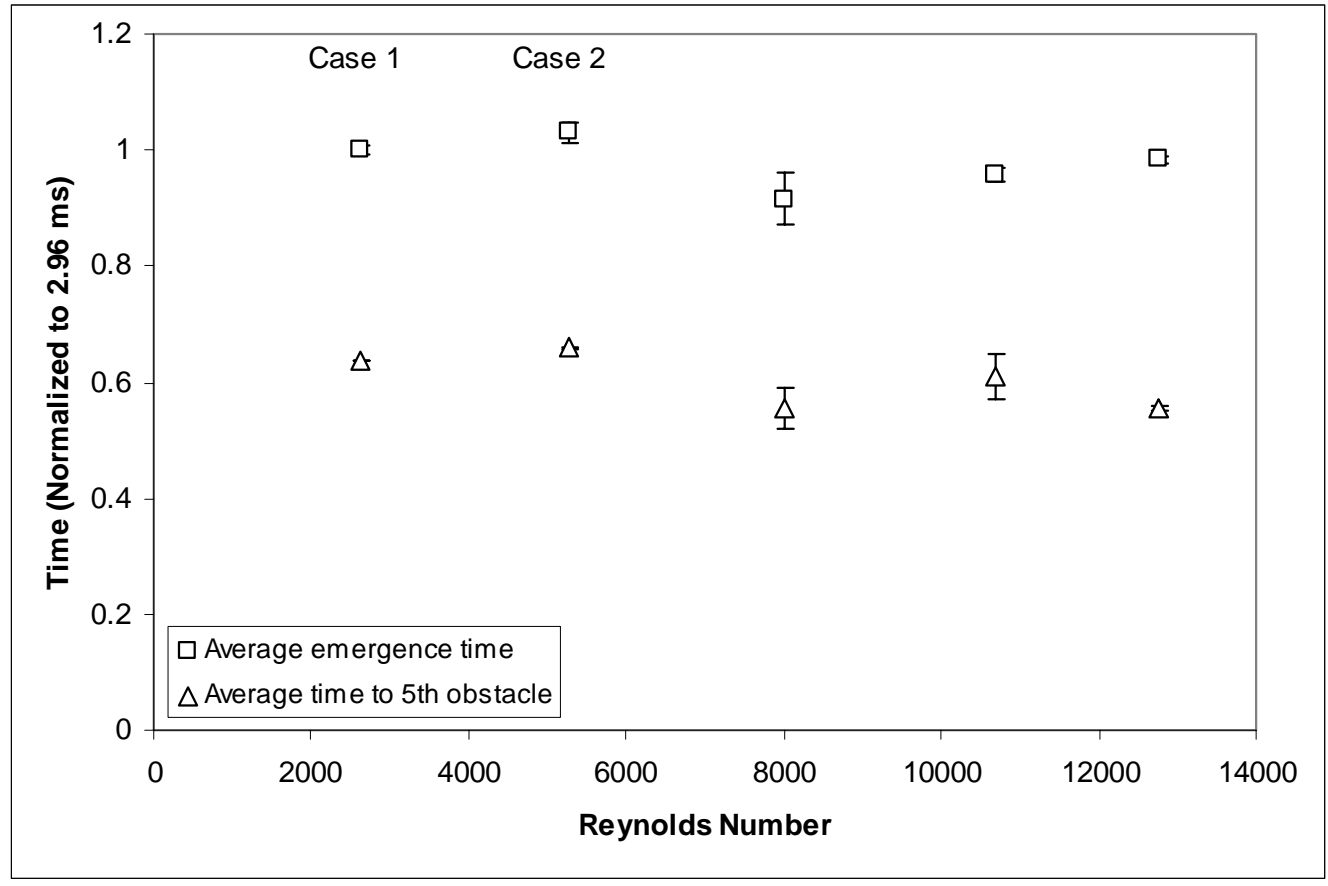

Figure 35: The average $t_{e}$ and $t_{5}$ for five different airflow velocity cases. The error bars represent the range between the two averaged detonations.

The $y$-axis has been normalized to the value of $t_{\mathrm{e}}$ for the Case 1 airflow, 4-spark, $1 \mathrm{~J}$ run. The error bars show $+/-$ half the range between the measured $t_{e}$ and $t_{5}$ for the two detonations. According to this data, there does not appear to be a strong correlation between Reynolds number, i.e. velocity, and emergence time. This is consistent with the observation made in the section 4.1, stating that the effect of airflow is minimal at lower total energies ( $1 \mathrm{~J}$ and below). It was shown in Figure 34 that at total energies reaching 4 $\mathrm{J}$, the effect of airflow becomes more significant. This is consistent with the findings by Cho et. al. who found that the effect of spark energy has a more significant effect on kernel growth than velocity, or in their case, turbulence. However, Cho et. al. found that as spark energy was increased, the influence of turbulence became less significant, while this study found a more pronounced effect of velocity at higher spark energies. 
When looking at high-speed video of certain velocity cases, one can observe a possible reason for the unpredictable relationship between velocity and propagation time at low spark energies. In Figure 36 it first appears that the highest velocity case is resulting in the fastest initial flame acceleration. However, once a millisecond elapses, the flame in the highest velocity case appears to stretch and be partially extinguished due to flame strain. This is most apparent in the $466 \mathrm{ft} / \mathrm{s}$ case at both 1.068 and $1.379 \mathrm{~ms}$. Pieces of the flame actually break off and the flame appears to lack the overall volumetric substance required to sustain a fast burn rate. Frame-by-frame versions of these three runs can be found in the Appendix.

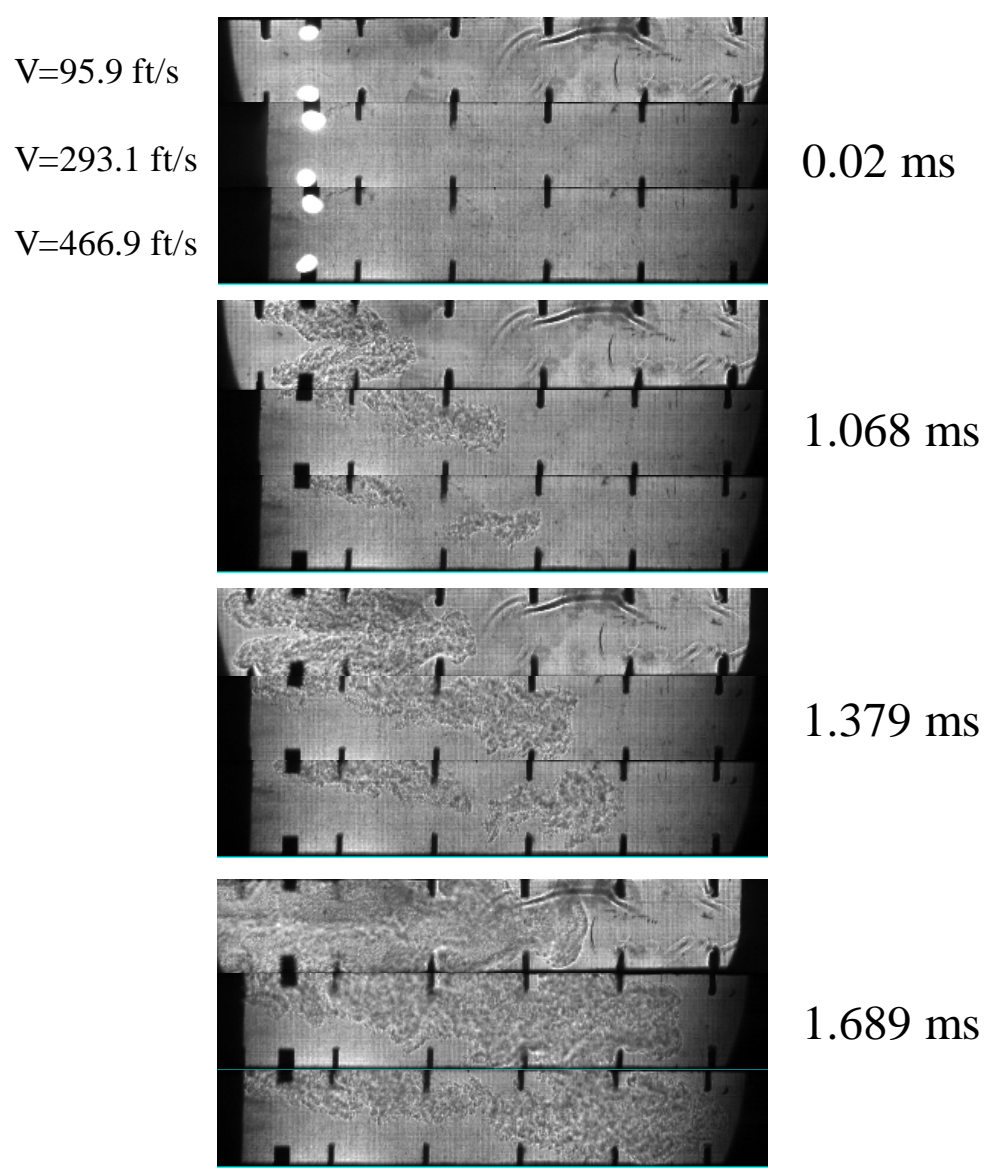

Figure 36: Sequential pictures of three velocity cases at four discrete time steps 
As stated previously, in order for a flame to be self-propagating, the volumetric burn rate must be able to overcome the conductive and radiative losses at the surface. With such extreme flame stretch, the increased surface area works against flame acceleration and the chemical time scale cannot keep up with the turbulent time scale. As a result, the Dahmköhler number which is a measure of a characteristic turbulent time scale (turbulent eddy turnover time) as compared to a chemical reaction time scale in this case is less than one [14]. As the air velocity is increased, the turbulence intensity also increases, thus bringing the Dahmköhler number even lower. When looking at a Borghi Diagram, the reaction discussed reaction falls in the "broken reaction zone" which approaches a well-stirred reactor. It can be assumed that at a certain threshold velocity and therefore turbulent time scale (yet to be experimentally verified) the entire flame will extinguish resulting in no propagation or DDT.

Again looking at Figure 36, the images indirectly explain the phenomenon seen in Figure 12 by Hickey et. al. Their drawn schematic shows an increase in flame acceleration when the secondary flames (with the initial benefit of being located farther down the tube) are enhanced by a primary "supporting flame" which provides volumetric substance upstream. It is this volumetric support or backing momentum, that the high velocity flame kernels lack by being spread so thinly. It appears that having downstream sparks (or in this study, quickly swept flames) cannot reliability result in faster flame acceleration without a significant upstream flame to propel the main front forward.

The results found in section 4.1 showed that increasing velocity did indeed have a predictive benefit on flame acceleration at higher total spark energies (on the order of 4 
J). Perhaps this is because these high energies provide a chemical burn rate that can keep up with the turbulent time scale, thus preventing the flame breakage and localized extinction.

Lastly, the experimental velocity cases in Figure 36 provide a quantitative and visual representation of the percentage of time that the flames takes to arrive at the $5^{\text {th }}$ obstacle as compared to the total time to exit the tube. The $5^{\text {th }}$ obstacle is $22.9 \mathrm{~cm}$ from the spark location, approximately $15 \%$ of the distance from the spark to the end of the tube; yet it takes on average $60 \%$ of the total cycle time to get there. This powerful observation is visually represented in Figure 37.

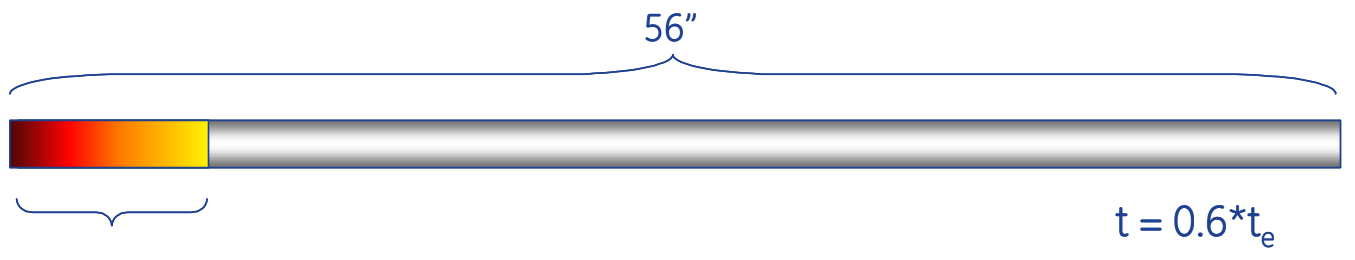

$8.4^{\prime \prime}$

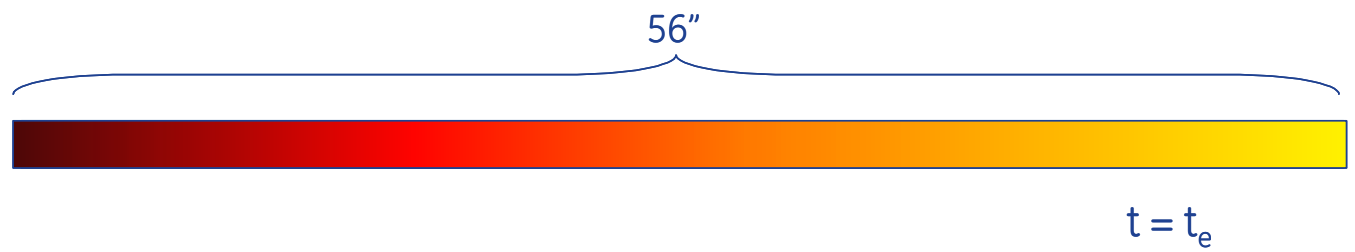

Figure 37: Comparison of total length of tube traveled by wave versus total duration of time traveled

This demonstrates why understanding and optimizing initial flame kernel development and growth can significantly reduce total flame propagation time, and therefore increase PDE operating frequency and performance. Although does not appear that airflow has an appreciable effect on these parameters at the low total energies, it was shown in section 4.1 that the 4 -spark, $4 \mathrm{~J}$ case at $0.136 \mathrm{~kg} / \mathrm{s}$ of airflow resulted in a $15 \%$ 
faster $\mathrm{t}_{5}$ than the $0.068 \mathrm{~kg} / \mathrm{s}$ 4-spark, $4 \mathrm{~J}$ case. It is recommended that a further investigation of the effect of airflow velocity on flame emergence time include higher spark energy cases. 


\section{CHAPTER 5: CONCLUSIONS}

The influence of spark energy and number of sparks on Deflagration-toDetonation Transition (DDT) was studied during cyclic operation of a small-scale PDE. For stoichiometric mixtures of ethylene and air at ambient temperature and pressure, the total spark energy was varied from $250 \mathrm{~mJ}$ to $4 \mathrm{~J}$ and was distributed between one and four spark plugs located in the same axial location. Initial flame acceleration, imaged using high-speed shadowgraph, showed that the flame front spread was faster at higher spark energies and with more spark locations. Initial flame acceleration, as characterized by measuring time for the flame front to reach $20 \mathrm{~cm}$ from the spark plug, was $40 \%$ faster

for 4 sparks each at $1 \mathrm{~J}$ compared to 1 spark at $250 \mathrm{~mJ}$, and $16 \%$ faster when compared to the baseline 1-spark, $1 \mathrm{~J}$ case. A closer look at the mechanism behind spark ignition including shockwave intensity and propagation radius helped uncover the reasons behind the observed trends. Further, a benefit to distributing energy among multiple sparks at this Case 1 airflow rather than collecting the energy in one spark also showed an enhanced flame acceleration. This was attributed to multi-kernel coalescence and a larger volumetric flame area.

Measurements of emergence time showed similar results to measurements of $t_{5}$. However, the benefits gained by increasing and distributing energy as found in $t_{5}$ was less substantial at $t_{e}$. This was due to the domination of $t_{5}$ in the total tube propagation time. The difference between $t_{e}$ and $t_{5}$ is almost identical from case to case and therefore dilutes the measurable changes as measured during the initial acceleration.

When looking at the effect of velocity on the influence of spark energy, it was found that airflow had a larger effect on $t_{e}$ and $t_{5}$ at high energies, versus energies less 
than $1 \mathrm{~J}$. This was attributed to faster chemical reaction time that could compete with the higher velocities and thus faster turbulent time scales. Finally, for a selected case of $1 / 4 \mathrm{~J}$ spark energy and 4 sparks, the velocity of the fuel-air mixture during fill was found to have only a minor influence on detonation initiation and emergence time. Shadowgraph images revealed significant flame strain and localized extinction. The high velocity cases created a thin, weak flame which lacked the volumetric core to accelerate the flame downstream. 


\section{CHAPTER 6: FUTURE WORK}

This study has shown a clear influence of spark energy on initial flame development and it would be useful to determine the entitlement of this influence by increasing spark energy and/or number of sparks even further, perhaps until approaching direct initiation values. With the high-speed movie data already collected, additional analysis could be done regarding the flame growth and propagation not only in the downstream direction, but also in the upstream and vertical directions. A measure of volumetric growth could be used as an indicator of chemical time scales to characterize the flame. Turbulence intensity measurements (hot wire), rather than airflow or velocity measurements would also be useful in characterizing the flame spread regime and to better quantify the localized flame extinction seen in the high-speed movies. Experiments with even higher air velocities should be conducted until total extinction is observed, and this threshold turbulence time scale versus chemical reaction time should be quantified. Also, as mentioned in section 4.2, it would be useful to repeat the velocity study at higher spark energies, to determine if the divergence seen in Figure 34 continues and provides an increased benefit.

Other interesting experiments include a study in which the sparks are arranged laterally along the length of the tube, or perhaps simply placed at the middle or the end of

the tube. Lastly, conducting CFD simulations to complement the data found in this study would be extremely valuable. 


\section{APPENDIX}

A. Spark energy/fuel energy calculation:

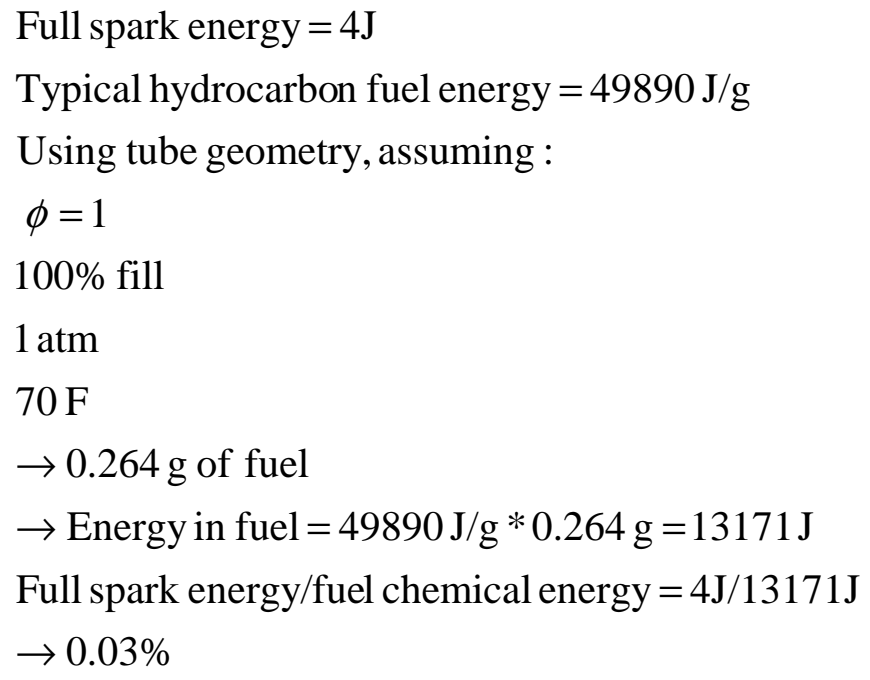

\section{B. Raw Data Sheets}

1) Spark Study: Case 1

2) Spark Study: Case 2

3) Velocity Study 


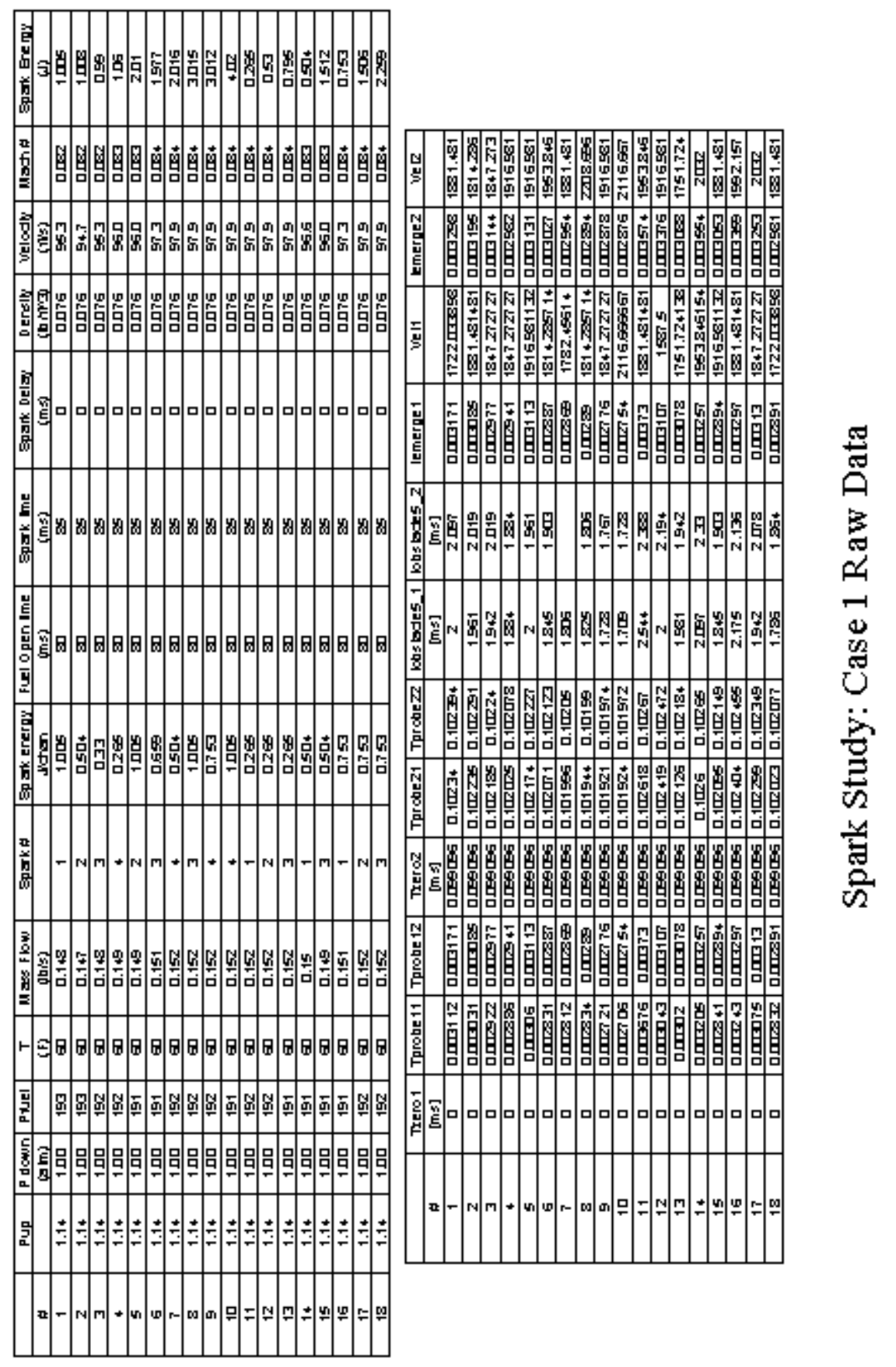



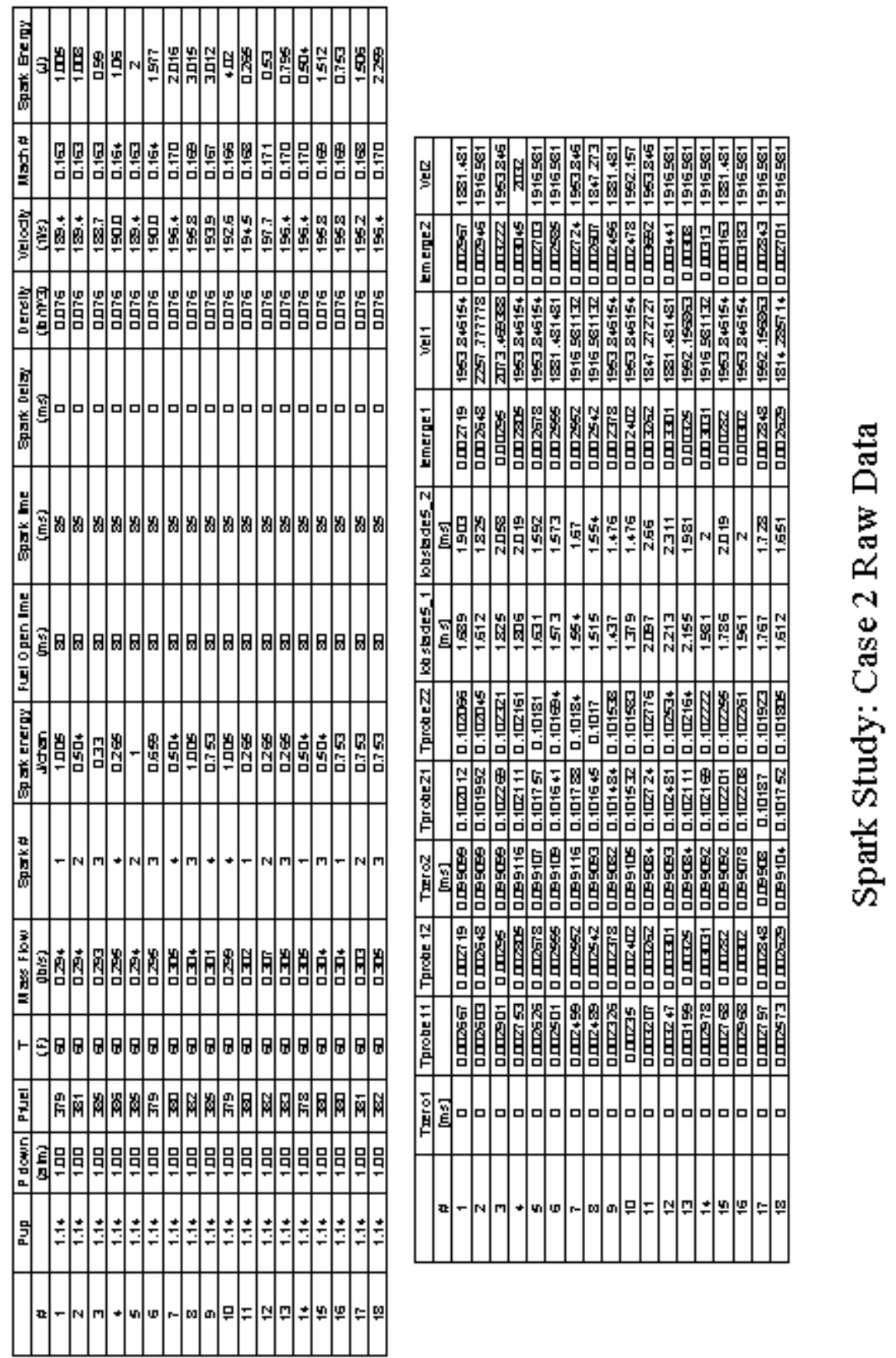

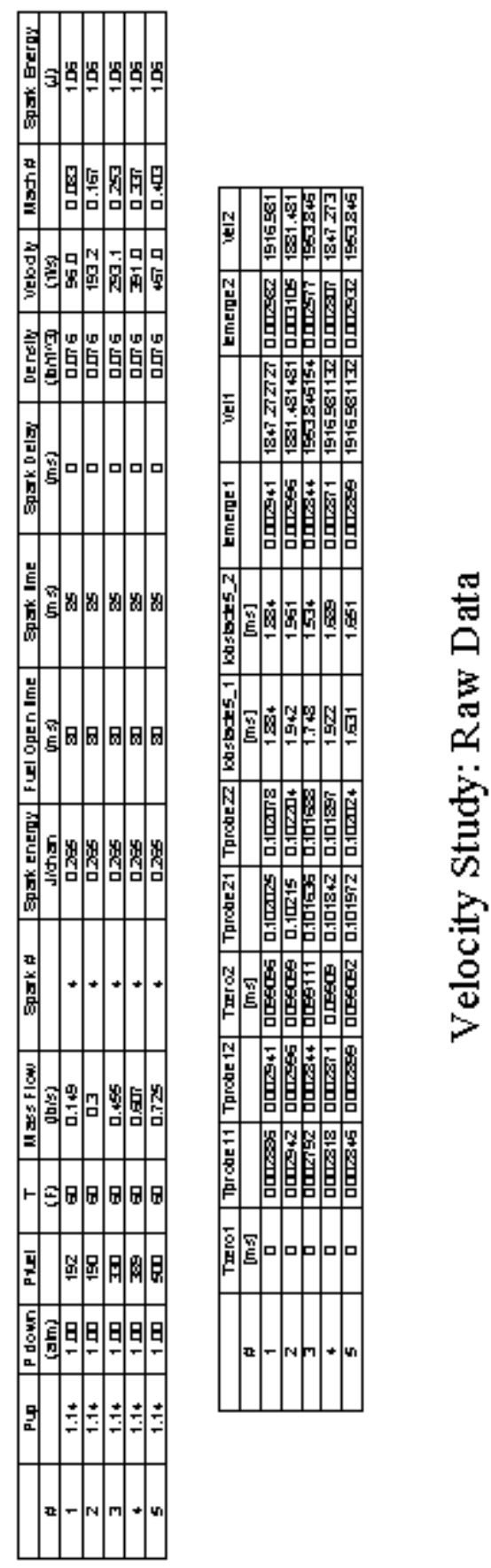


\section{Selected Full Frame Shadowgraph Movies}

Baseline (Case 1, run 1)

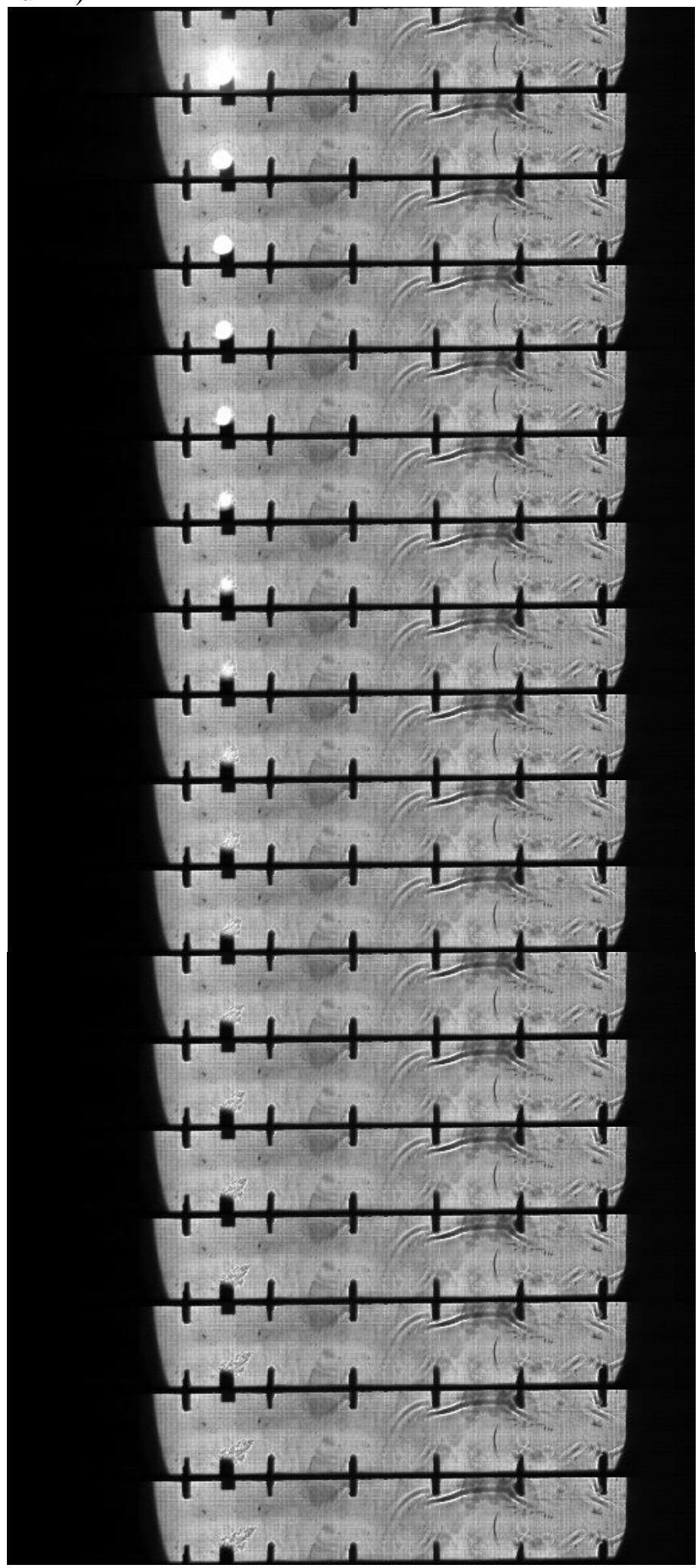




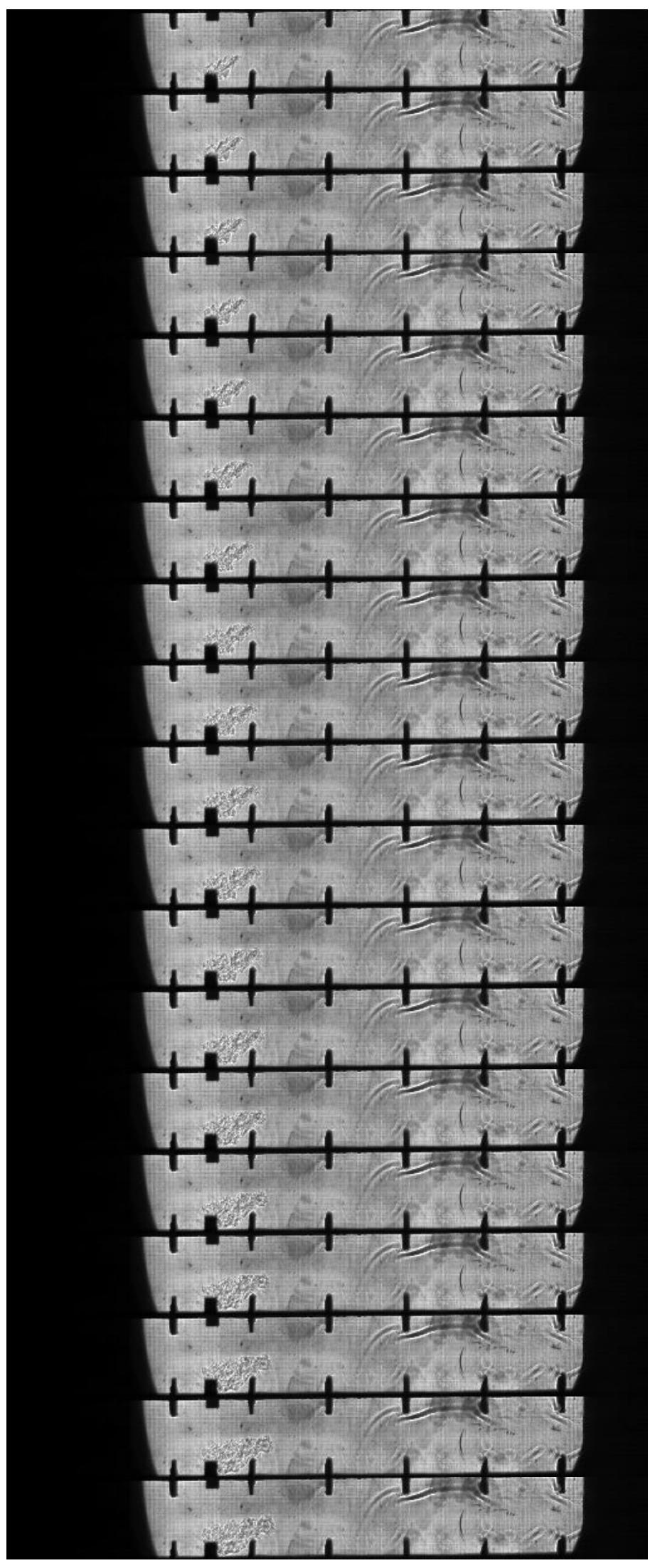




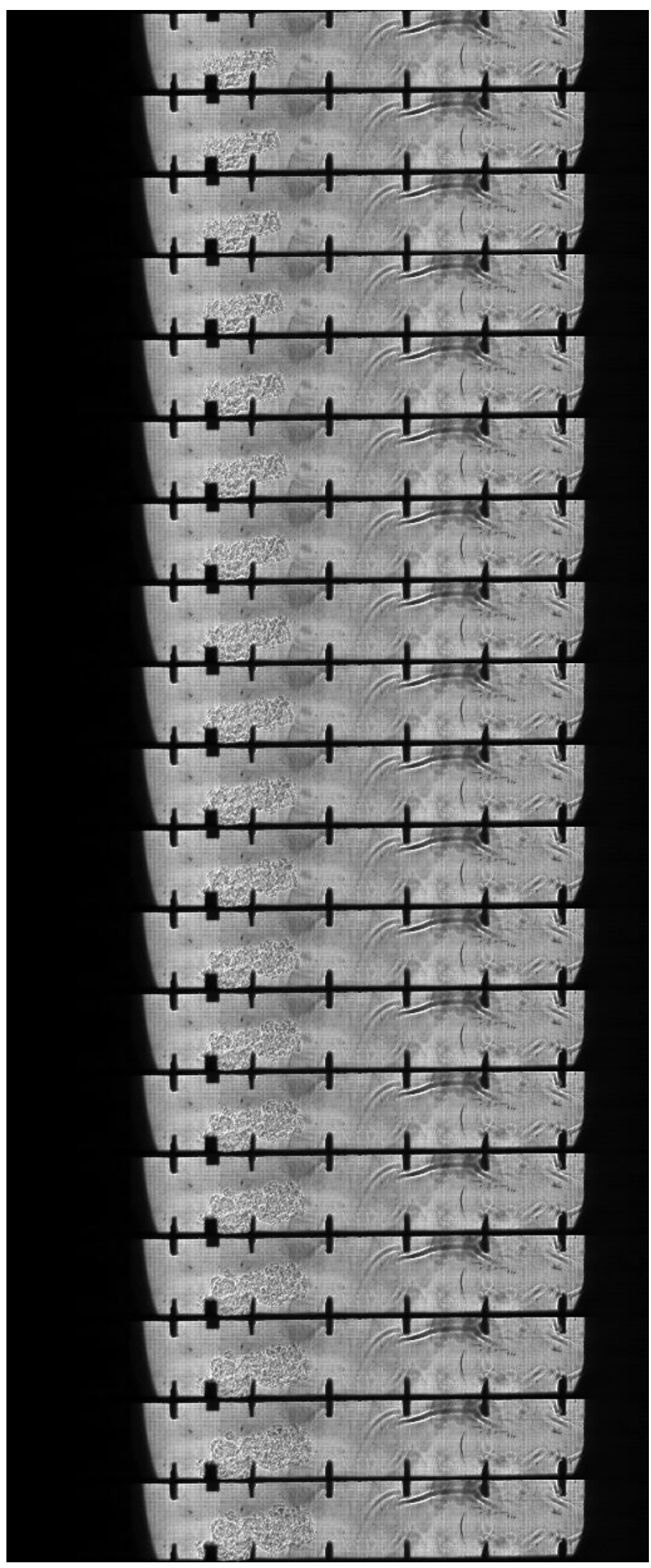




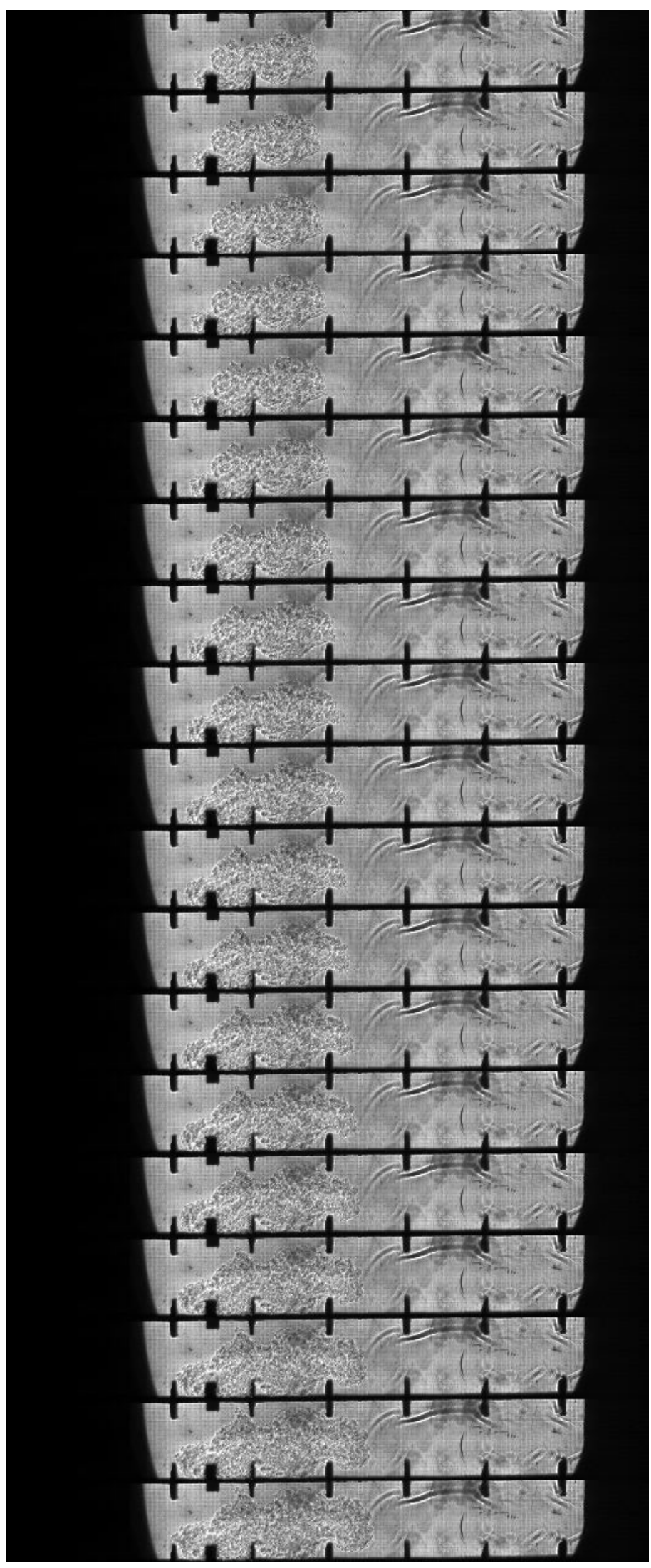




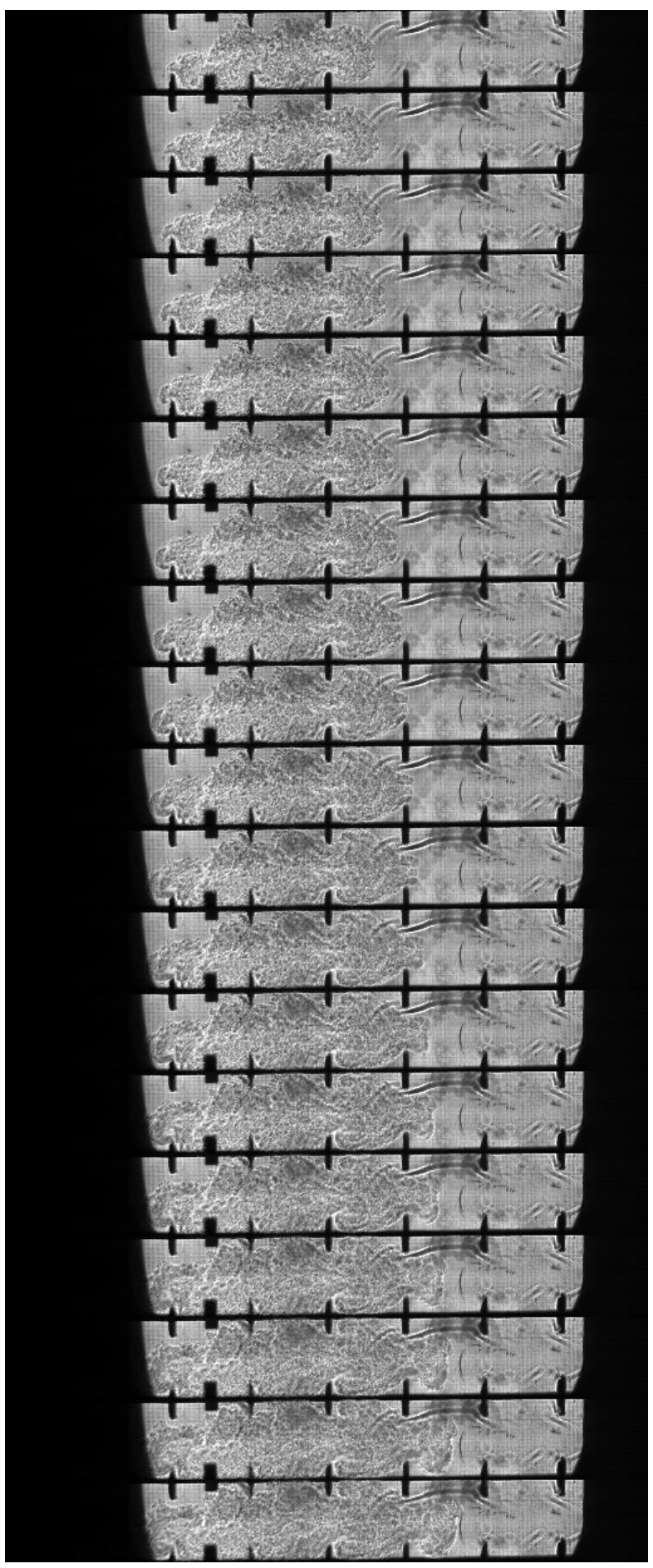




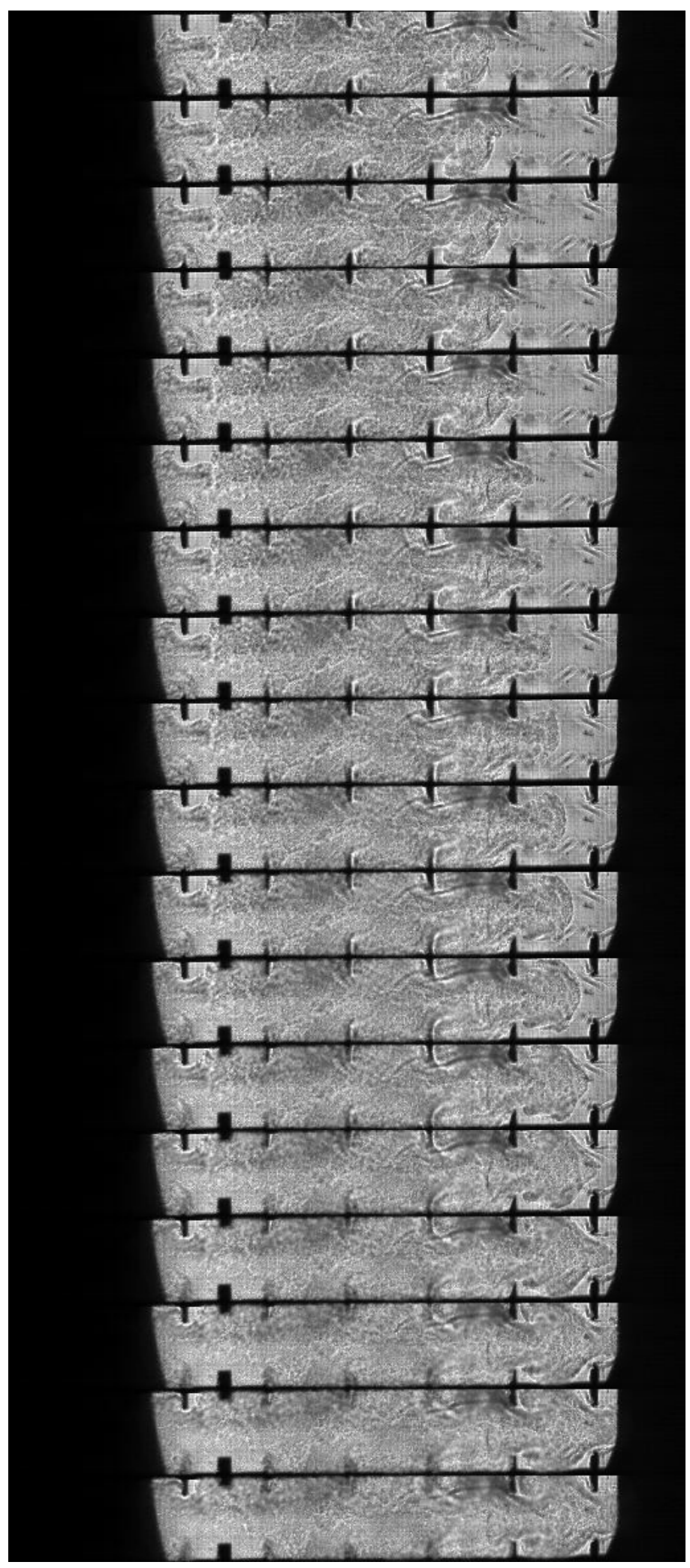




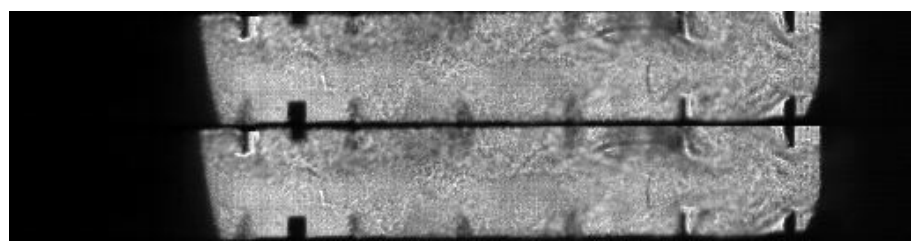

Case 1 , run 10

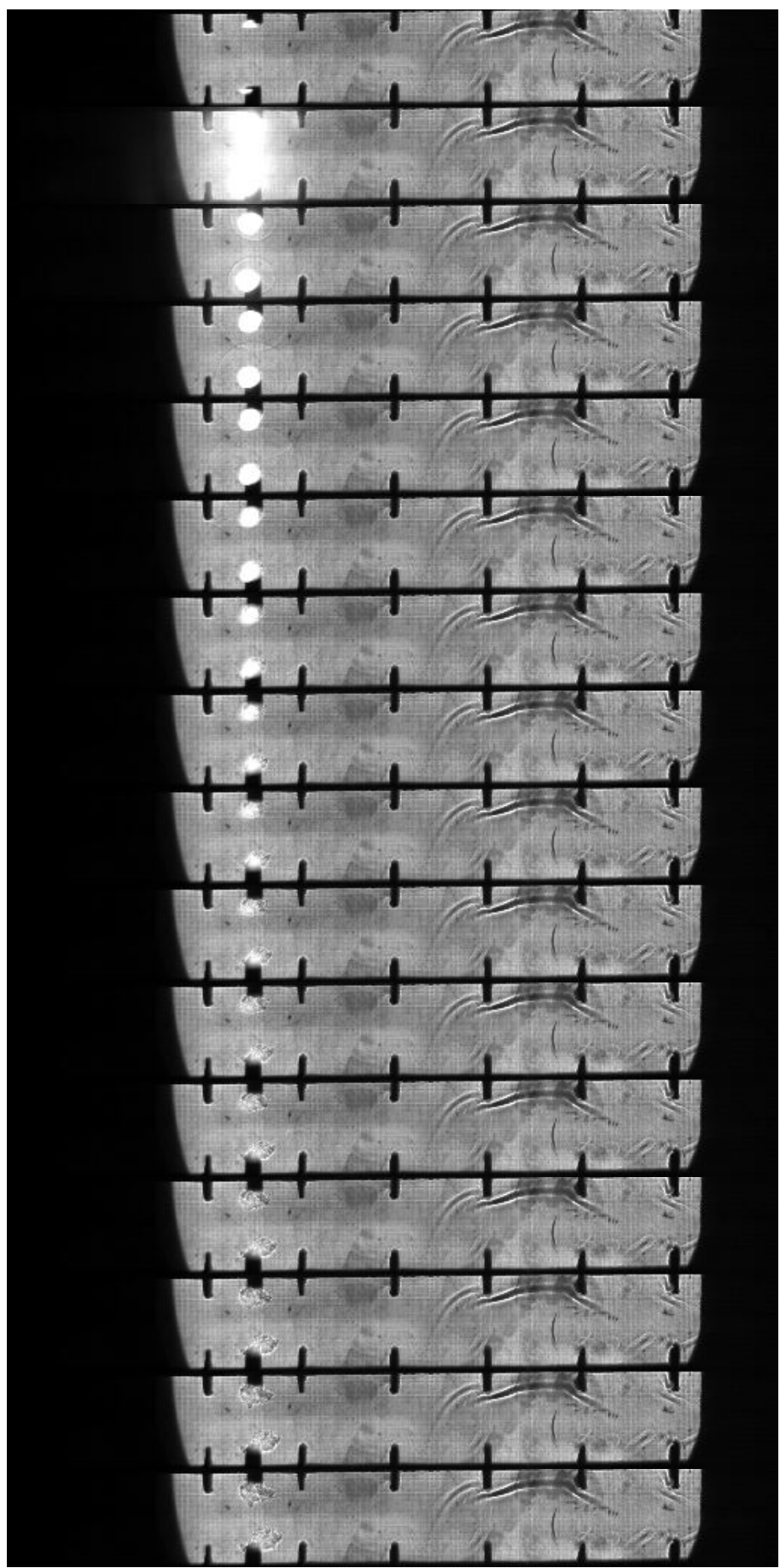




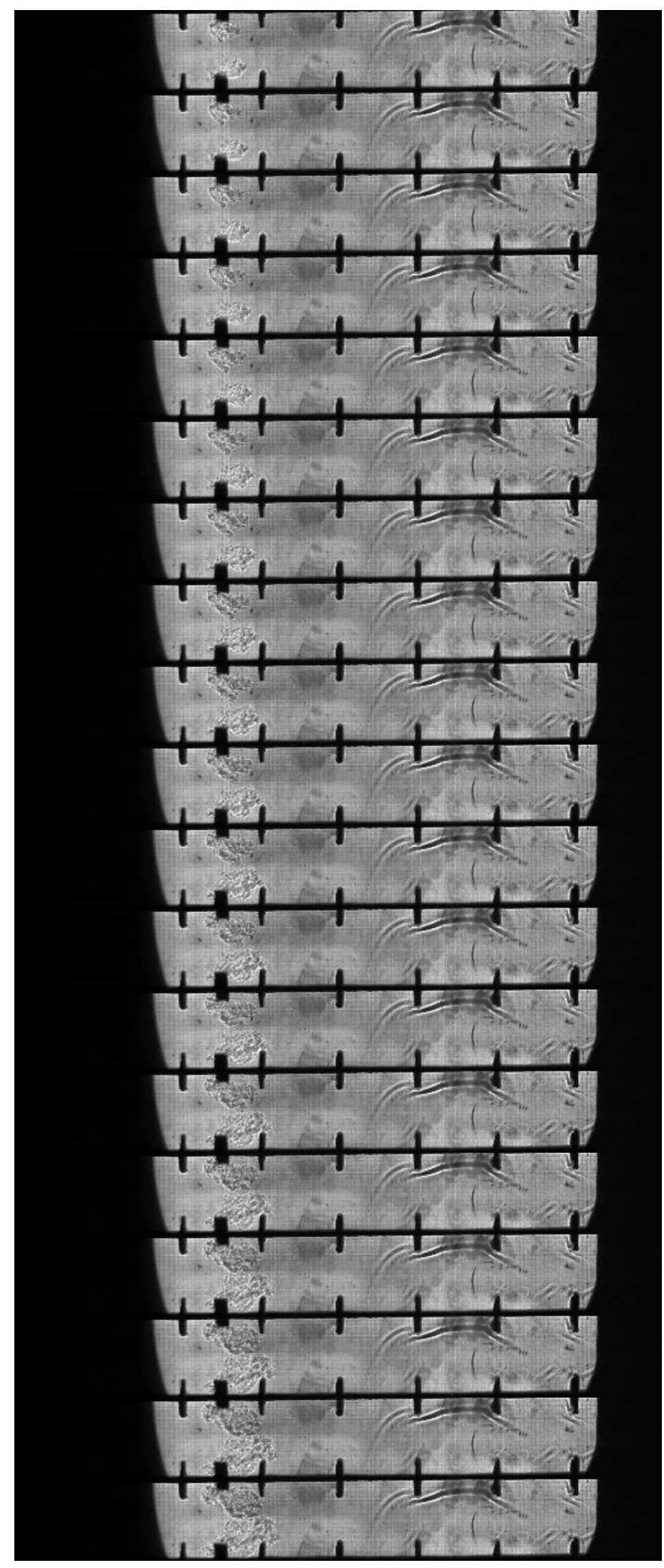




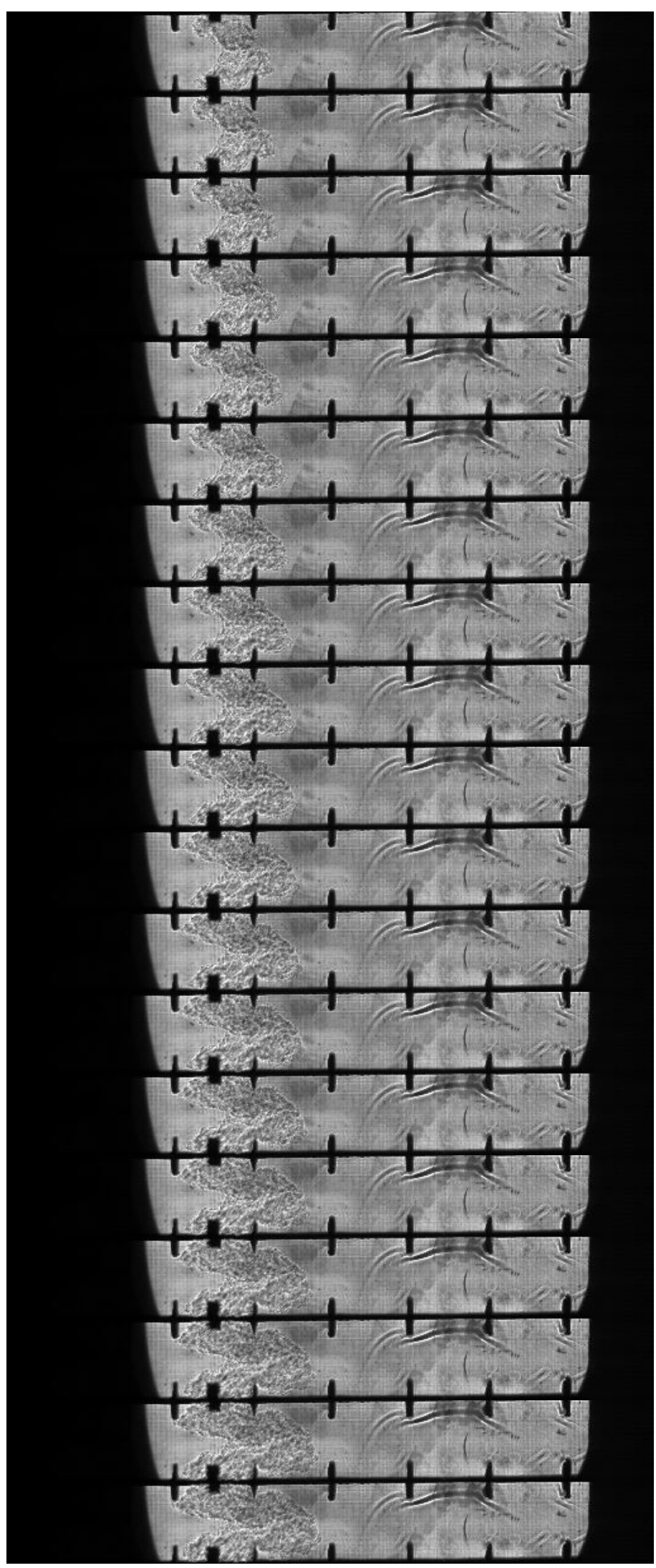




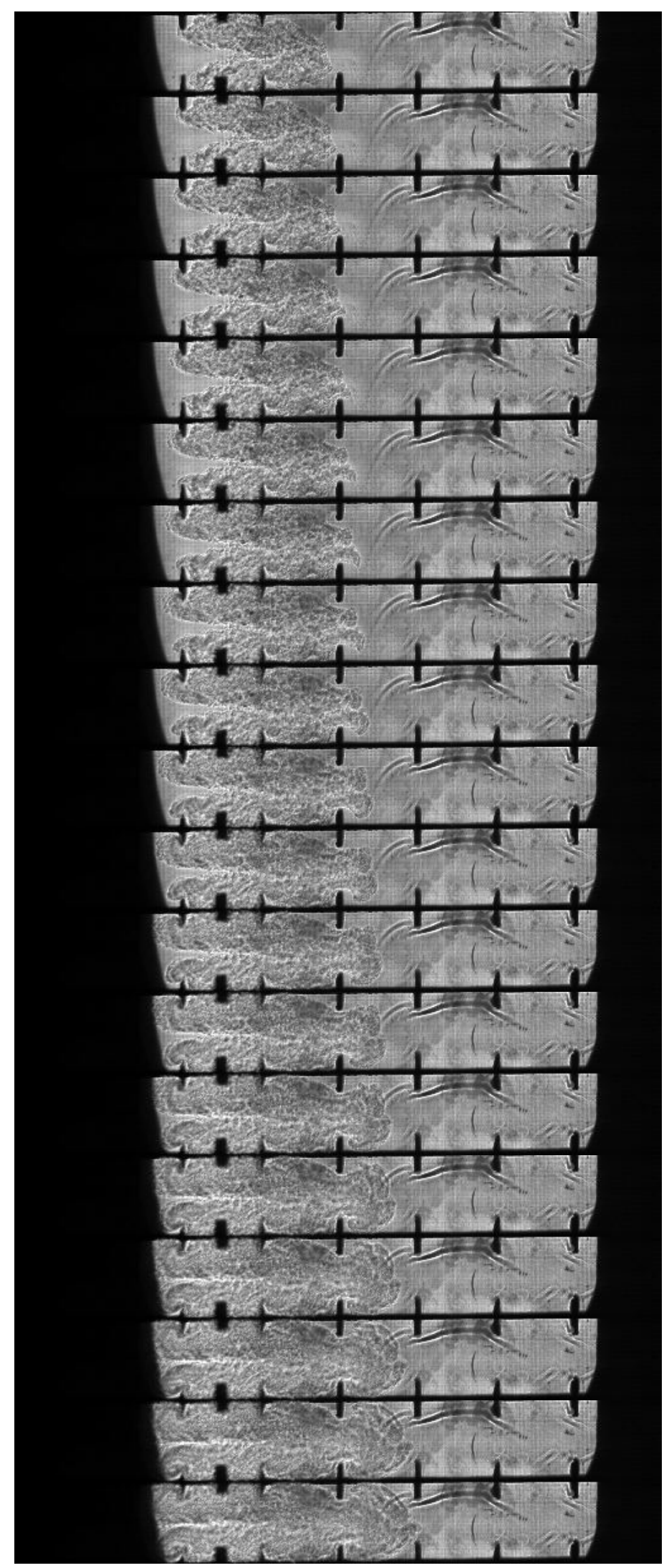




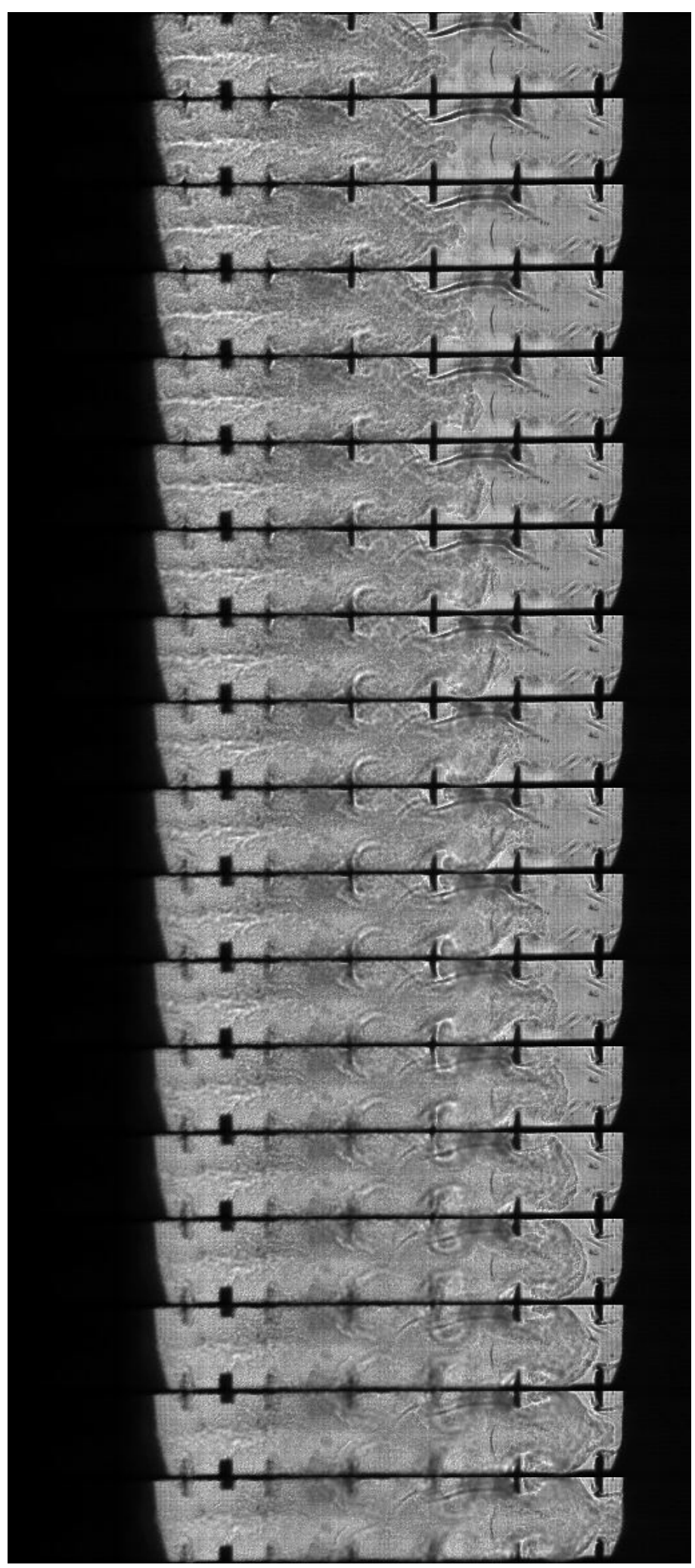




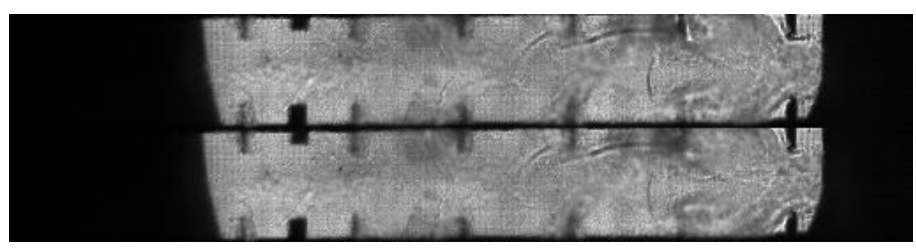

Velocity Study, run 1

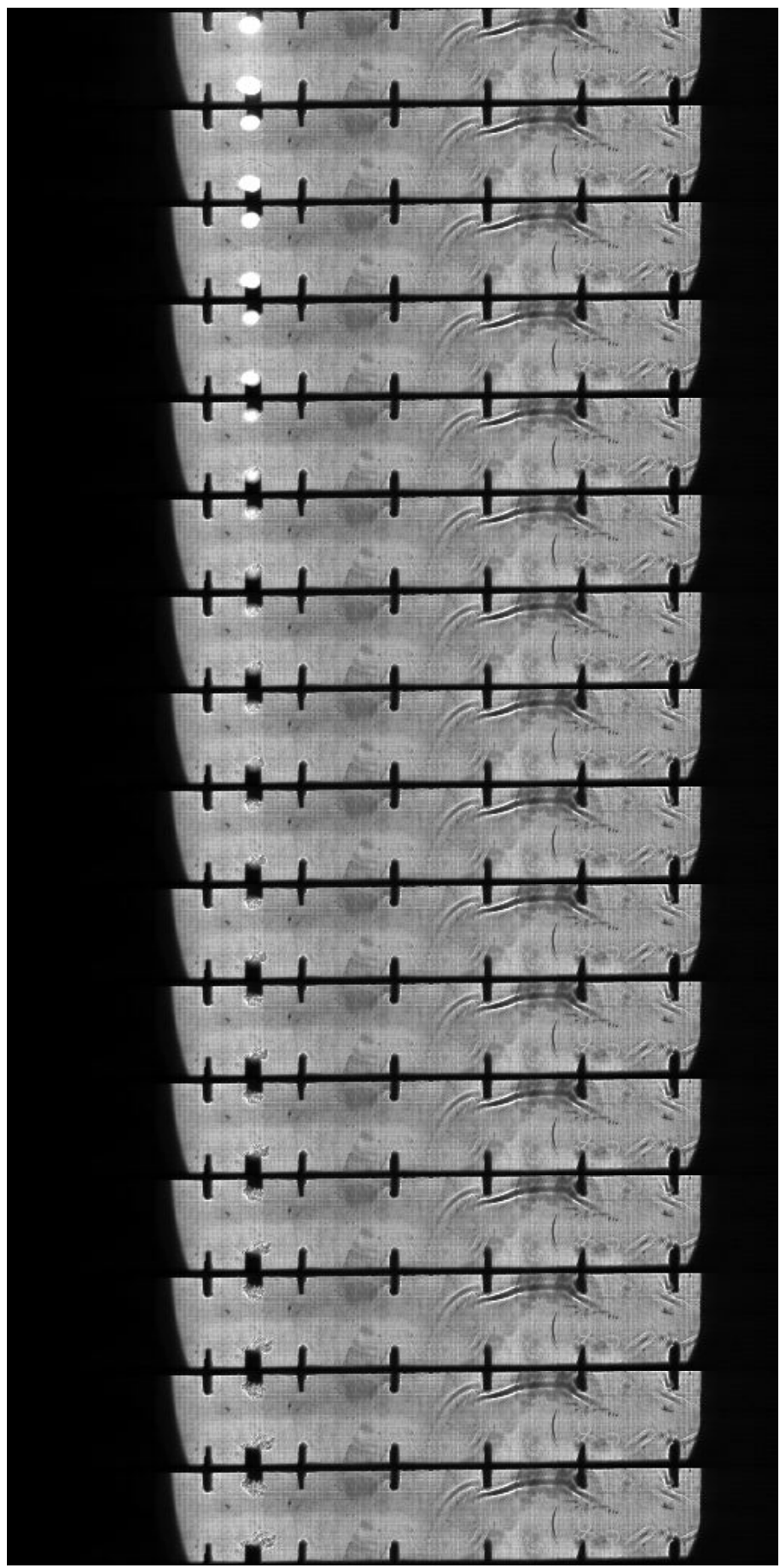




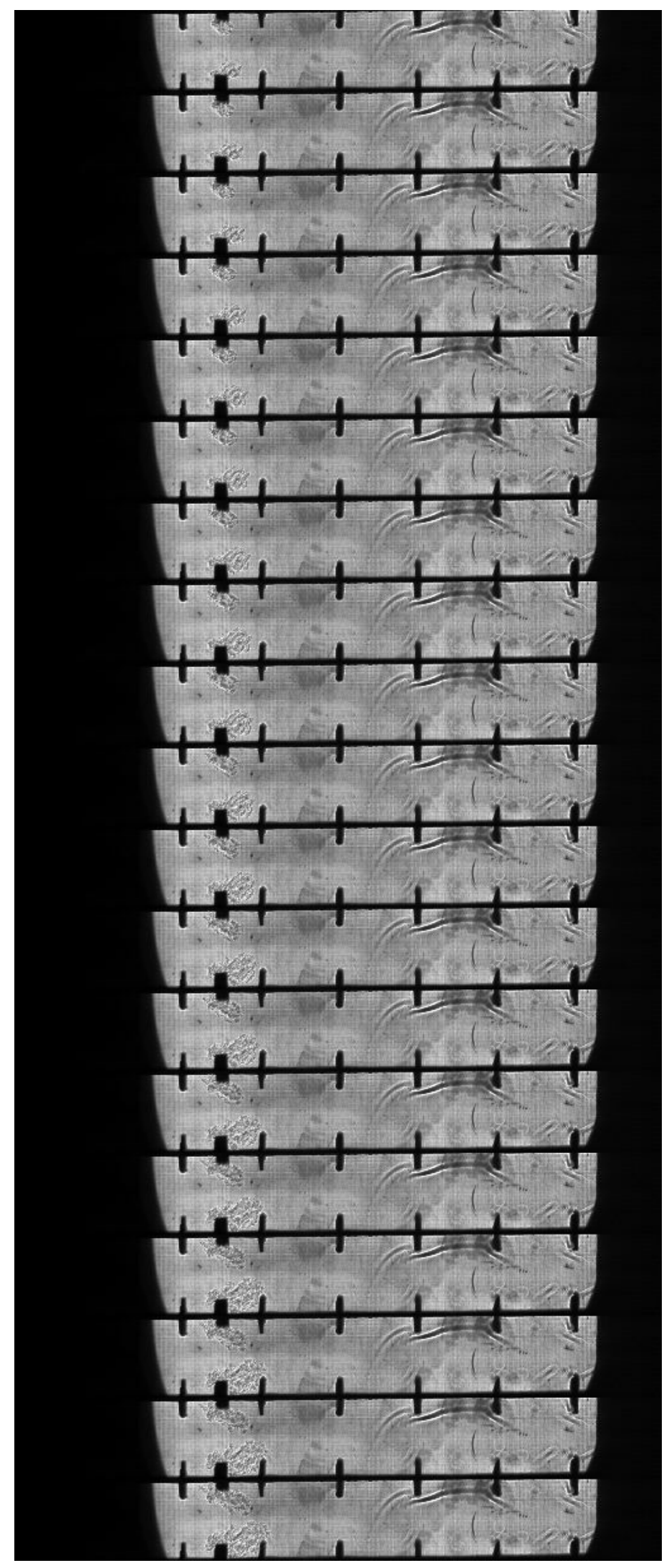




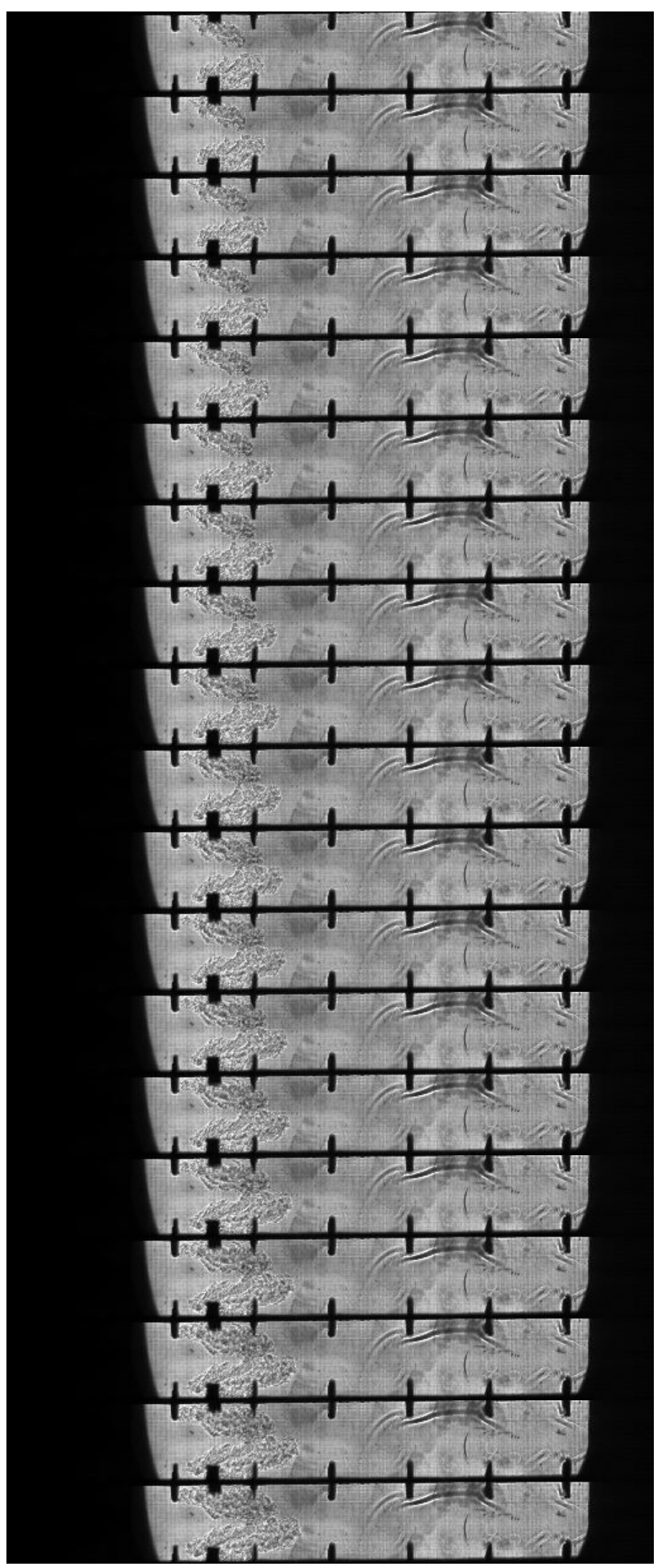




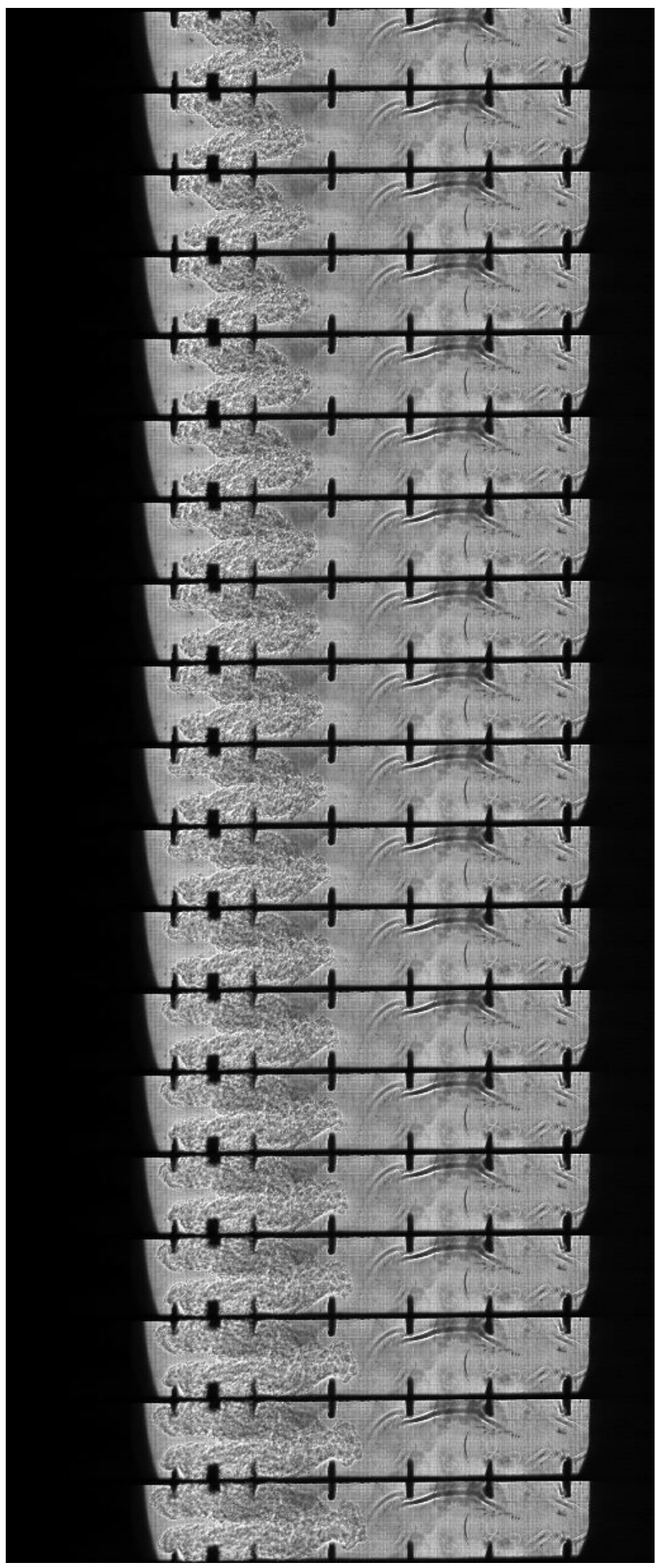




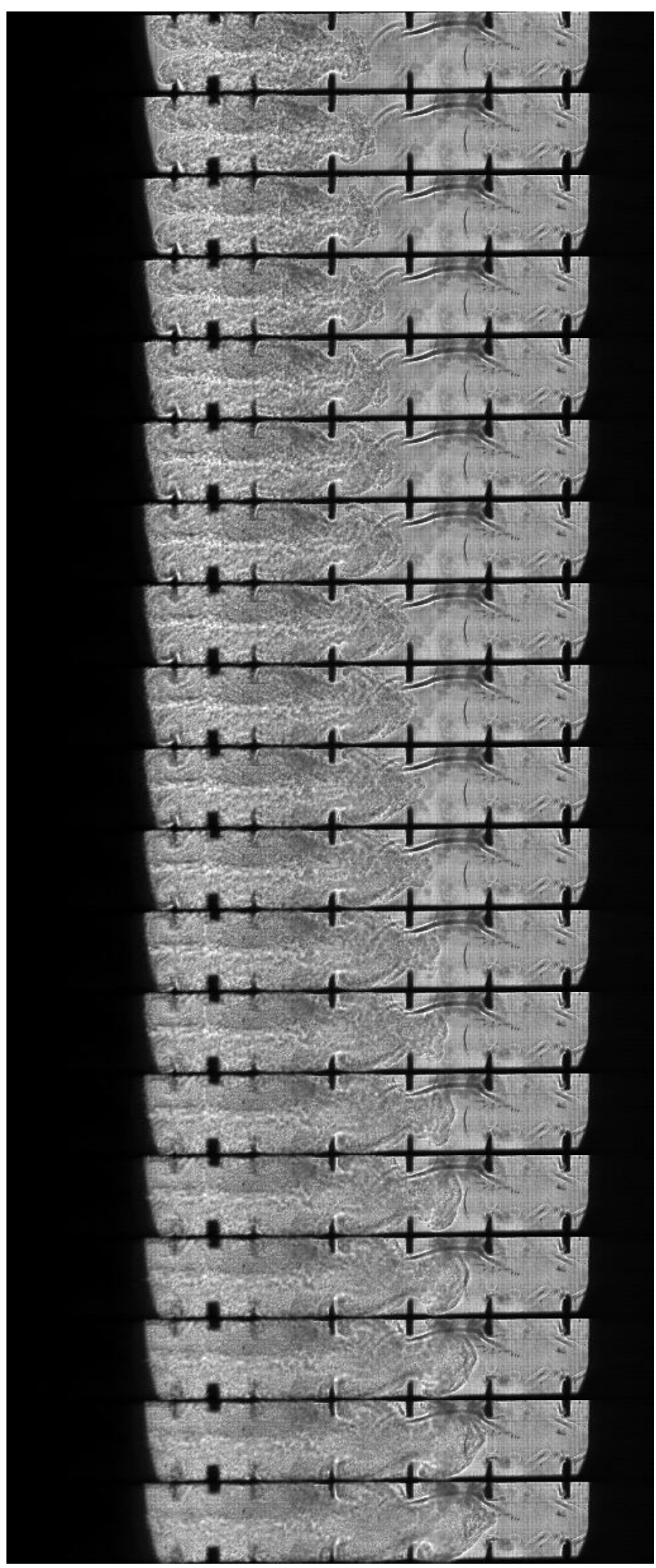




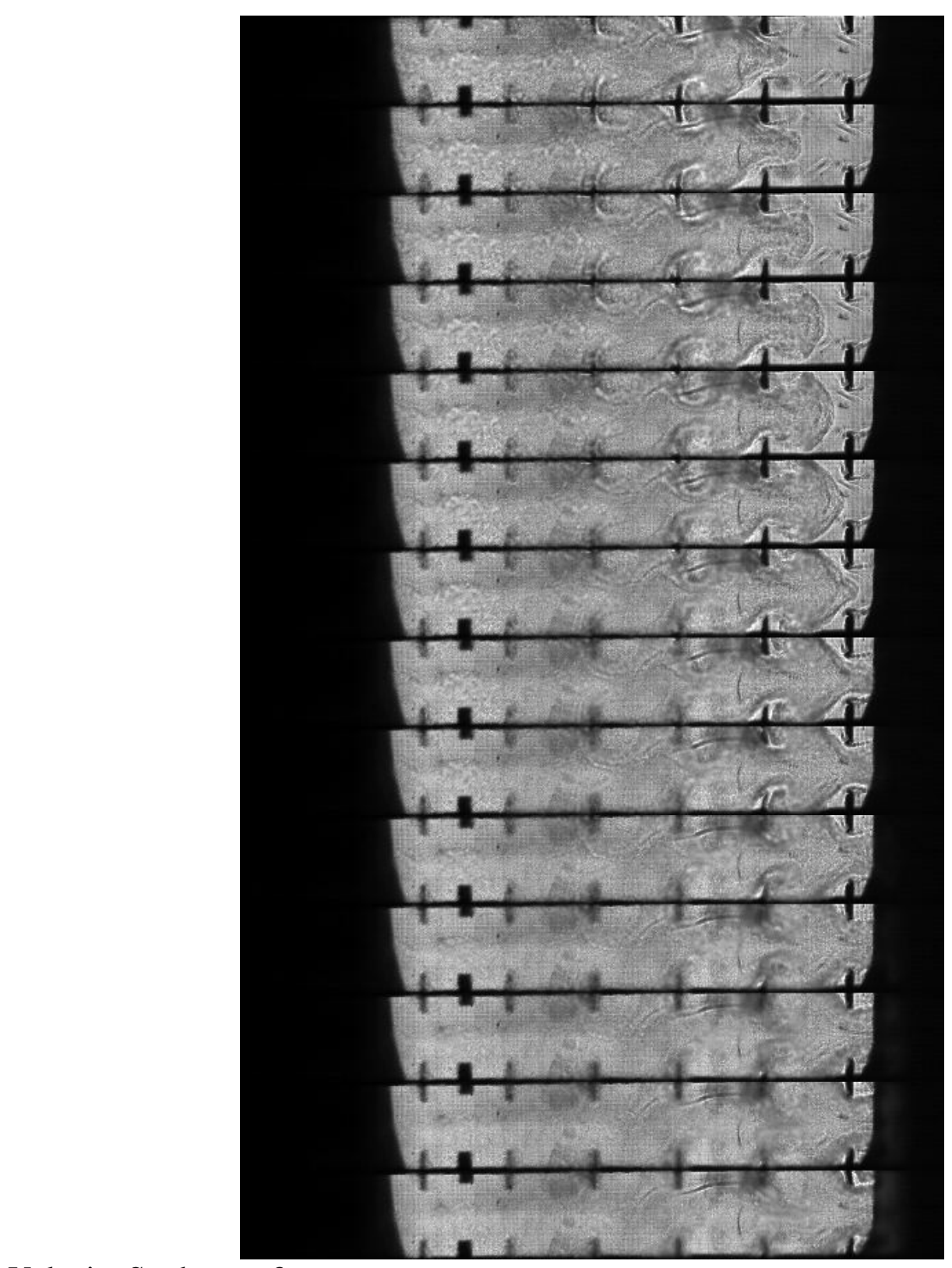

Velocity Study, run 3

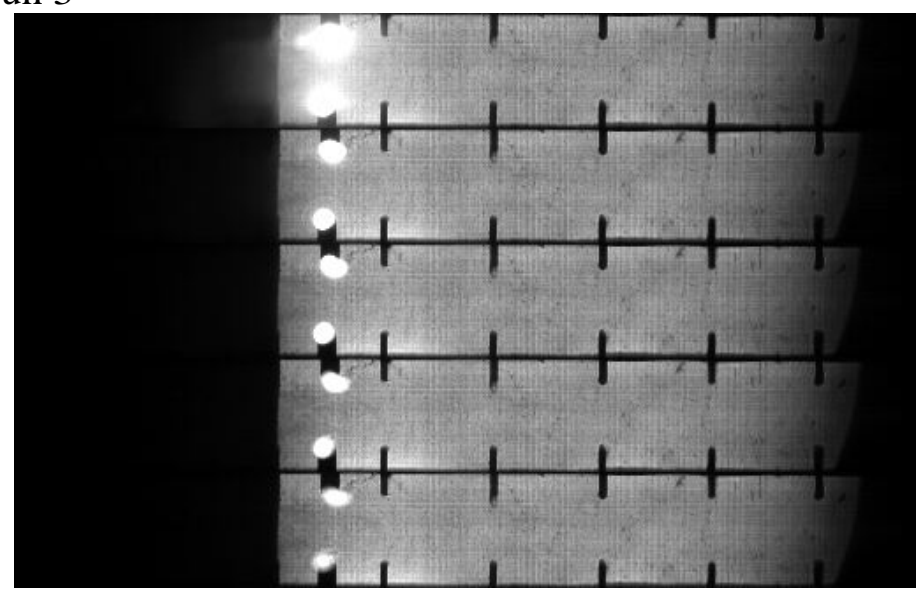




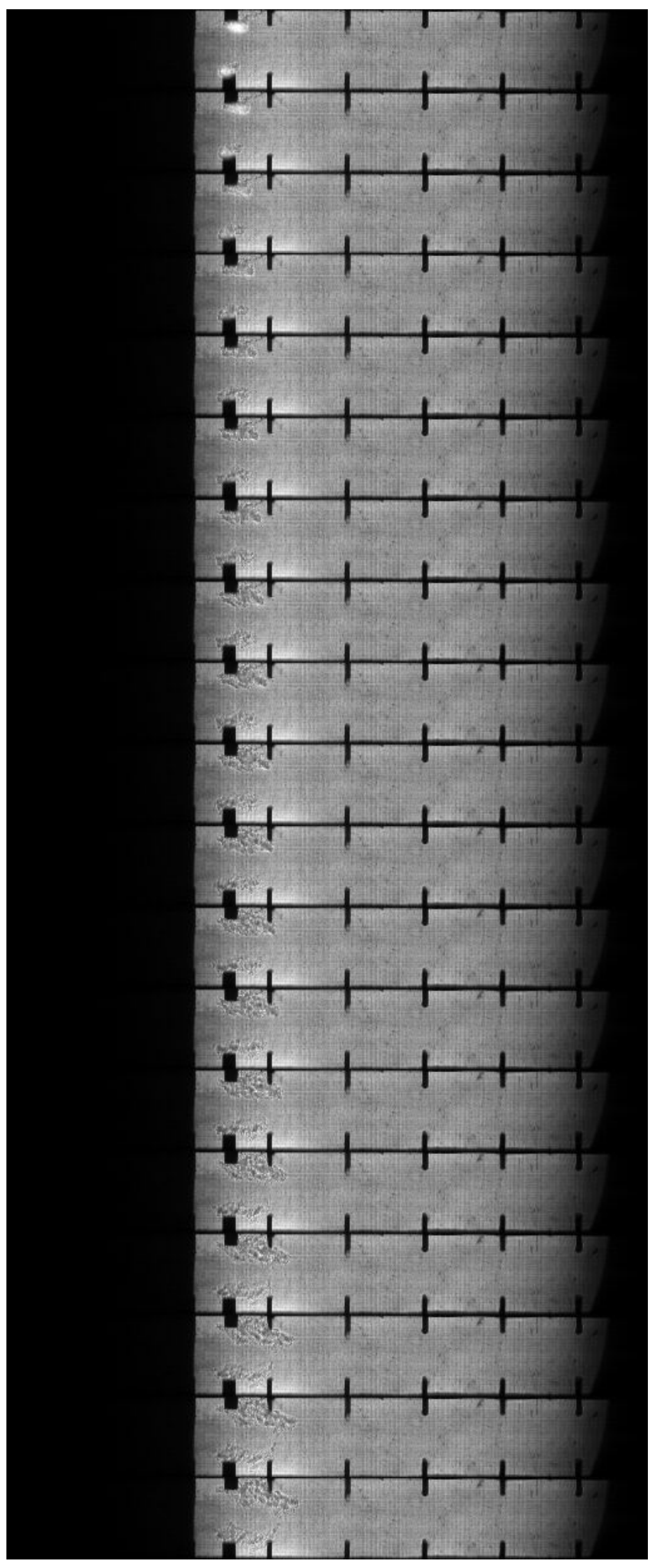




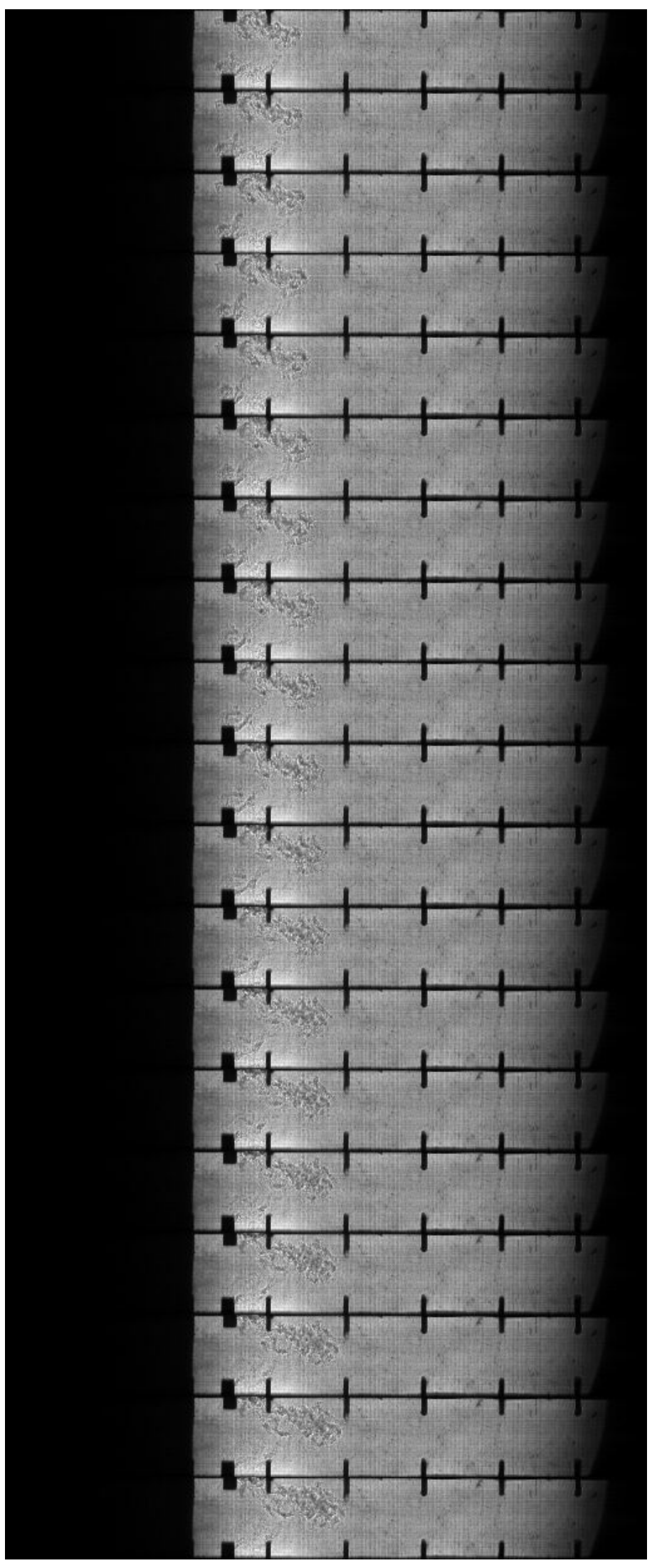




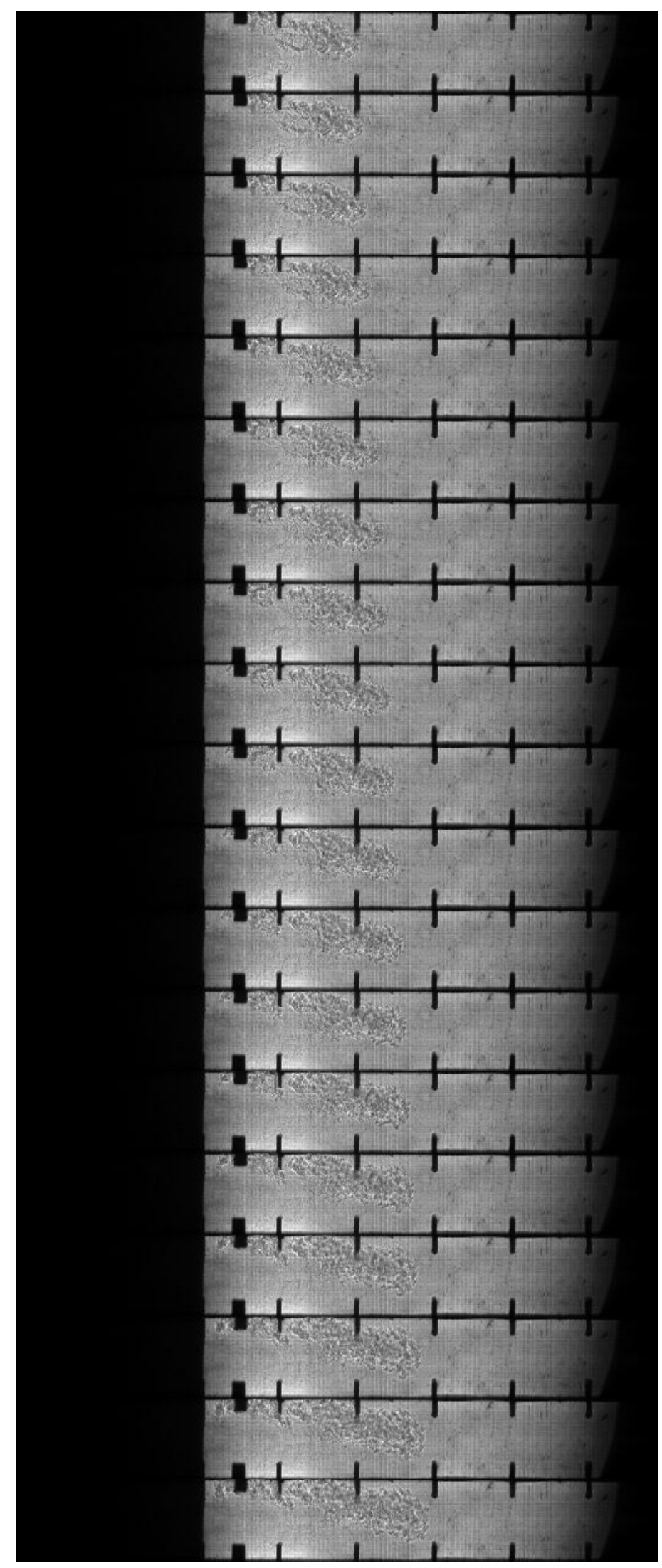




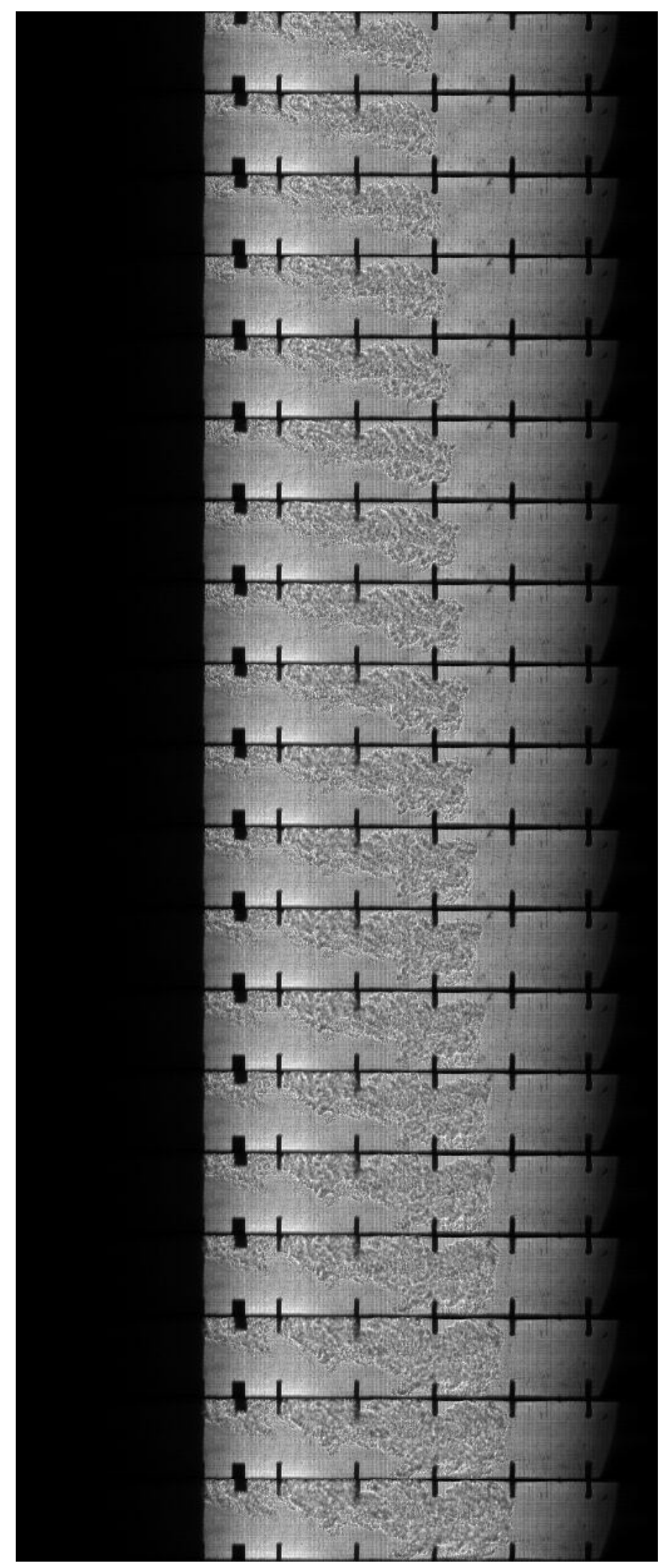




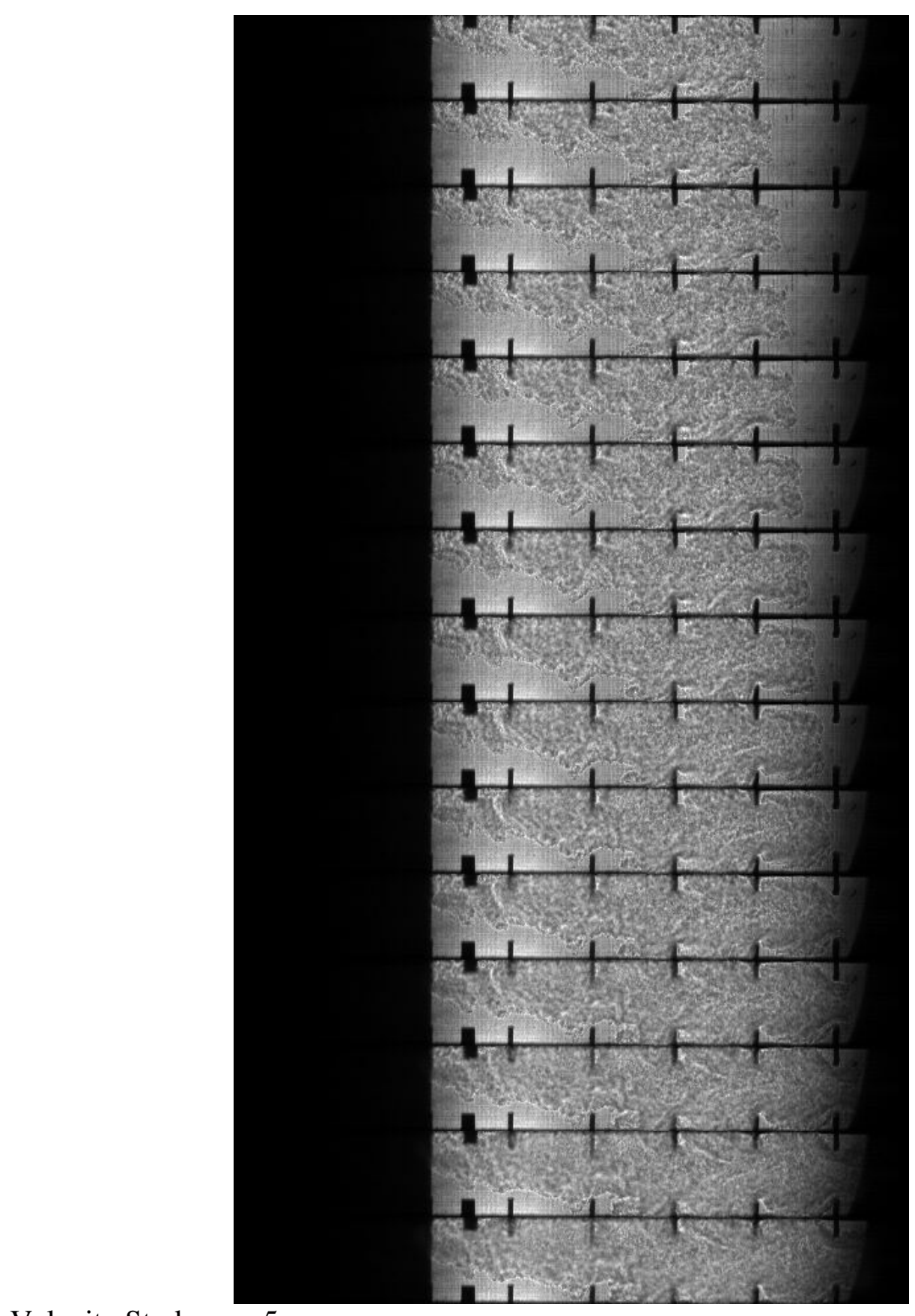

Velocity Study, run 5

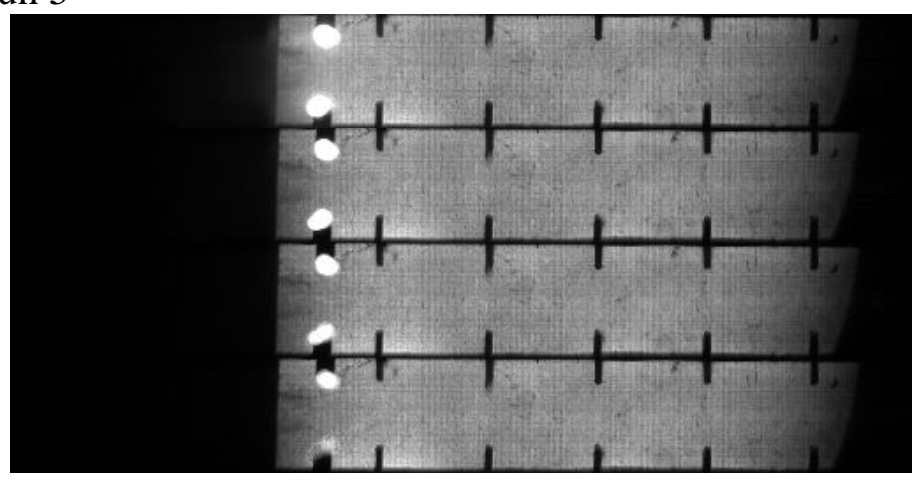




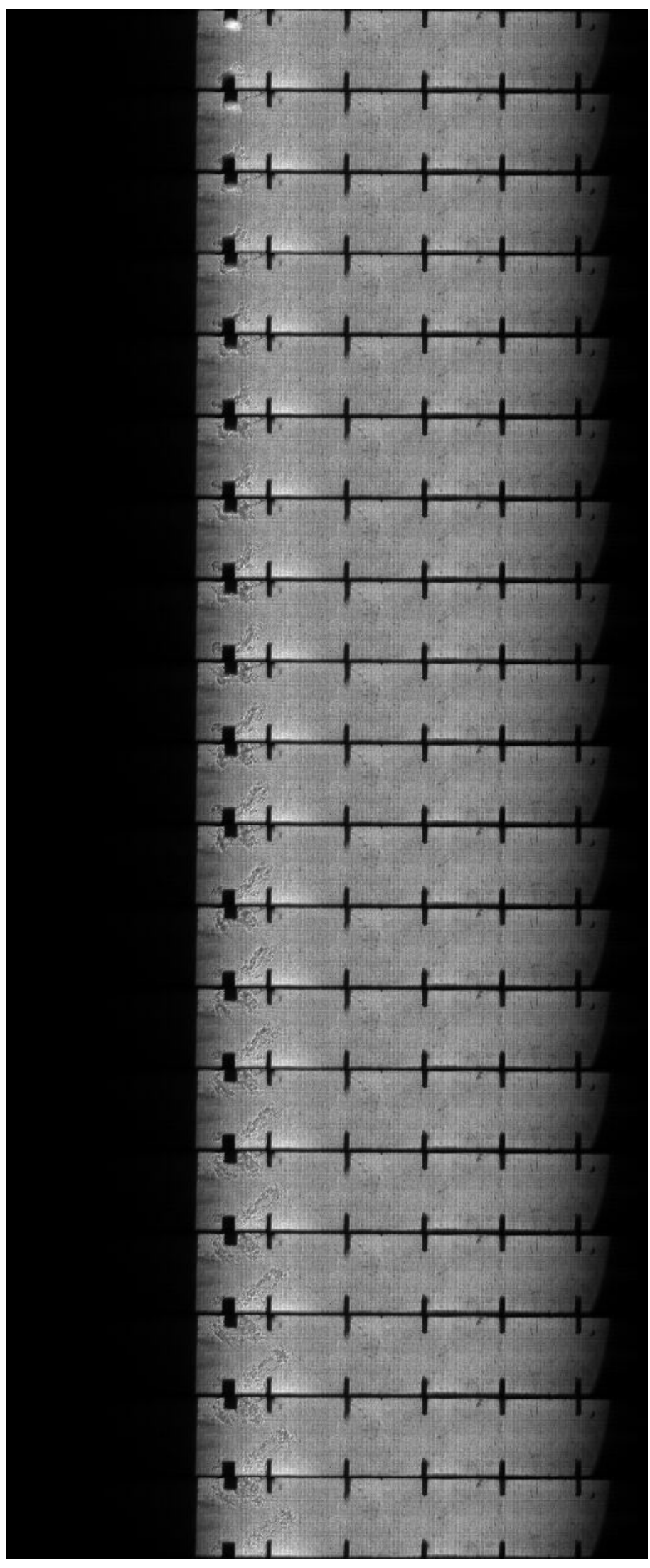




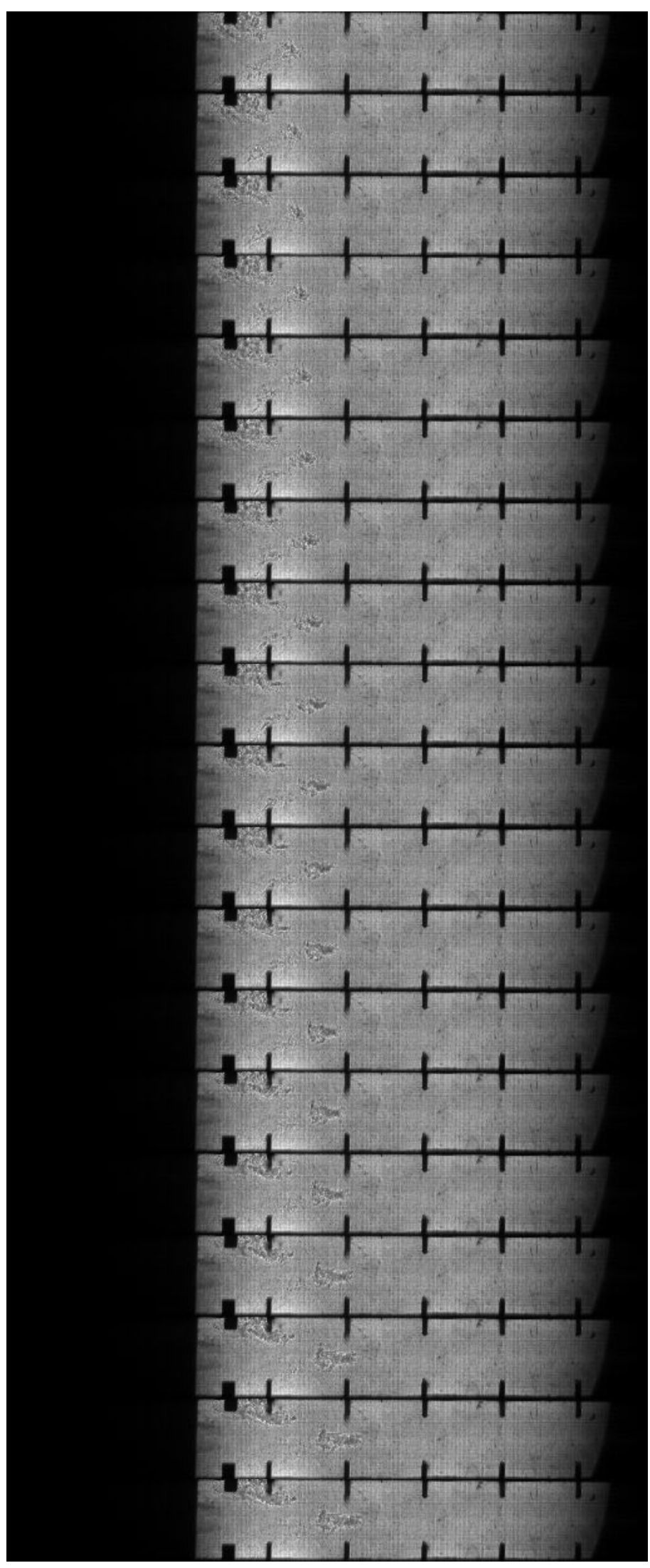




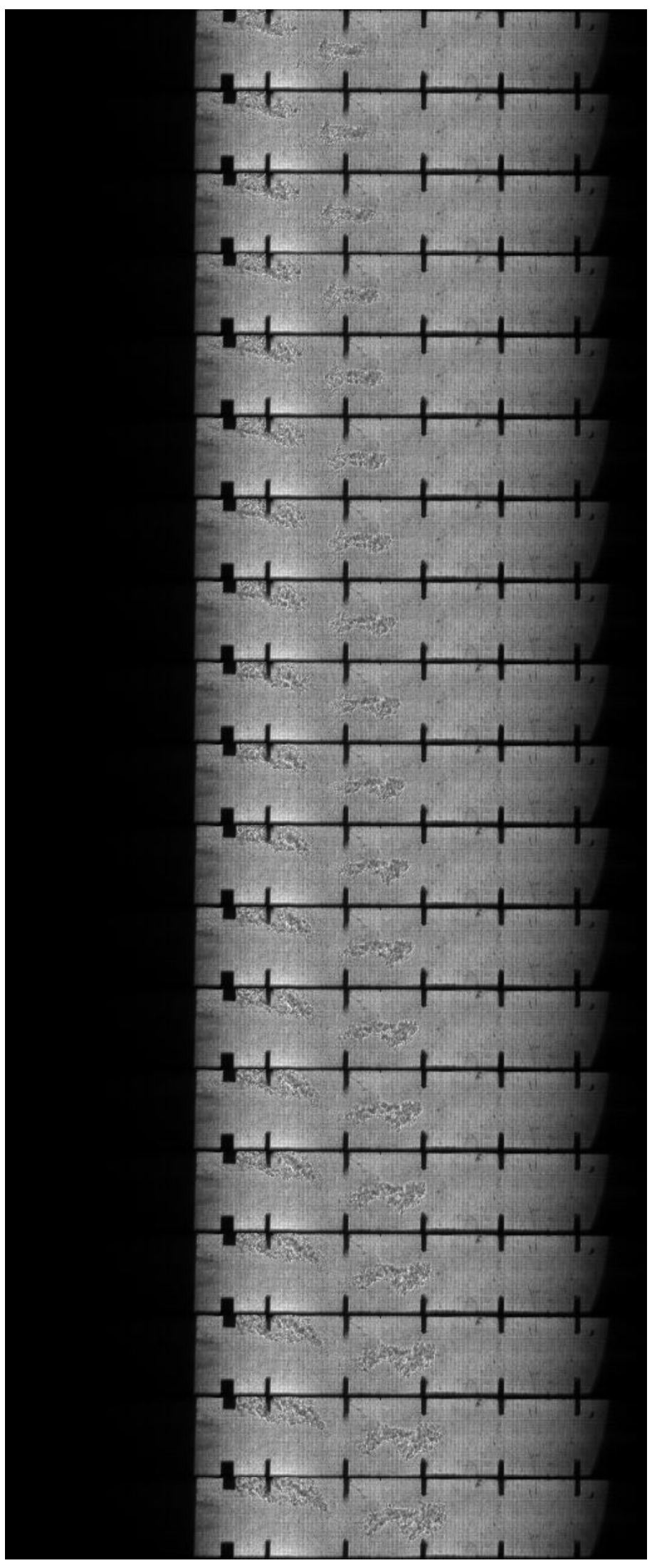




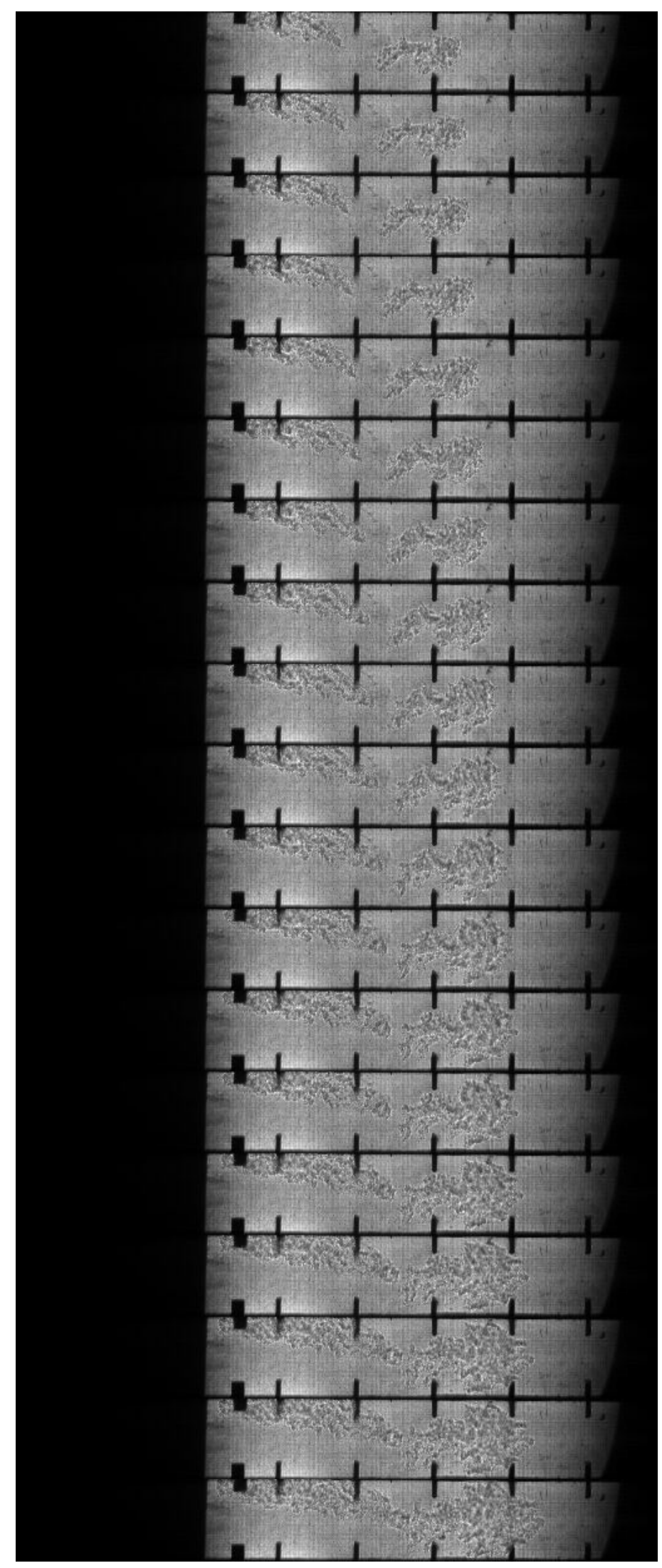




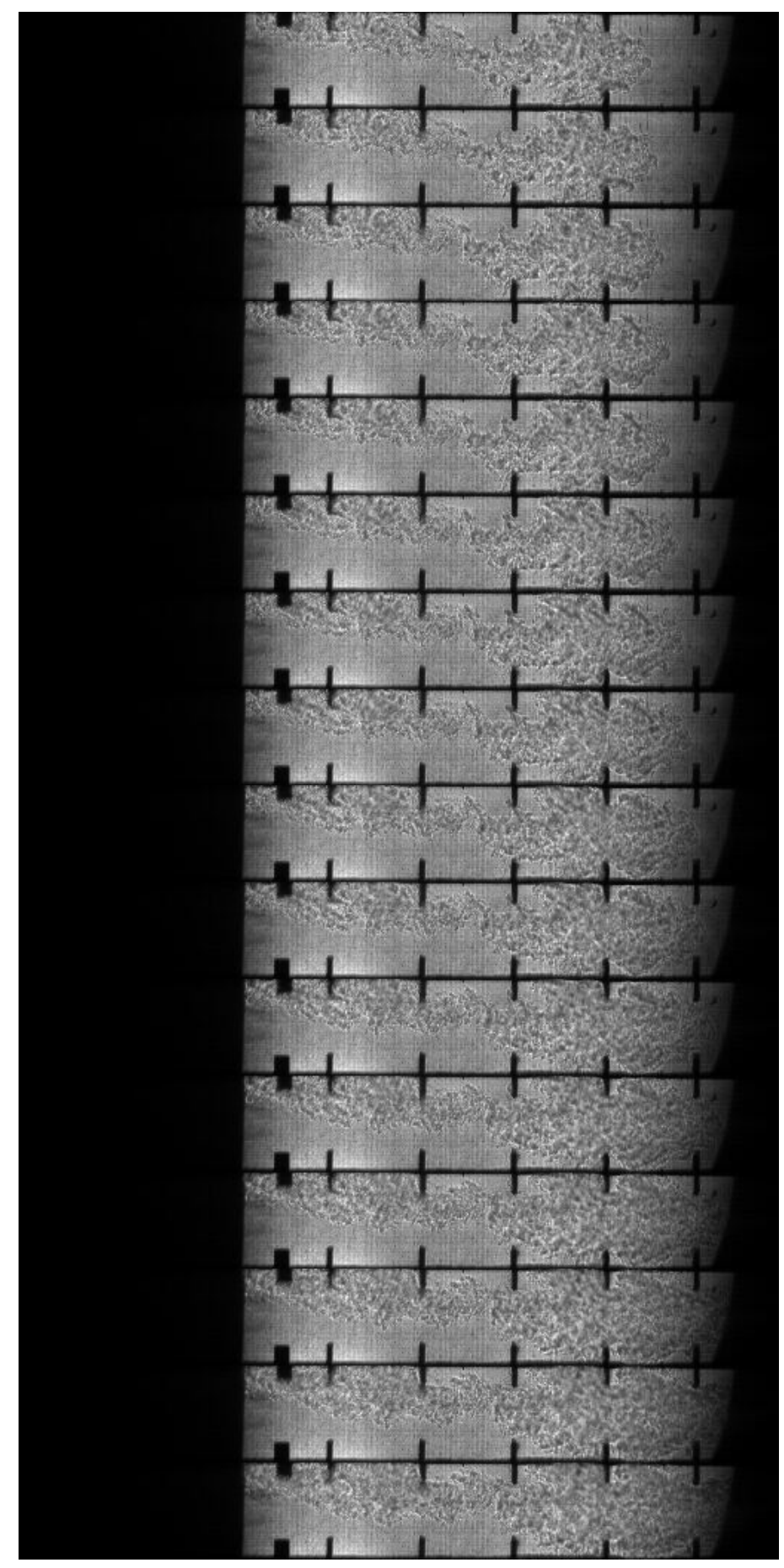




\section{REFERENCES}

${ }^{1}$ A. J. Dean, "Recent Developments in Approaches to Pulsed Detonation Propulsion (Invited)," AIAA paper 2003-4510, 39th Joint Propulsion Conference, 2003.

${ }^{2}$ K. Kailasnath, AIAA Journal, Vol. 38, No. 9, pp. 1698-1708, 2000.

${ }^{3}$ Roy, G.D., Frolov, S.M., Borisov, A.A., Netzer, D.W., "Pulsed detonation propulsion: challenges, current status, and future perspective", Progress in Energy and Combustion Science, 30(2004) 545-672.

${ }^{4}$ Turns, Stephen R. An Introduction to Combustion: Concepts and Applications. $2^{\text {nd }}$. ed. Boston: McGraw Hill, 2000. 598-606.

${ }^{5} 25$ Oct. 2005 <http://www.cococubed.com/images/cj/hugoniot.jpg〉.

${ }^{6}$ Shepherd, J.E., "GALCIT Explosion Dynamics Laboratory Detonation Database," $<\mathrm{http}: / /$ www.galcit.caltech.edu/detn_db/html/db.html>, California Institute of Technology, Pasadena, CA.

${ }^{7}$ Courtesy of Joanna Austin, Graduate Student, California Institute of Technology, 2001

${ }^{8}$ Chapin, David C. "A Study of Deflagration to Detonation Transition in a Pulsed Detonation Engine." Georgia Institute Of Technology Masters Thesis, 2005.

${ }^{9}$ Cho, Y.S., Santavicca, D.A. and R. M. Sonntag, "The Effect of Spark Power on SparkIgnited Flame Kernel Growth," International Fuels and Lubricants Meeting and Exposition, San Francisco, California, 1992.

${ }^{10}$ Shen, Huixian and Deming Jiang, "Investigation of the Flame Initiation and Early Development in a Spark Ignition Engine," International Fuels and Lubricants Meeting and Exposition, San Francisco, California, 1992.

${ }^{11}$ Frolov, S. M., Basevich, V. Ya., Aksenov, V. S., and Polikhov, S. A., "Initiation of Spray Detonation by Successive Triggering of Electric Discharges," Advances in Confined Detonations, edited by G. Roy, S. Frolov, R. Santoro, and S. Tsyganov, Torus Press, Moscow, 2002, pp. 150-157.

${ }^{12}$ Hickey, M.C., Ciccarelli, G., Gardiner, D., and M. Bardon, "The Reduction of Detonation Run-Up Distance using a Multi-Point Ignition System," Queen's Unversity, Canada. 2003.

${ }^{13}$ Maly, R.: "Spark Ignition: Its Physics and Effect on the Internal Combustion Process," in J.C. Hilliard and G.S. Springer (eds.), Fuel Economy in Road Vehicles Powered by Spark Ignition Engines, chap. 3, Plenum Press, New York, 1984. 
${ }^{14}$ Heywood, John B. Internal Combustion Engine Fundamentals. New York: McGraw Hill, 1988. 595-597. 